\title{
Carbon Monoxide Concentrations and Carboxyhemoglobin Profiles from Commercially Available Portable Generators Equipped with a CO Hazard Mitigation System
}

Stephen M. Zimmerman

Steven J. Emmerich

Matthew J. Brookman

This publication is available free of charge from:

https://doi.org/10.6028/NIST.TN.2200 


\section{Carbon Monoxide Concentrations and Carboxyhemoglobin Profiles from Commercially Available Portable Generators Equipped with a CO Hazard Mitigation System}

Stephen M. Zimmerman

Steven J. Emmerich Building Energy and Environment Division Engineering Laboratory

Matthew J. Brookman U.S. Consumer Product Safety Commission

This publication is available free of charge from: https://doi.org/10.6028/NIST.TN.2200

January 2022

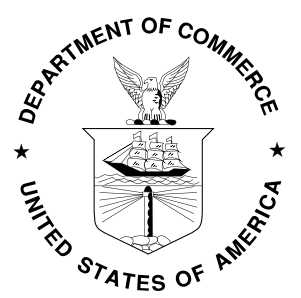

U.S. Department of Commerce

Gina M. Raimondo, Secretary 
Certain commercial entities, equipment, or materials may be identified in this document in order to describe an experimental procedure or concept adequately. Such identification is not intended to imply recommendation or endorsement by the National Institute of Standards and Technology, nor is it intended to imply that the entities, materials, or equipment are necessarily the best available for the purpose.

National Institute of Standards and Technology Technical Note 2200 Natl. Inst. Stand. Technol. Tech. Note 2200, 92 pages (January 2022) CODEN: NTNOEF

This publication is available free of charge from: https://doi.org/10.6028/NIST.TN.2200 


\section{Abstract}

The U.S. Consumer Product Safety Commission (CPSC) is focused on addressing the hazard of acute carbon monoxide $(\mathrm{CO})$ poisoning of consumers from portable generators that can result in serious, long-term health effects or death in exposed individuals. Under an interagency agreement with CPSC (CPSC-I-17-0023), the National Institute of Standards and Technology (NIST) conducted a series of tests on four commercially available portable generators advertised as being certified to one of two voluntary standards requiring $\mathrm{CO}$ hazard mitigation systems for portable generators. These tests characterized the indoor $\mathrm{CO}$ concentrations and the resulting calculated carboxyhemoglobin $(\mathrm{COHb})$ profiles on simulated occupants when the generators were operated in or near a test house under various operational and environmental conditions. This report presents the measured $\mathrm{CO}$ data and calculated $\mathrm{COHb}$ levels from those tests. In addition, model validation tests and simulations were performed for two cases (three tests for each) to supplement those already reported in NIST Technical Note 2049.

\section{Keywords}

Generator; carbon monoxide; carboxyhemoglobin; CONTAM; exposure; indoor air quality; health; measurements; multizone airflow model; simulation. 


\section{Table of Contents}

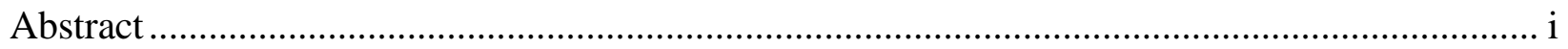

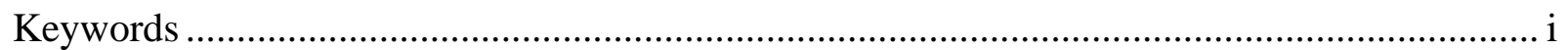

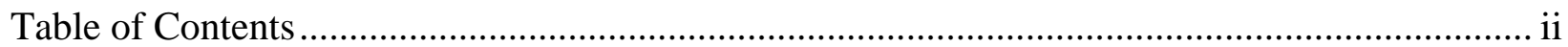

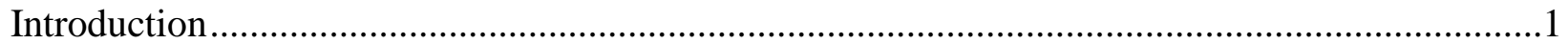

Experimental Design

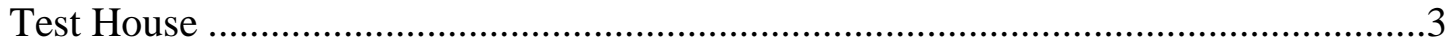

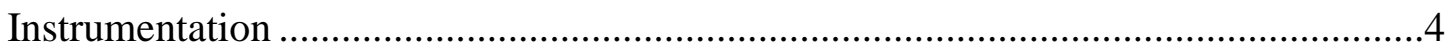

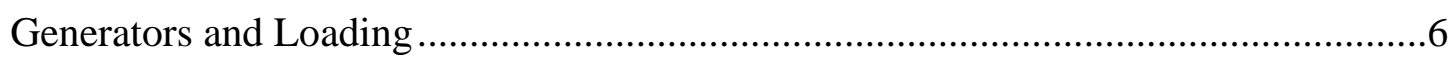

Testing and Analysis Methods................................................................................

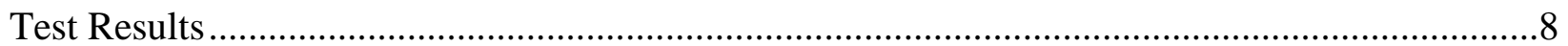

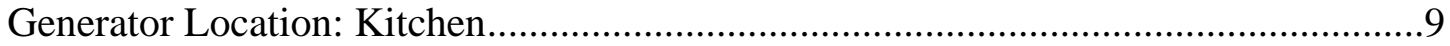

Generator Location: Garage..................................................................................34

CO Concentrations at Shutoff for Voluntary Standard Test Measurement Locations and the Onboard Sensor ..................................................................................75

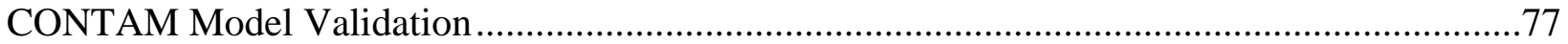

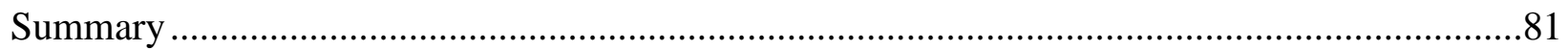

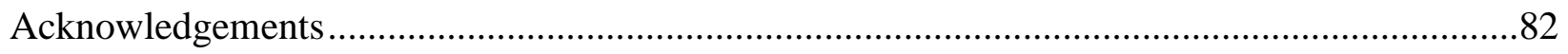

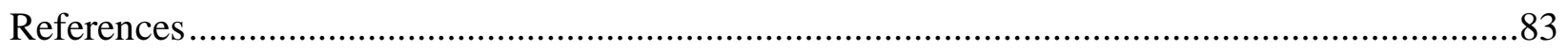

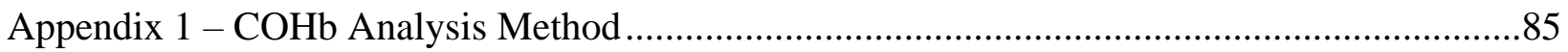




\section{Introduction}

The U.S. Consumer Product Safety Commission (CPSC, Commission) is focused on addressing the hazard of acute carbon monoxide $(\mathrm{CO})$ poisonings of consumers from portable generators that can result in serious, long-term health effects or death in exposed individuals. CPSC produces two annual reports which contain information on $\mathrm{CO}$ poisoning in regards to generator usage, a $\mathrm{CO}$ poisoning from Engine-Driven Tools (EDT) report (Hnatov 2021a) and a report that contains annual estimates of CO poisoning from consumer products (Hnatov 2021b).

The first report contains only the actual data as reported to CPSC through 2020 and should not be assumed to be annual estimates. It should also be noted that the latter years of the report should be considered incomplete as often new data becomes available to CPSC staff up to a few years after the incident occurred due to reporting delays. This report contains more detailed information on the specific incidents and the victims involved than does the estimates report. As of May 17, 2021, CPSC databases contain records of at least 753 consumer deaths (711 from generator use alone, 42 from generator use in conjunction with another $\mathrm{CO}$-producing consumer product) from CO poisoning associated with non-work-related use of generators between 2010 and 2020. Typically, these deaths occur when consumers use a generator in an enclosed or partially enclosed space or outdoors near an open door, window or vent, and they often occur after severe weather events such as hurricanes and ice or snow storms.

The second report contains the annual estimates of generator $\mathrm{CO}$ fatalities and indicates the magnitude of generator-related $\mathrm{CO}$ poisoning deaths in relation to all consumer product-related $\mathrm{CO}$ poisoning deaths. The estimated percentage of $\mathrm{CO}$ poisoning deaths specifically associated with generators, excluding the estimates that involved a generator and another CO-producing consumer product, for five most recent years of data are $33 \%$ (2014), $49 \%$ (2015), $38 \%$ (2016), $51 \%$ (2017) and 42\% (2018). Per the Hnatov 2021 report, the estimated CO fatalities from all consumer products under CPSC's jurisdiction has risen for the sixth straight year. Part of this increase in the estimated $\mathrm{CO}$ fatalities is due to an increase in the number of $\mathrm{CO}$ fatalities associated with EDTs. In the eleven years covered by this report, portable generators are responsible for over $81 \%$ of all EDTrelated $\mathrm{CO}$ deaths, and approximately $87 \%$ when another $\mathrm{CO}$ producing product may have also contributed.

The health impact of CO is caused by anoxia: deprivation of oxygen supply. When inhaled, CO preferentially binds with the oxygen carrier in the red blood cells, hemoglobin $(\mathrm{Hb})$, to form carboxyhemoglobin $(\mathrm{COHb})$, which causes the anoxia (Stewart 1975). The COHb level reflects the percentage of the body's total hemoglobin pool occupied by $\mathrm{CO}$. In considering $\mathrm{CO}$ exposure, the $\mathrm{COHb}$ level serves as a useful measure of expected poisoning severity.

In previous work, documented in National Institute of Standards and Technology (NIST) Technical Note (TN) 1925, a computer simulation study was conducted to provide CPSC staff with information to support model-based estimates of residential $\mathrm{CO}$ exposures reflecting operation of current designs of portable engine-driven electric generators, both inside homes and in attached garages. These results were compared to simulated operation of reduced $\mathrm{CO}$ emission generators by CPSC staff to estimate the effectiveness of the reduced $\mathrm{CO}$ emission rates in preventing deaths that occurred with current generators. CPSC staff then recommended specific reduced $\mathrm{CO}$ emission rates as performance requirements to the Commission in a briefing package for a notice of proposed rulemaking (NPR) as the means to address the CO hazard associated with 
portable generators. The Commission subsequently voted to approve the NPR. (Proposed Safety Standard for Portable Generators, Federal Register, 81 FR 83556, November 21, 2016.).

After CPSC issued the NPR, two voluntary industry standards were published in 2018 to address portable generator CO safety: ANSI/PGMA G300-2018, Safety and Performance of Portable Generators (referred to as PGMA G300) and ANSI/UL 2201-2018, Carbon Monoxide (CO) Emission Rate of Portable Generators (referred to as UL 2201).

PGMA G300 includes a requirement for generators to be equipped with an onboard CO sensor. This sensor, when tested to the requirements in the standard, must shut off the generator before the $\mathrm{CO}$ concentration measured at a location 1 inch to 2 inches above the approximate center of the portable generator's top surface exceeds either a rolling 10-minute average of 400 ppmv or an instantaneous reading of 800 ppmv. PGMA G300 also requires notification after a shutoff event, which must be a red indicator that remains active for a minimum of 5 minutes after shutoff occurs, unless the generator is restarted. Furthermore, PGMA G300 requires a label about the automatic shutoff near the indicator, instructing the consumer about moving the generator to an outdoor area and seeking medical help if feeling sick.

UL 2201 includes a requirement for maximum weighted $\mathrm{CO}$ emission rate of $150 \mathrm{~g} / \mathrm{h}$ and an additional requirement for generators to shut off when the $\mathrm{CO}$ concentration one foot above the centerline of the top of the generator registers either an average of $150 \mathrm{ppmv}$ of $\mathrm{CO}$ for a 10 -minute period or an instantaneous reading of 400 ppmv. UL 2201 does not contain a requirement for notification after a shutoff event.

Following publication of the G300 and UL2201 standards, NIST and CPSC conducted a study on generators with prototype shutoff mechanisms based on these standards. The study was meant to provide CPSC staff with information to support model-based estimates of residential $\mathrm{CO}$ exposures reflecting operation of current designs of portable engine-driven electric generators, both inside homes and in attached garages. (This study was reported in NIST Technical Note 2049). The current work builds on that reported in NIST TN 2049, as this study was conducted on generators in the marketplace that come equipped with G300/UL 2201-based shutoff mechanisms.

CPSC staff purchased from commercial retail suppliers three different models of portable generators, produced by three different manufacturers, that were advertised as certified to PGMA G300 and equipped with CO safety shutoff systems. In addition, CPSC staff purchased one model advertised as certified to UL 2201, for a total of four models from four different manufacturers. NIST and CPSC staff operated these generators in a test house under various use and environmental conditions, including generator location, load, operating schedules, weather conditions, and ventilation conditions. NIST and CPSC performed this series of tests to measure the $\mathrm{CO}$ concentration profiles throughout the house while the generator was operating and after it shut off, from activation of the generator's CO safety shutoff system, or after exhausting a full tank of fuel. This test report documents the $\mathrm{CO}$ data from those tests and the resulting calculated $\mathrm{COHb}$ profiles of simulated occupants. It also compares the concentration near the onboard sensor built into the unit and the concentration at the PGMA G300 and UL 2201 conformance test location above the generator at the time of shutoff. 


\section{Experimental Design}

This section describes the experimental work performed, including the test house in which the measurements were made, the instrumentation employed in the test, the generators that were tested, and the testing and analysis methods used.

\section{Test House}

The test house used in this study is a manufactured house located on the NIST campus, which was erected in 2002 (Nabinger and Persily 2008, Nabinger et al., 2010). An aerial view and floorplan of the house are shown in Figures 1 and 2. The house includes three bedrooms (MBd, B2, and B3), two bathrooms (MBa and $\mathrm{HB}$ ), a living room (LR), a dining room (DR), a kitchen (Kit), a family room (FR), a utility room (UR) and an attached garage (Gar). The house has a floor area of 140 $\mathrm{m}^{2}$ and a volume of $340 \mathrm{~m}^{3}$. The attached garage, which was built as an addition to the house in 2007, has a floor area of $36.5 \mathrm{~m}^{2}$ and a volume of $90 \mathrm{~m}^{3}$. The interior of the garage, including the ceiling, is finished with painted gypsum board. As part of the garage construction, the underlayment and siding of the exterior west wall of the house were removed and replaced with 3/4- inch gypsum board on studs with fibrous glass batt insulation in the wall cavity. Figure 3 shows the location of $\mathrm{CO}$ sensors, thermocouples and generators, and the generator exhaust direction.

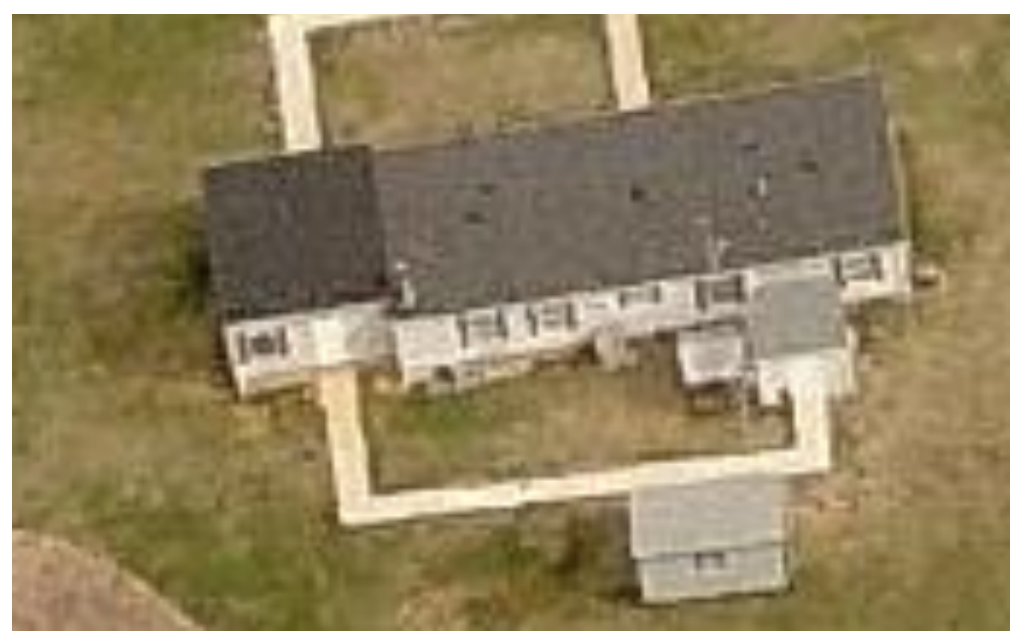

Figure 1 Aerial view of NIST manufactured test house

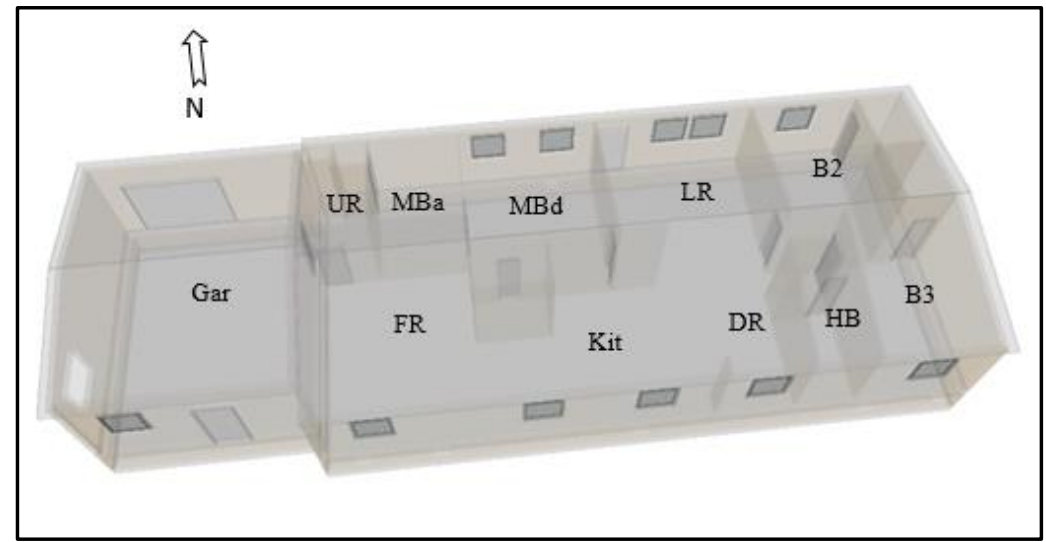

Figure 2 Floorplan of NIST manufactured test house 


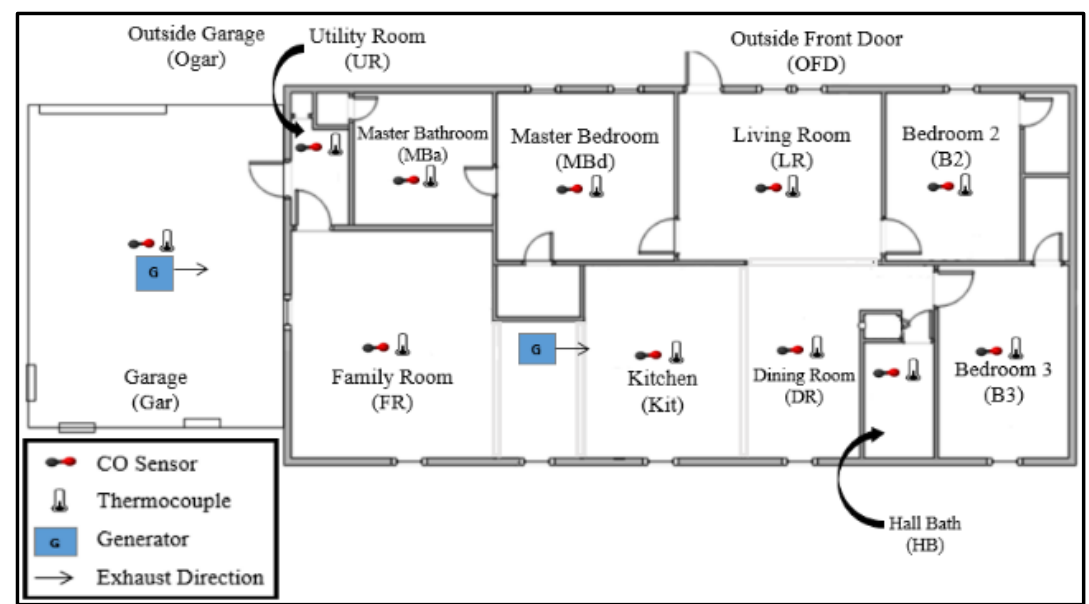

Figure 3 NIST manufactured test house layout showing the location of CO sensors, thermocouples, and generator placement with exhaust direction.

\section{Instrumentation}

$\mathrm{CO}$ concentrations in the test house were measured using a non-dispersive infrared (NDIR) multigas analyzer and arrays of electrochemical sensors. Thermocouples were placed near all electrochemical sensors and within each room. The measurement equipment was connected to a custom data acquisition system. In addition to $\mathrm{CO}$ concentrations and interior temperature, weather conditions, including wind and temperature near the test house, were also recorded.

The NDIR analyzer was used with a range of 0 to 1000 ppmv to measure the $\mathrm{CO}$ concentration near the generator's CO safety shutoff sensor. Ultra-pure CO with a nitrogen balance was used to calibrate the multi-gas analyzer at the beginning of each test day.

The electrochemical sensors were used to measure $\mathrm{CO}$ concentrations in each room of the test house. Either a four-point or an eight-point sensor array was also used to measure concentrations near the generator. Two ranges (a low range and a high range) of sensors were placed at each measurement point. The low-range sensor had a range up to $800 \mathrm{ppmv}$ with integrated temperature correction, and the high-range sensor had a range up to $5000 \mathrm{ppmv}$ without integrated temperature correction. A low-range sensor and high-range sensor were placed in the center of each room, 0.84 $\mathrm{m}$ above the floor. The position of the four-point and eight-point sensor array used to measure concentrations around the generator was dependent on the test case (Figure 4). Sensor locations for different tests are indicated with letters and letters with asterisks in Figure 4. For example, when the generator was in the Kitchen, the A1 and A2 sensors for the four-point array were located at position ' $a$ ' in Figure 4, and the A3 and A4 sensors were located at position 'a. ${ }^{*}$ ' Because the high-range electrochemical sensors were not equipped with integrated temperature correction, type $\mathrm{J}$ thermocouples were placed near each of these sensors. Temperature correction was then performed in real-time by the data acquisition program. 


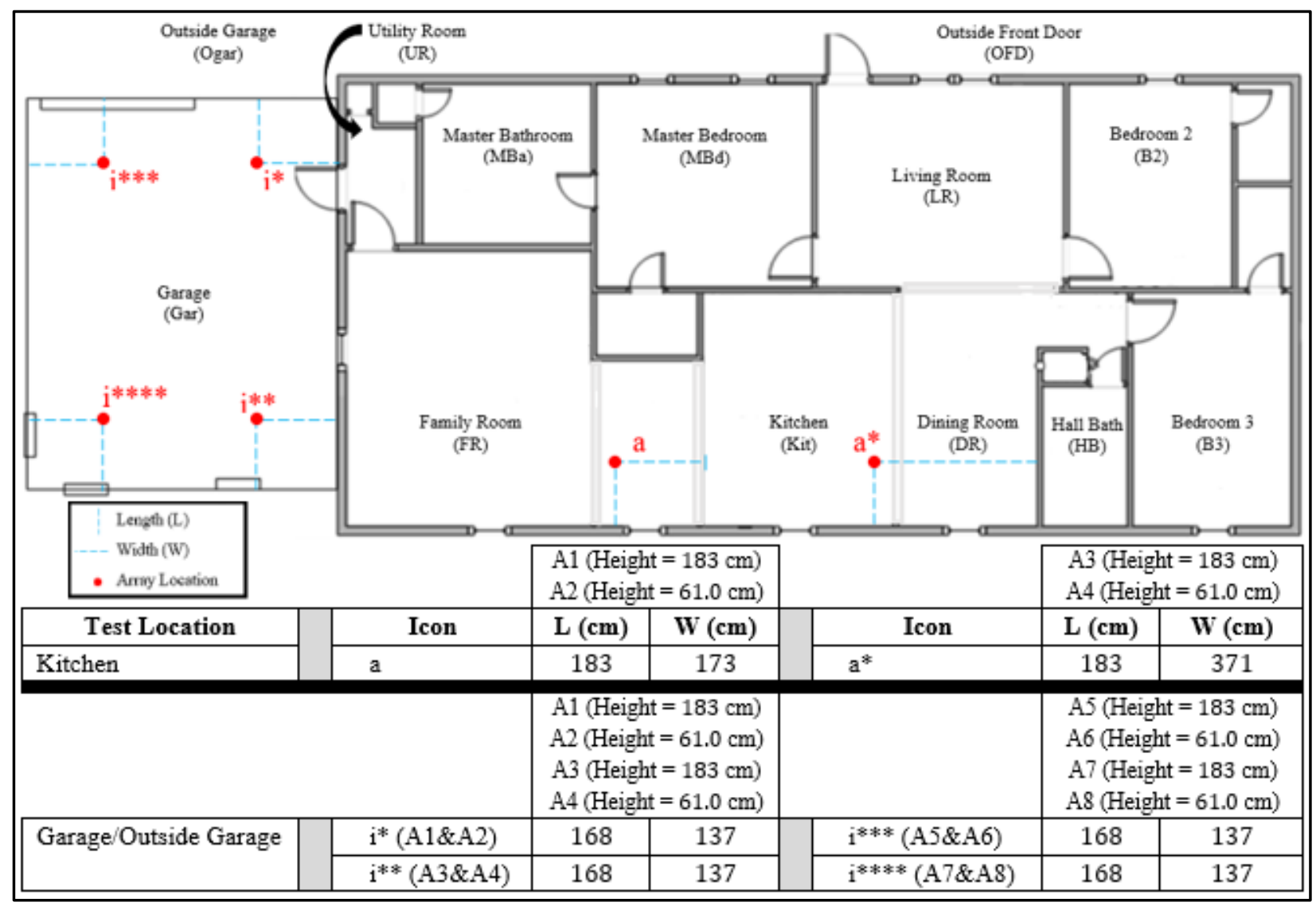

Figure 4 NIST manufactured test house layout showing positions of the four- and eight-point arrays for measuring $\mathrm{CO}$ concentration at each test location.

The electrochemical sensor modules were calibrated against a NDIR gas analyzer in CPSC's Combustion Lab. First, the analyzer was calibrated with NIST traceable primary standard gas across a range up to 800 ppmv for the low-range sensors and 5000 ppmv for the high-range sensors. The sensors were tested in batches inside a sealed conditioning chamber with a high degree of mixing. A sample was withdrawn from the center of the chamber near the center of the set of sensors being calibrated and directed to the NDIR analyzer. The same power supply and data acquisition hardware used in field testing were used to power and read the NDIR analyzer and sensor outputs during these calibrations. The sensors were calibrated by gradually increasing the concentration of $\mathrm{CO}$ in the chamber through a series of steps, then gradually decreasing the concentration back to zero. The time series data from the sensors and the analyzer were sampled at $1 \mathrm{~Hz}$. The measurement from each sensor was then compared to the measurement from the analyzer to determine a calibration factor for the sensors. Both the low- and high-range sensors were within $+/-4 \%$ of the concentrations reported by the analyzer. This results in an expanded uncertainty of $8 \%$ with a coverage factor of $k=2$. A single calibration factor was applied in the data acquisition system for each low-range and high-range sensor. The sensors were not found to drift significantly during testing based on calibrations performed before and after the test program, as well as random sensor verification during testing.

The data acquisition system consisted of hardware and software with a custom program to record $\mathrm{CO}$ concentrations with temperature correction, test start and stop time, generator load, and 
weather conditions, all at a frequency of $1 \mathrm{~Hz}$. Analog to digital converters with a minimum resolution of 16 bits were used for the $\mathrm{CO}$ channel and integrated cold junction correction for the thermocouples.

A local weather station located about $5 \mathrm{~m}$ behind the house was used to measure ambient conditions including temperature, humidity, wind speed and wind direction. All air temperature and humidity data were recorded by an automated data acquisition system. Nabinger and Persily (2008) provide more details on the temperature, humidity, and ambient weather condition measurements including uncertainties.

\section{Generators and Loading}

Four commercially available (also called production in this report) portable generators from four different manufacturers were tested. These generators are identified throughout this report as G65S, G65C, G85, and G7S. The first three (G65S, G65C, and G85) were advertised as certified to PGMA G300 and the fourth (G7S) was advertised as certified to UL 2201.

G65S: $6.5 \mathrm{~kW}$ continuous power gasoline-powered generator (G300)

G65C: $6.5 \mathrm{~kW}$ continuous power gasoline-powered generator (G300)

G85: $6.25 \mathrm{~kW}$ continuous power gasoline-powered generator (G300)

G7S: $7 \mathrm{~kW}$ continuous power gasoline-powered generator (UL 2201)

The generators were operated using commercially available gasoline with $10 \%$ ethanol obtained from an off-campus fueling station. The generators were cold-started for all tests in this report except as specifically noted.

A portable alternating current (AC) resistive load bank connected to the generator's 120-volt receptacle was used to draw electrical power, and thereby, act as a surrogate for consumer appliance loads. The load bank has manual switches for specific loads and a variable transformer for infinite load step resolution with a maximum setting of $20 \mathrm{~kW}$.

\section{Testing and Analysis Methods}

To characterize the emission and transport of $\mathrm{CO}$ and the resulting $\mathrm{COHb}$ profiles, the generators were operated until either their CO safety shutoff system shut the generator off or the generator ran out of fuel. Ventilation conditions, including window and door opening, were specified for each scenario, including any changes during the tests, as described in the results section. Exterior doors and windows were closed, and interior doors were fully open, except as specifically noted. The test house HVAC system was off at all times during tests. Upon activation of the CO safety shutoff system, the generator was left in place but not running. Ventilation conditions were not changed unless specifically noted.

Estimated $\mathrm{COHb}$ profiles were calculated from the $\mathrm{CO}$ measurements using the Coburn-ForsterKane (CFK) non-linear differential equation (Peterson and Stewart 1975, Coburn et al. 1965) and input values determined in consultation with CPSC. These input values include a respiratory minute volume (RMV) value of $10 \mathrm{~L} / \mathrm{min}$ (representing a time-weighted average 24-hour value for males and females 16 to 80 years old, for residential indoor activity) (CPSC 2016). COHb levels were calculated assuming an individual remained in the same room for the duration of the test. Calculations were performed for all rooms except the bathrooms, utility room and the garage; 
however, $\mathrm{COHb}$ calculations were performed for the garage when the generator was in the garage or outside but near the garage. Additional details on the \% COHb calculation are included in Appendix 1 of this report. According to Inkster 2012, "The \% $\mathrm{COHb}$ can serve as a useful approximation of expected $\mathrm{CO}$ poisoning severity in healthy adults during acute uptake of $\mathrm{CO}$, although it is recognized that the relationship is not absolute, and there is variation among individuals due to different physiological characteristics and/or health status. It should also be noted that measured $\mathrm{COHb}$ levels are influenced by the timing of the $\mathrm{COHb}$ measurement, relative to cessation of the $\mathrm{CO}$ exposure, and by provision of any oxygen therapy in the intervening period. Notwithstanding these caveats, increasing \% COHb levels are generally related to progressively worsening symptoms." See the table below from Burton 1996.

\begin{tabular}{|l|l|}
\hline$\%$ COHb & Symptoms \\
\hline$<10$ & $\begin{array}{l}\text { No perceptible ill effects (Some studies have reported adverse health effects in } \\
\text { some cardiac patients at } 2 \% \text { to } 5 \% \text { COHb }\end{array}$ \\
\hline 10 to 20 & Mild headache, labored breathing, decreased exercise tolerance \\
\hline 20 to 30 & Throbbing headache, mild nausea \\
\hline 30 to 40 & Severe headache, dizziness, nausea, vomiting, cognitive impairment \\
\hline 40 to 50 & Confusion, unconsciousness, coma, possible death \\
\hline 50 to 70 & Coma, brain damage, seizures, death \\
\hline$>70$ & Typically fatal \\
\hline
\end{tabular}




\section{Test Results}

As described above, NIST conducted a series of tests to provide empirical data to characterize the emission and transport of CO in the NIST manufactured test house, as well as the resulting calculated $\mathrm{COHb}$ profiles, when operating PGMA G300 or UL 2201 certified portable generators in the living space and attached garage. The resulting data, presented in this section, are organized by the location of the generator. The tests performed at each location are summarized in Tables 1 and 2. The tables include columns listing the generator location, the generator tested, the load (as a $\%$ of the maximum continuous generator capacity), the case (a combination of generator location, load and ventilation condition) and test number (PCase\#/Test\# in the tables), the voluntary standards the generator was advertised as certified to, the average outdoor temperature, the average wind speed, the peak $\mathrm{CO}$ concentration in the house or garage, the $\mathrm{CO}$ concentration measured near the sensor of the onboard safety shutoff system at the time of shutoff, the calculated shutoff ratio, the range of peak $\mathrm{COHb}$ values reached, the ventilation settings of the house, and notes. The column labeled "Peak CO in House and Garage" is the maximum CO concentration measured by any sensor located within the test house and garage (i.e., the four-point or eight-point arrays and the centrally located room sensors) during the test. The "Shutoff Ratio" column presents the ratio of the average source room $\mathrm{CO}$ concentration to the $\mathrm{CO}$ concentration measured near the generator's CO safety shutoff sensor at the time of shutoff. The average source room concentration is determined by averaging the values at the time of shutoff from the centrally located room sensor and any sensors from the sensor array that were in the source room. Note that these results apply to the specific generators tested and that other generators, houses, and test conditions may produce different results. Also note that the combinations of generator location, load, exhaust direction, and door/window positions were selected to represent a wide range of possible conditions and with consideration of reported incidents.

The following sections contain the individual test results organized by generator location. In each of these sections, four to five figures are presented for each test, designated as Figure $\mathrm{Xa}, \mathrm{Xb}, \mathrm{Xc}$, $\mathrm{Xd}$ and $\mathrm{Xe}$. Figure $\mathrm{Xa}$ shows the position of the generator, the generator exhaust direction, and the position of the $\mathrm{CO}$ sensor array used to measure $\mathrm{CO}$ around the generator. Figure $\mathrm{Xb}$, for the cases where the generator is positioned in the kitchen, shows the $\mathrm{CO}$ concentrations measured near the generator's CO safety shutoff sensor, by the CO sensor array, and by the centrally located room sensor. Figure $\mathrm{Xb}$, for the cases where the generator is positioned in the garage, shows $\mathrm{CO}$ concentrations measured near the generator's CO safety shutoff sensor, by the CO sensor array, by the $\mathrm{G} 300$ height sensor ( $3 \mathrm{~cm}$ to $5 \mathrm{~cm}$ above the centerline of the top of the generator), and by the UL 2201 height sensor (30 cm above the centerline of the top of the generator). Figure Xc shows the $\mathrm{CO}$ concentrations measured by the centrally located room sensors in each room. Figure $\mathrm{Xd}$ shows the $\mathrm{CO}$ concentrations averaged over a 1-minute time step measured by the centrally located room sensors in the areas of the home likely to be occupied (i.e., not including bathrooms, hallways, utility room, and closets). This figure also presents projected $\mathrm{CO}$ concentrations after the test was ended. These estimates are obtained for each room by applying the equation $\mathrm{C}=\mathrm{C}_{0} \mathrm{e}^{-\mathrm{rt}}$, where $\mathrm{C}$ is the concentration of $\mathrm{CO}$ in the room at time $\mathrm{t}, \mathrm{C}_{0}$ is the last $\mathrm{CO}$ measurement taken from the room (the initial $\mathrm{CO}$ concentration for projected values), and $\mathrm{r}$ is the exponential decay constant of the room (calculated by an exponential fit to the measured data typically over the last hour of the test). These data were used to develop the $\mathrm{COHb}$ profiles in the corresponding Figure $\mathrm{Xe}$, assuming a simulated occupant stays in each room for the duration of the test. 


\section{Generator Location: Kitchen}

Table 1 summarizes the results for all tests performed with a generator located in the test house kitchen. The details are discussed below and shown in Figures 5 through 16.

\begin{tabular}{|c|c|c|c|c|c|c|c|c|c|c|c|c|}
\hline $\begin{array}{l}\text { Generator } \\
\text { Location }\end{array}$ & Generator & $\begin{array}{r}\text { Load } \\
(\%) \\
\end{array}$ & $\begin{array}{c}\text { PCase \# / } \\
\text { Test \# }\end{array}$ & $\begin{array}{l}\text { Voluntary } \\
\text { Standard }\end{array}$ & $\begin{array}{l}\text { Avg Temp } \\
\text { Out } \\
\text { (C) } \\
\end{array}$ & $\begin{array}{c}\text { Avg } \\
\text { Wind } \\
\text { Speed } \\
\\
(\mathrm{m} / \mathrm{s}) \\
\end{array}$ & $\begin{array}{c}\text { Peak CO } \\
\text { in House } \\
\text { and Garage } \\
(\mu \mathrm{L} / \mathrm{L}) \\
\end{array}$ & $\begin{array}{c}\text { Concentration } \\
\text { @ Shutoff + } \\
(\mu \mathrm{L} / \mathrm{L}) \\
\end{array}$ & $\begin{array}{c}\text { Shutoff Ratio } \\
\text { (Zone Avg: } \\
\text { Near Shutoff Sensor) } \\
\end{array}$ & $\begin{array}{c}\text { Range of } \\
\text { Peak COHb } \\
\text { Values H } \\
(\%) \\
\end{array}$ & $\begin{array}{c}\text { Ventilation } \mathrm{H} \\
\text { (W=window open, } \\
\mathrm{D}=\text { door open })\end{array}$ & $\begin{array}{c}\text { Shutoff } \\
\text { Activation } \\
\\
(\mathrm{min}) \\
\end{array}$ \\
\hline \multirow{12}{*}{$\begin{array}{l}\text { Kitchen } \\
\text { (Kit) }\end{array}$} & G65S & 100 & $1 / 1$ & G300 & 27.7 & 1.0 & 1038 & 535 & 1.33 & 25 to 30 & \multirow[t]{12}{*}{$\mathrm{W}($ Kit $)-10 \mathrm{~cm}$} & $\approx 4$ \\
\hline & G65C & 100 & $1 / 1$ & G300 & 25.3 & 0.9 & 543 & 245 & 1.74 & 10 to 13 & & $\approx 4$ \\
\hline & G7S & 100 & $1 / 1$ & UL2201 & 23.1 & 1.3 & 189 & 114 & 1.33 & 5 to 7 & & $\approx 39$ \\
\hline & G85 & 100 & $1 / 1$ & G300 & 27.6 & 1.2 & 588 & 492 & 1.26 & 14 to 16 & & $\approx 3$ \\
\hline & G65S & 50 & $2 / 1$ & G300 & 22.2 & 3.4 & 1161 & 486 & 1.36 & 18 to 22 & & $\approx 7$ \\
\hline & G65C & 50 & $2 / 1$ & G300 & 23.5 & 1.2 & 440 & 311 & 1.26 & 15 to 18 & & $\approx 23$ \\
\hline & G7S & 50 & $2 / 1$ & UL2201 & 23.1 & 3.2 & 219 & 131 & 1.26 & 6 to 8 & & $\approx 38$ \\
\hline & G85 & 50 & $2 / 1$ & G300 & 26.6 & 1.3 & 439 & 339 & 1.20 & 6 to 8 & & $\approx 3$ \\
\hline & G65S & 10 & $3 / 1$ & G300 & 31.1 & 2.0 & 631 & 453 & 1.05 & 15 to 18 & & $\approx 10$ \\
\hline & G65C & 10 & $3 / 1$ & G300 & 20.9 & 1.3 & 289 & 230 & 1.16 & 12 to 16 & & $\approx 171$ \\
\hline & G7S & 10 & $3 / 1$ & UL2201 & 22.9 & 1.2 & 145 & - & - & 5 to 8 & & $\approx 294 \mathrm{HH}$ \\
\hline & G85 & 10 & $3 / 1$ & G300 & 31.8 & 2.2 & 509 & 329 & 1.33 & 8 to 10 & & $\approx 4$ \\
\hline
\end{tabular}

+Measured by the low-range electrochemical sensor placed near the sensor of onboard shutoff system.

HPeak COHb Values are for house zones only.

HVentilation Note: Unless specified otherwise, during the test - all exterior doors are closed, all interior doors are fully open, and all windows are closed. H+ Shutoff not activated, generator manually shut down due to high temperatures in the house (approaching $50^{\circ} \mathrm{C}$ )

Table 1. Summary of test results for Kitchen (Kit) tests 


\section{Production Case 1 Test 1 - G65S G300}

The following figures illustrate the results for Production Case 1 Test 1. The G65S generator, which the manufacturer stated as being certified to PGMA G300, was fully fueled, positioned in the kitchen ( $30 \mathrm{~cm}$ from the master bedroom closet wall with the exhaust facing the dining room), and tested at $100 \%$ load $(6,500 \mathrm{~W})$. The kitchen window nearest to the generator was open $10 \mathrm{~cm}$. The generator's CO safety shutoff system activated to shut off the generator after approximately 4 min. Figure 5a shows the test house layout with generator location, generator exhaust direction, and sensor array locations. Figure 5b shows the CO concentrations measured in the kitchen (by the dedicated room sensor), by two sensors located on the kitchen-family room boundary (A1: height $183 \mathrm{~cm}, \mathrm{~A} 2$ : height $61 \mathrm{~cm}$ ), by the other two sensors located on the kitchen-dining room boundary (A3: height $183 \mathrm{~cm}, \mathrm{~A} 4$ : height $61 \mathrm{~cm}$ ), and by an electrochemical sensor measuring CO near the generator's CO safety shutoff sensor. The timeframe of the figure has been selected to show the degree of CO uniformity among these locations near the time of shutoff. Figure 5c shows the $\mathrm{CO}$ concentration measured in each room of the house over the test. Figure 5d shows the $\mathrm{CO}$ concentration in the house, with each room represented by a single line composed of both a 'solidline' pattern (showing measured CO concentration) and a 'dotted-line with a symbol' pattern (showing projected $\mathrm{CO}$ concentration). Figure 5e shows the calculated $\mathrm{COHb}$ profiles of simulated house occupants in each room of the house.

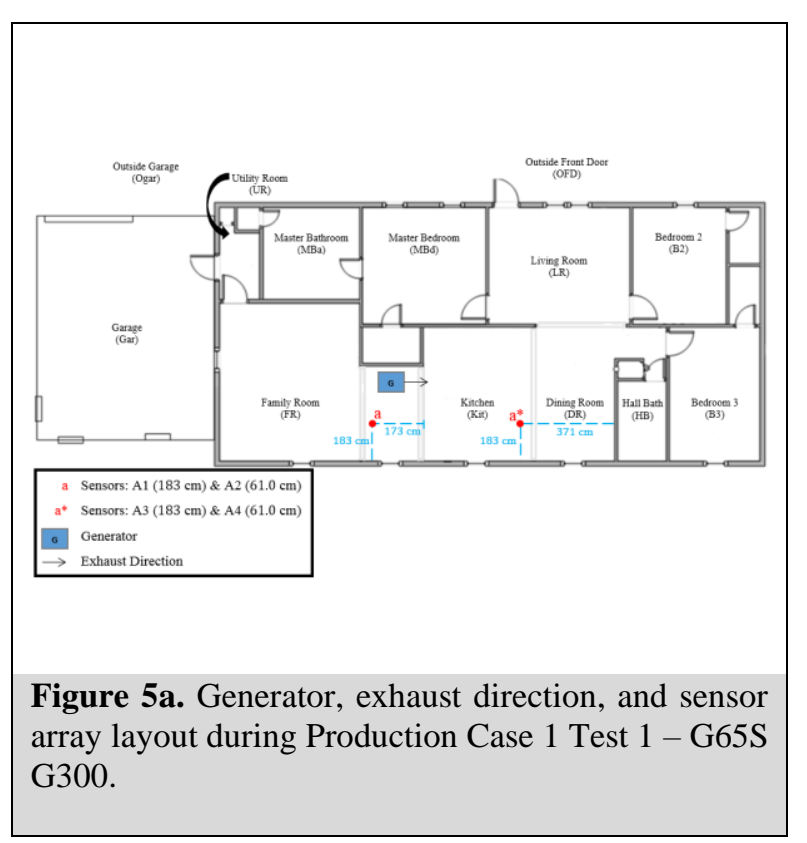

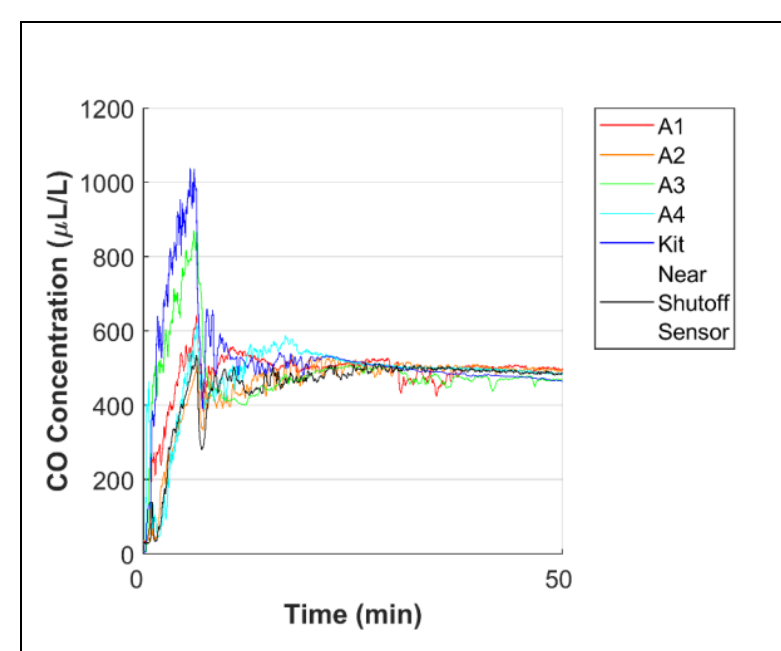

Figure 5b. CO concentration measured by the sensor array, the sensor placed near generator's $\mathrm{CO}$ safety shutoff sensor, and the designated Kitchen sensor during Production Case 1 Test 1 - G65S G300. 


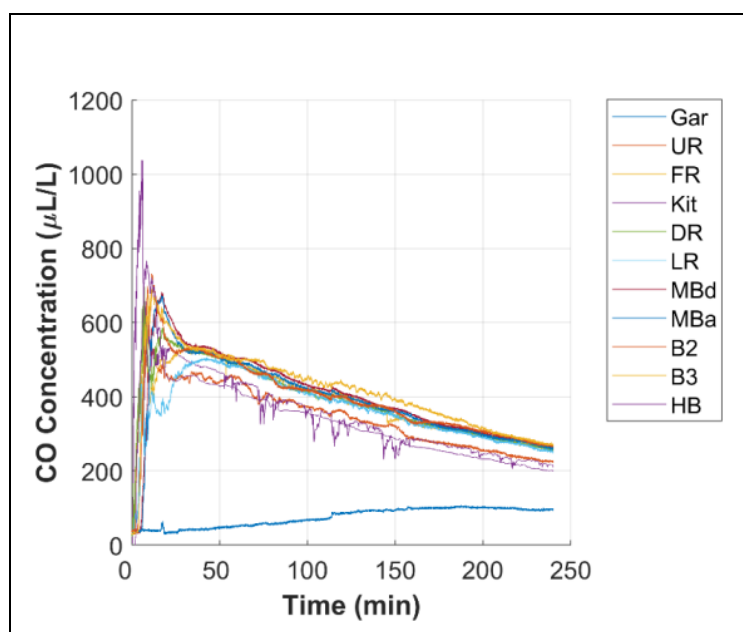

Figure 5c. $\mathrm{CO}$ concentration measured in each room of the house during Production Case 1 Test 1 - G65S G300.

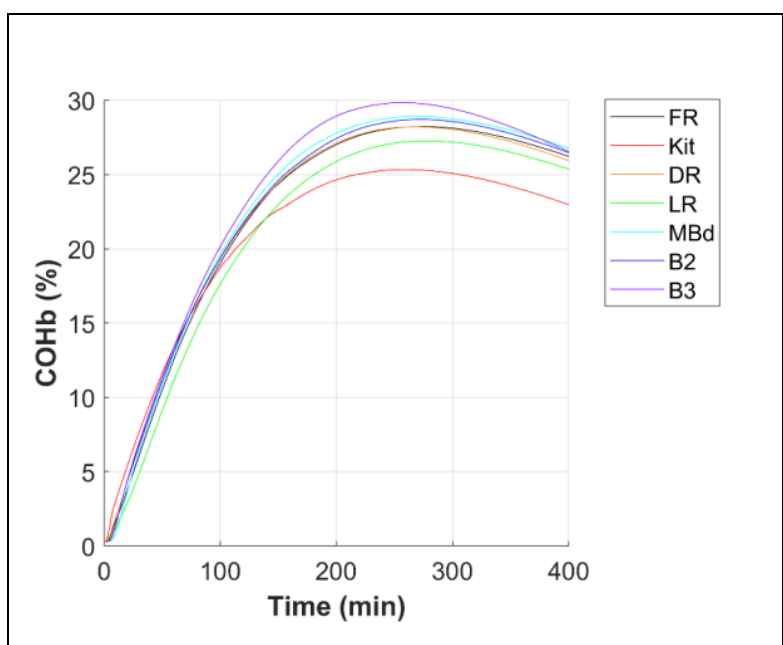

Figure 5e. $\mathrm{COHb}$ of simulated house occupants during Production Case 1 Test 1 - G65S G300.

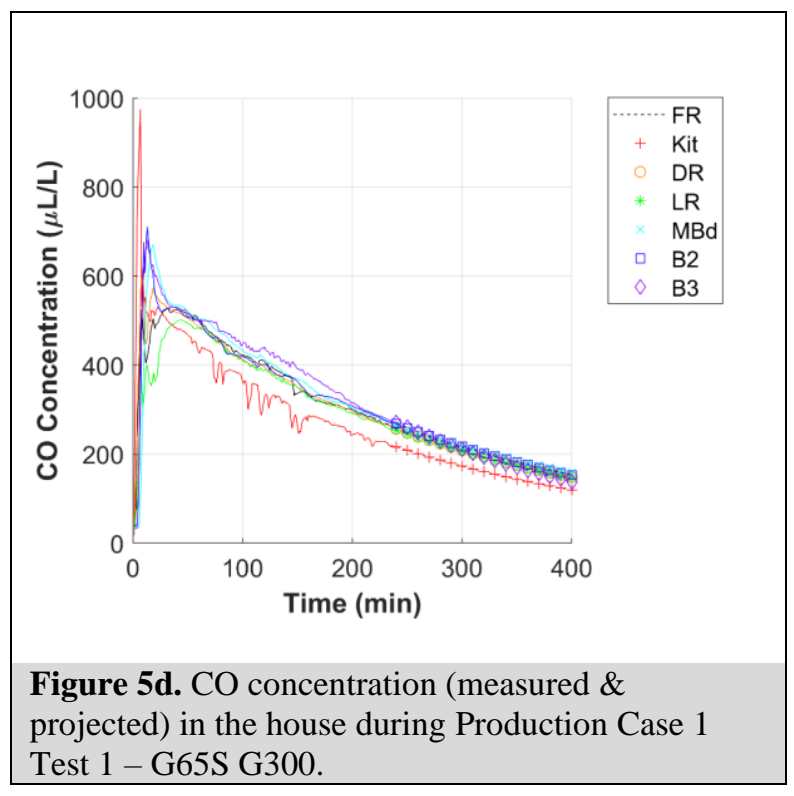

Figure 5d. CO concentration (measured \& Test 1 - G65S G300. 


\section{Production Case 1 Test 1 - G65C G300}

The following figures illustrate the results for Production Case 1 Test 1 . The G65C generator, which the manufacturer stated as being certified to PGMA G300, was fully fueled, positioned in the kitchen $(30 \mathrm{~cm}$ from the master bedroom closet wall with the exhaust facing the dining room), and tested at $100 \%$ load $(6,500 \mathrm{~W})$. The kitchen window nearest to the generator was open $10 \mathrm{~cm}$. The generator's CO safety shutoff system activated to shut off the generator after approximately 4 min. Figure 6a shows the test house layout with generator location, generator exhaust direction, and sensor array locations. Figure $\mathbf{6 b}$ shows the $\mathrm{CO}$ concentrations measured in the kitchen (by the dedicated room sensor), by two sensors located on the kitchen-family room boundary (A1: height $183 \mathrm{~cm}, \mathrm{~A} 2$ : height $61 \mathrm{~cm}$ ), by the other two sensors located on the kitchen-dining room boundary (A3: height $183 \mathrm{~cm}, \mathrm{~A} 4$ : height $61 \mathrm{~cm}$ ), and by an electrochemical sensor measuring CO near the generator's $\mathrm{CO}$ safety shutoff sensor. The timeframe of the figure has been selected to show the degree of $\mathrm{CO}$ uniformity among these locations near the time of shutoff. Figure $\mathbf{6 c}$ shows the $\mathrm{CO}$ concentration measured in each room of the house over the test. Figure 6d shows the CO concentration in the house, with each room represented by a single line composed of both a 'solidline' pattern (showing measured CO concentration) and a 'dotted-line with a symbol' pattern (showing projected $\mathrm{CO}$ concentration). Figure 6e shows the calculated $\mathrm{COHb}$ profiles of simulated house occupants in each room of the house.

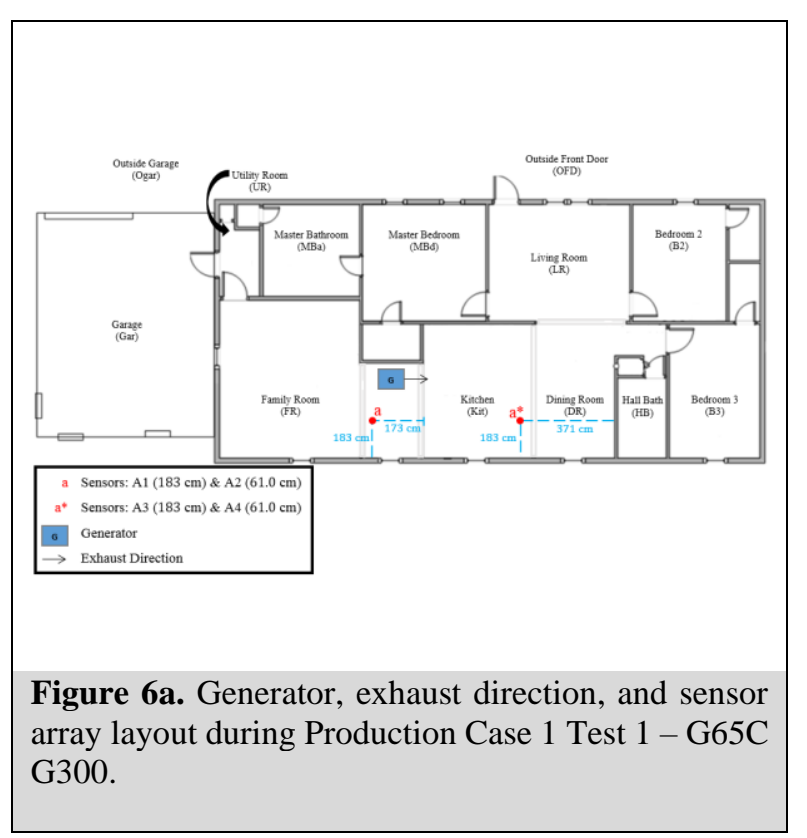

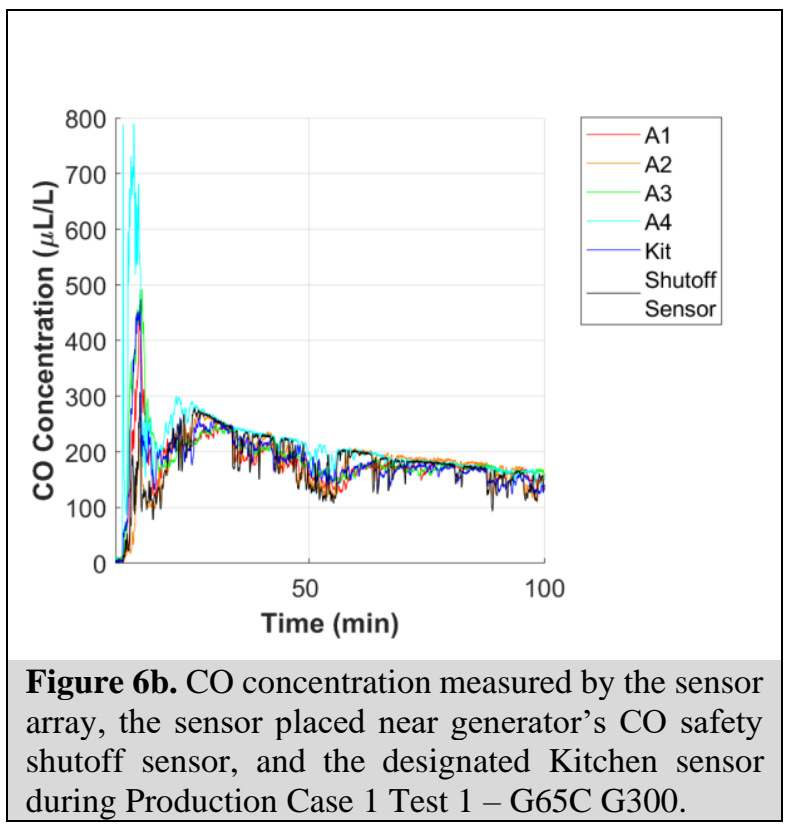




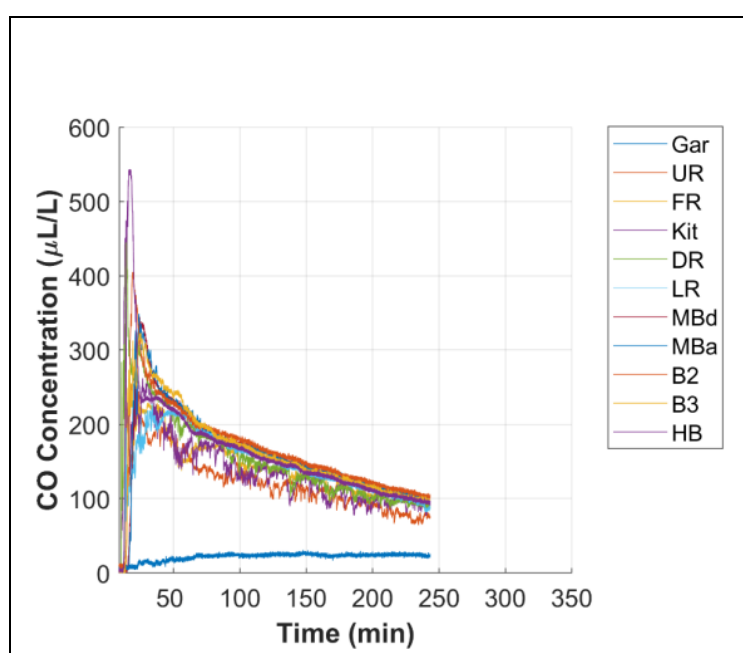

Figure 6c. $\mathrm{CO}$ concentration measured in each room of the house during Production Case 1 Test $1-$ G65C G300.

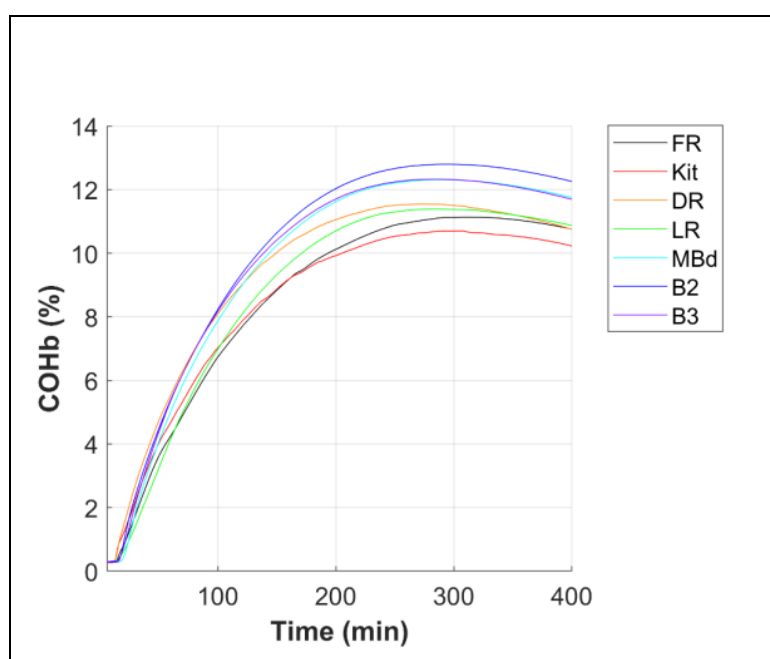

Figure 6e. $\mathrm{COHb}$ of simulated house occupants during Production Case 1 Test 1 - G65C G300.

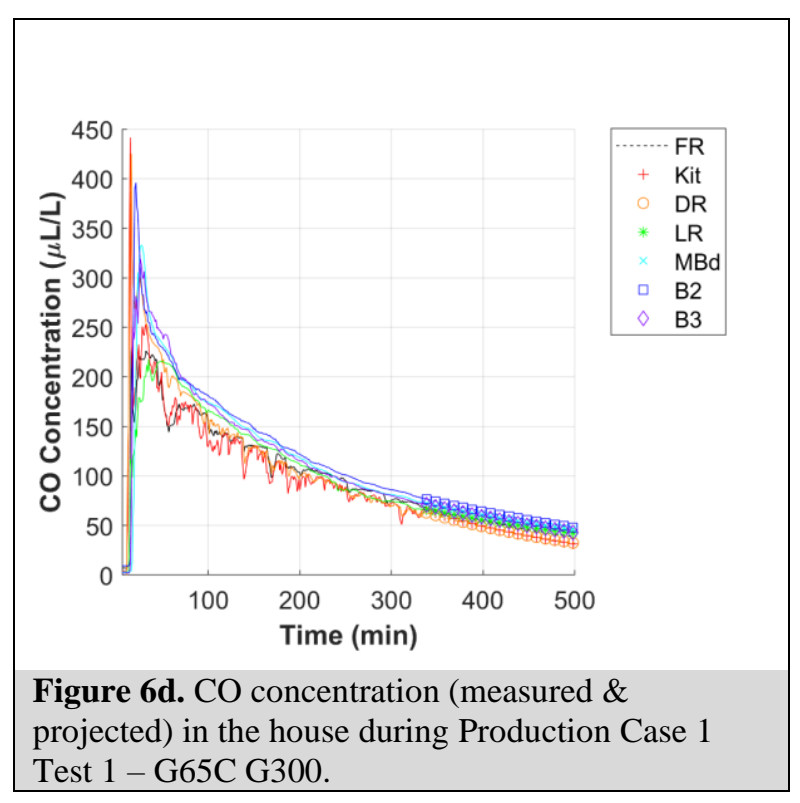

projected) in the house during Production Case 1 


\section{Production Case 1 Test 1 - G7S UL 2201}

The following figures illustrate the results for Production Case 1 Test 1. The G7S generator, which the manufacturer stated as being certified to UL 2201, was fully fueled, positioned in the kitchen (30 $\mathrm{cm}$ from the master bedroom closet wall with the exhaust facing the dining room), and tested at $100 \%$ load $(7,000 \mathrm{~W})$. The kitchen window nearest to the generator was open $10 \mathrm{~cm}$. The generator's $\mathrm{CO}$ safety shutoff system activated to shut off the generator after approximately $39 \mathrm{~min}$. Figure 7a shows the test house layout with generator location, generator exhaust direction, and sensor array locations. Figure 7b shows the $\mathrm{CO}$ concentrations measured in the kitchen (by the dedicated room sensor), by two sensors located on the kitchen-family room boundary (A1: height $183 \mathrm{~cm}, \mathrm{~A} 2$ : height $61 \mathrm{~cm}$ ), by the other two sensors located on the kitchen-dining room boundary (A3: height $183 \mathrm{~cm}, \mathrm{~A} 4$ : height $61 \mathrm{~cm}$ ), and by an electrochemical sensor measuring CO near the generator's $\mathrm{CO}$ safety shutoff sensor. The timeframe of the figure has been selected to show the degree of $\mathrm{CO}$ uniformity among these locations near the time of shutoff. Figure $7 \mathbf{c}$ shows the $\mathrm{CO}$ concentration measured in each room of the house over the test. Figure 7d shows the CO concentration in the house, with each room represented by a single line composed of both a 'solidline' pattern (showing measured CO concentration) and a 'dotted-line with a symbol' pattern (showing projected $\mathrm{CO}$ concentration). Figure $\mathbf{7 e}$ shows the calculated $\mathrm{COHb}$ profiles of simulated house occupants in each room of the house.

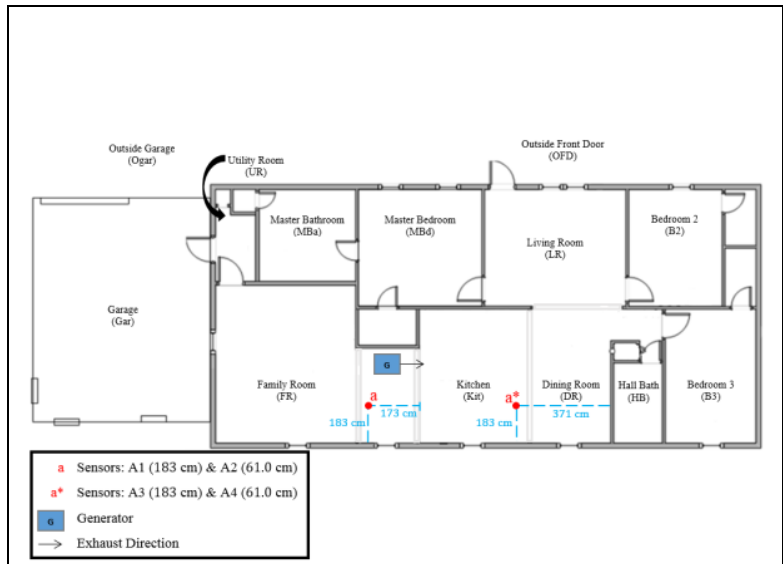

Figure 7a. Generator, exhaust direction, and sensor array layout during Production Case 1 Test 1 - G7S UL 2201.

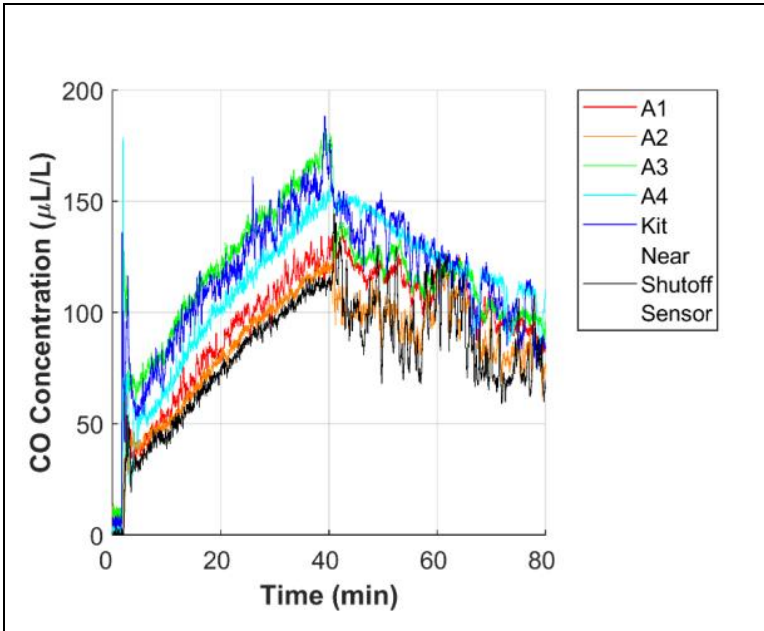

Figure $7 \mathbf{b}$. CO concentration measured by the sensor array, the sensor placed near generator's CO safety shutoff sensor, and the designated Kitchen sensor during Production Case 1 Test 1 - G7S UL 2201. 


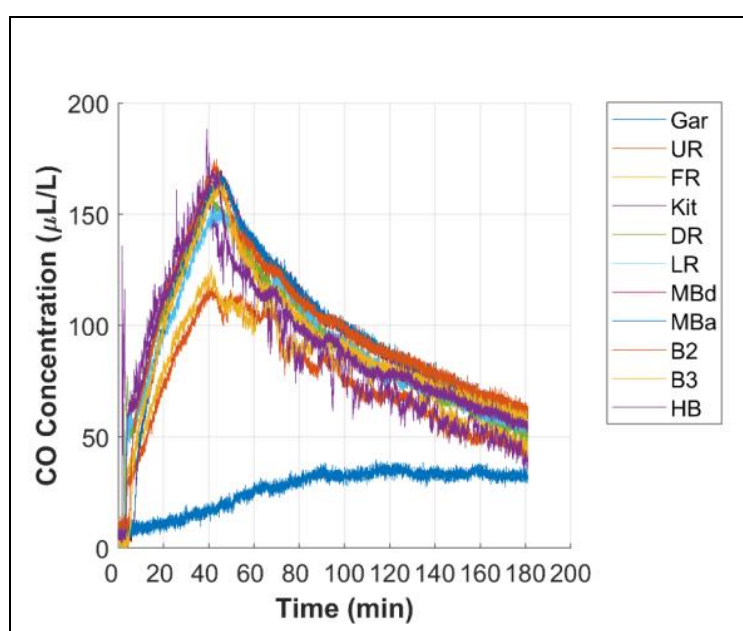

Figure 7c. $\mathrm{CO}$ concentration measured in each room of the house during Production Case 1 Test $1-$ G7S UL 2201.

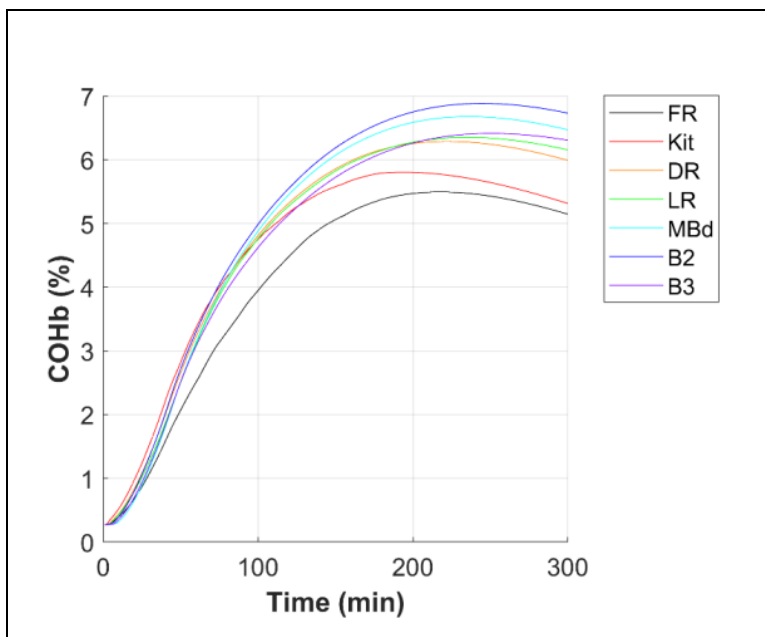

Figure 7e. $\mathrm{COHb}$ of simulated house occupants during Production Case 1 Test 1 - G7S UL 2201.

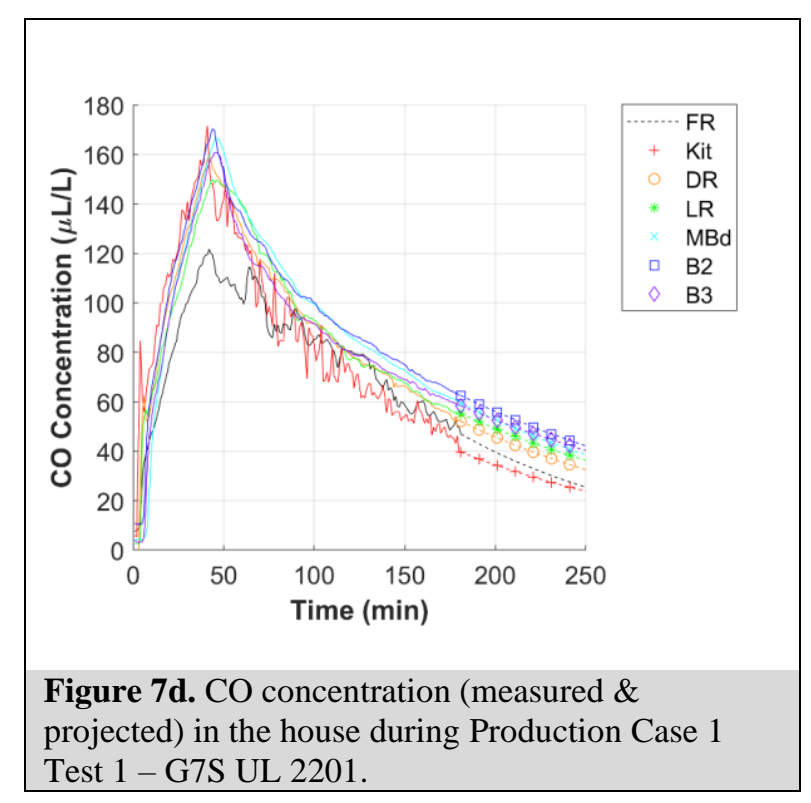

Figure 7d. CO concentration (measured \& projected) in the house during Production Case 1 Test 1 - G7S UL 2201. 


\section{Production Case 1 Test 1 - G85 G300}

The following figures illustrate the results for Production Case 1 Test 1. The G85 generator, which the manufacturer stated as being certified to PGMA G300, was fully fueled, positioned in the kitchen ( $30 \mathrm{~cm}$ from the master bedroom closet wall with the exhaust facing the dining room), and tested at $100 \%$ load $(6,250 \mathrm{~W})$. The kitchen window nearest to the generator was open $10 \mathrm{~cm}$. The generator's CO safety shutoff system activated to shut off the generator after approximately $3 \mathrm{~min}$. Figure 8a shows the test house layout with generator location, generator exhaust direction, and sensor array locations. Figure 8b shows the $\mathrm{CO}$ concentrations measured in the kitchen (by the dedicated room sensor), by two sensors located on the kitchen-family room boundary (A1: height $183 \mathrm{~cm}, \mathrm{A2}$ : height $61 \mathrm{~cm}$ ), by the other two sensors located on the kitchen-dining room boundary (A3: height $183 \mathrm{~cm}, \mathrm{~A} 4$ : height $61 \mathrm{~cm}$ ), and by an electrochemical sensor measuring $\mathrm{CO}$ near the generator's CO safety shutoff sensor. The timeframe of the figure has been selected to show the degree of $\mathrm{CO}$ uniformity among these locations near the time of shutoff. Figure 8c shows the CO concentration measured in each room of the house over the test. Figure 8d shows the CO concentration in the house, with each room represented by a single line composed of both a 'solidline' pattern (showing measured CO concentration) and a 'dotted-line with a symbol' pattern (showing projected $\mathrm{CO}$ concentration). Figure 8e shows the calculated $\mathrm{COHb}$ profiles of simulated house occupants in each room of the house.

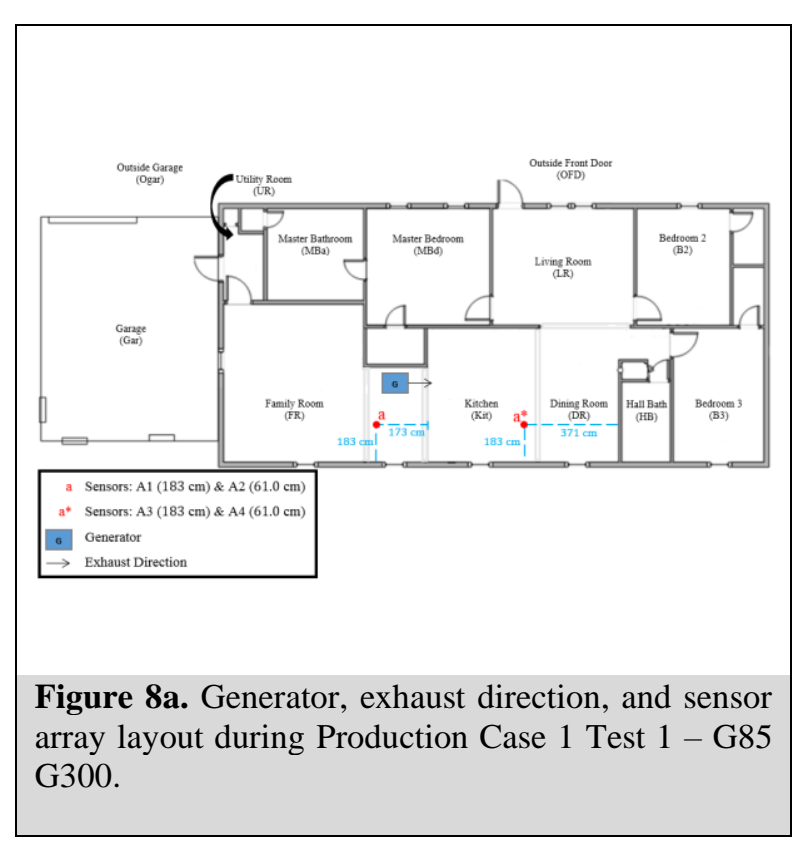

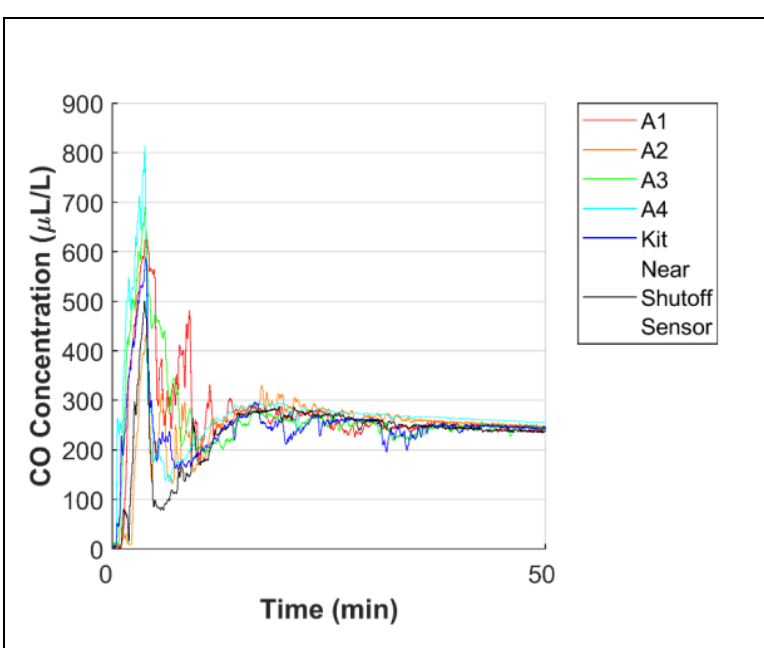

Figure $8 \mathbf{b}$. CO concentration measured by the sensor array, the sensor placed near generator's $\mathrm{CO}$ safety shutoff sensor, and the designated Kitchen sensor during Production Case 1 Test 1 - G85 G300. 


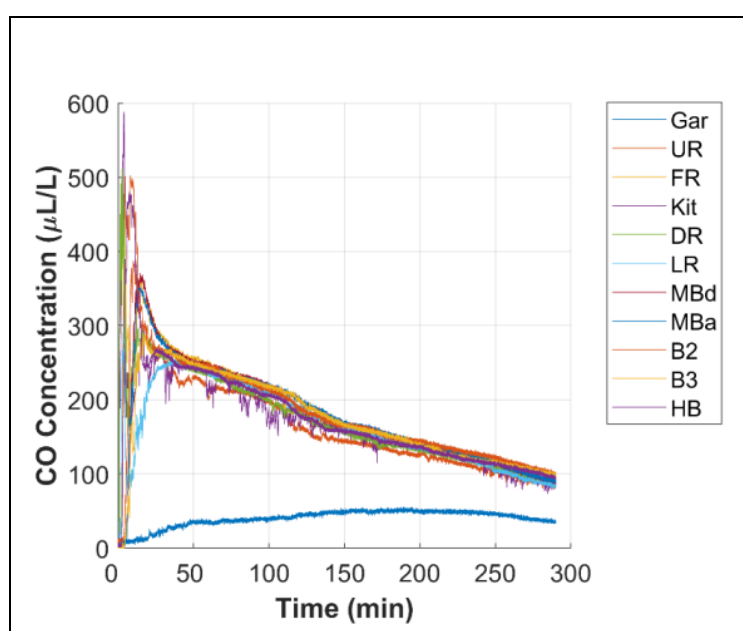

Figure 8c. $\mathrm{CO}$ concentration measured in each room of the house during Production Case 1 Test $1-$ G85 G300.

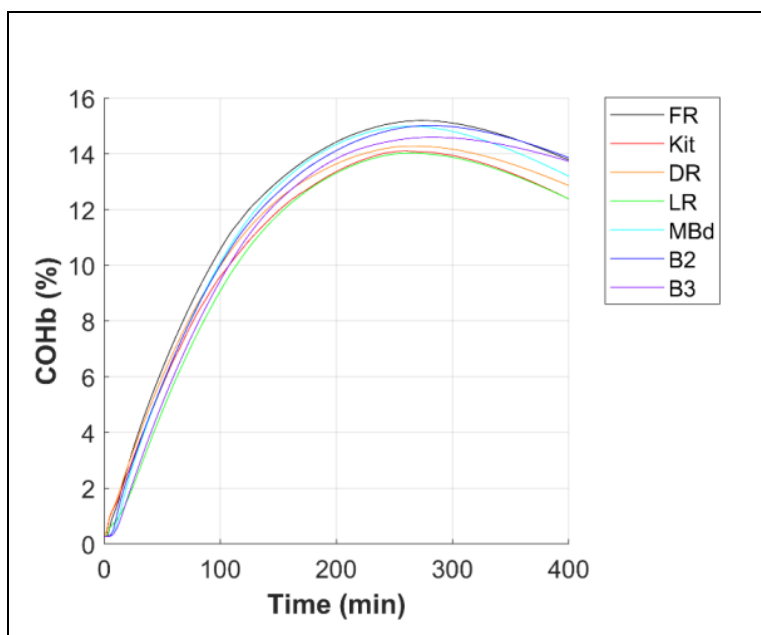

Figure 8e. $\mathrm{COHb}$ of simulated house occupants during Production Case 1 Test 1- G85 G300.

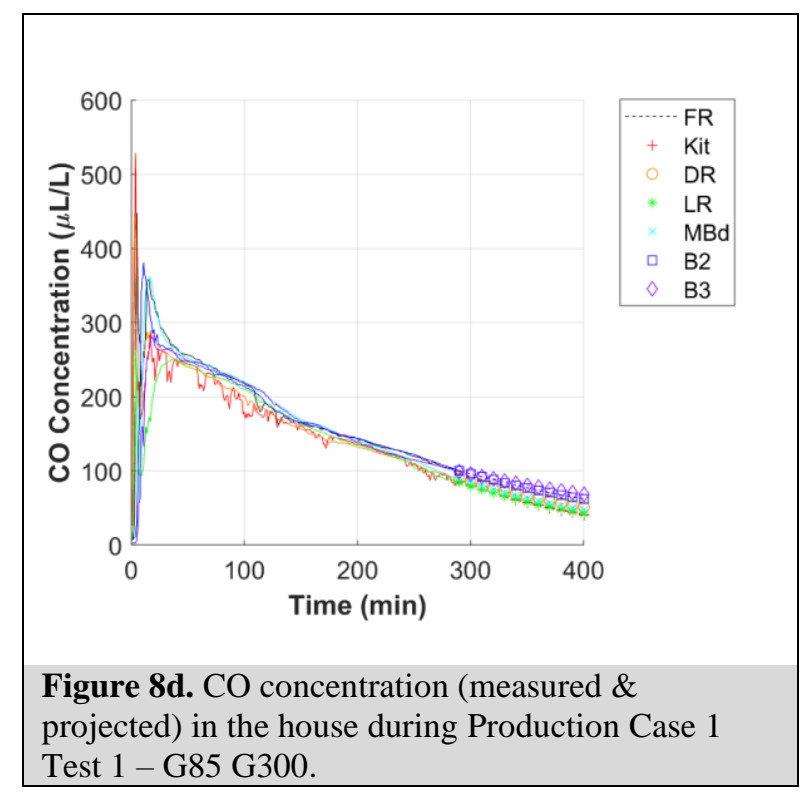

projected) in the house during Production Case 1 


\section{Production Case 2 Test 1 - G65S G300}

The following figures illustrate the results for Production Case 2 Test 1. The G65S generator, which the manufacturer stated as being certified to PGMA G300, was fully fueled, positioned in the kitchen (30 cm from the master bedroom closet wall with the exhaust facing the dining room), and tested at $50 \%$ load $(3,250 \mathrm{~W})$. The kitchen window nearest to the generator was open $10 \mathrm{~cm}$. The generator's CO safety shutoff system activated to shut off the generator after approximately 7 min. Figure 9a shows the test house layout with generator location, generator exhaust direction, and sensor array locations. Figure 9b shows the $\mathrm{CO}$ concentrations measured in the kitchen (by the dedicated room sensor), by two sensors located on the kitchen-family room boundary (A1: height $183 \mathrm{~cm}, \mathrm{~A} 2$ : height $61 \mathrm{~cm}$ ), by the other two sensors located on the kitchen-dining room boundary (A3: height $183 \mathrm{~cm}, \mathrm{~A} 4$ : height $61 \mathrm{~cm}$ ), and by an electrochemical sensor measuring CO near the generator's CO safety shutoff sensor. The timeframe of the figure has been selected to show the degree of $\mathrm{CO}$ uniformity among these locations near the time of shutoff. Figure 9c shows the $\mathrm{CO}$ concentration measured in each room of the house over the test. Figure 9d shows the $\mathrm{CO}$ concentration in the house, with each room represented by a single line composed of both a 'solidline' pattern (showing measured CO concentration) and a 'dotted-line with a symbol' pattern (showing projected $\mathrm{CO}$ concentration). Figure 9e shows the calculated $\mathrm{COHb}$ profiles of simulated house occupants in each room of the house.

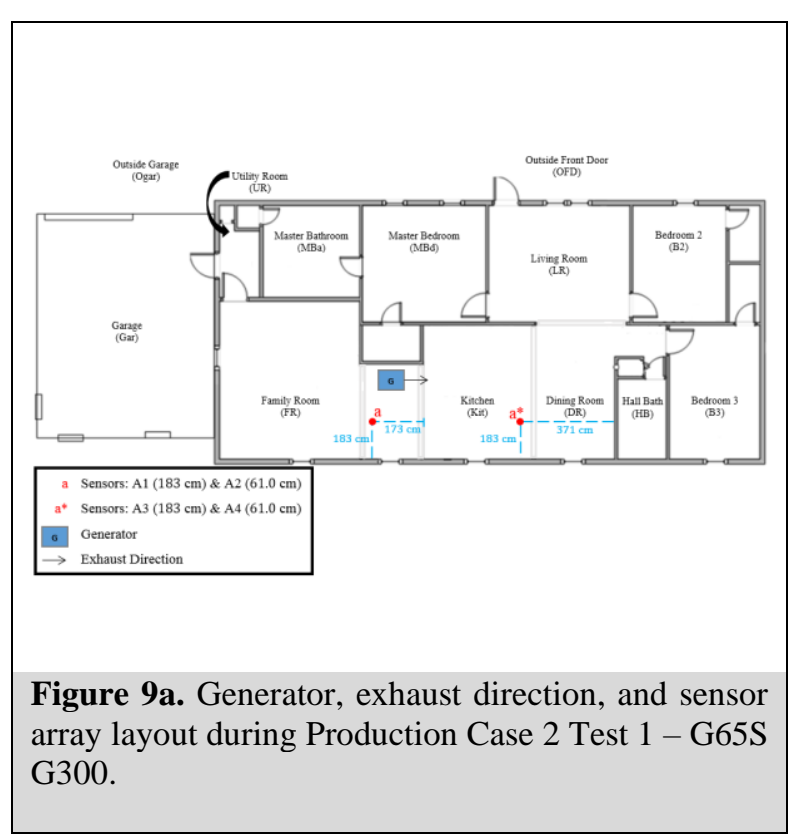

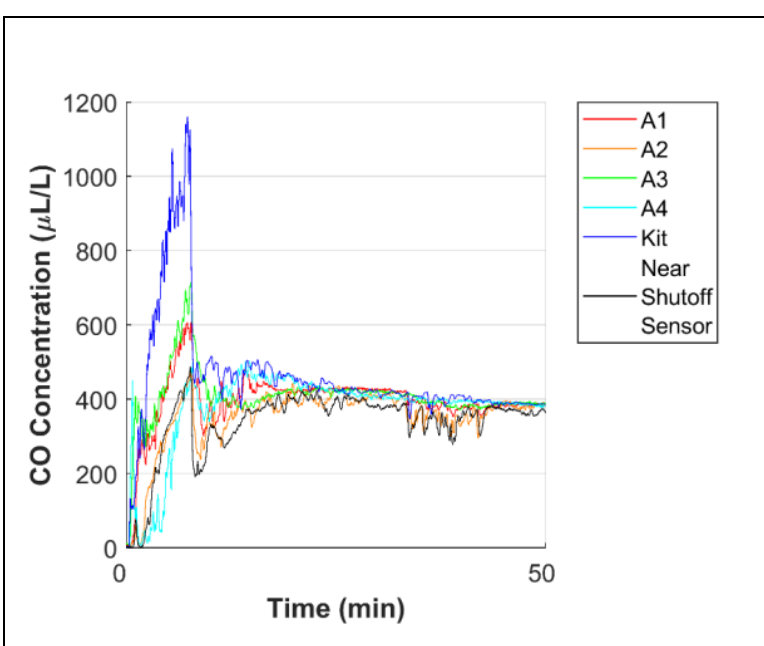

Figure 9b. CO concentration measured by the sensor array, the sensor placed near generator's CO safety shutoff sensor, and the designated Kitchen sensor during Production Case 2 Test 1 - G65S G300. 


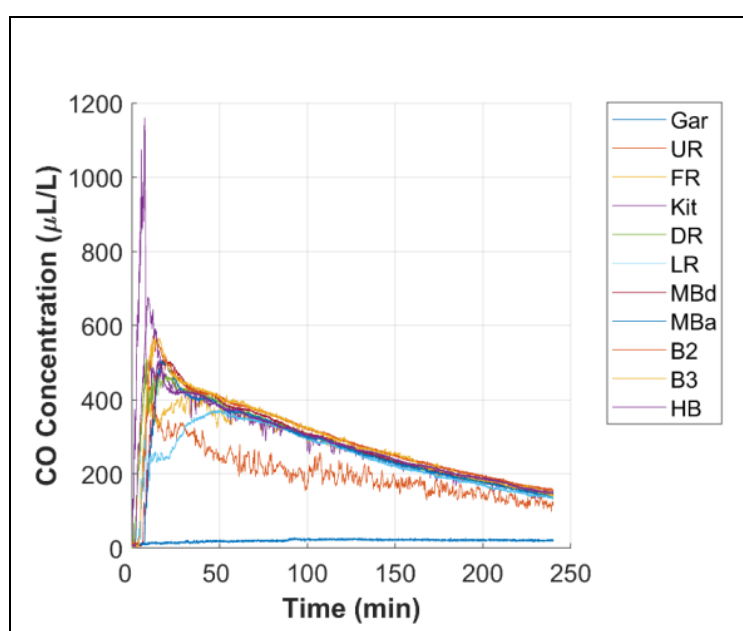

Figure 9c. $\mathrm{CO}$ concentration measured in each room of the house during Production Case 2 Test 1 - G65S G300.

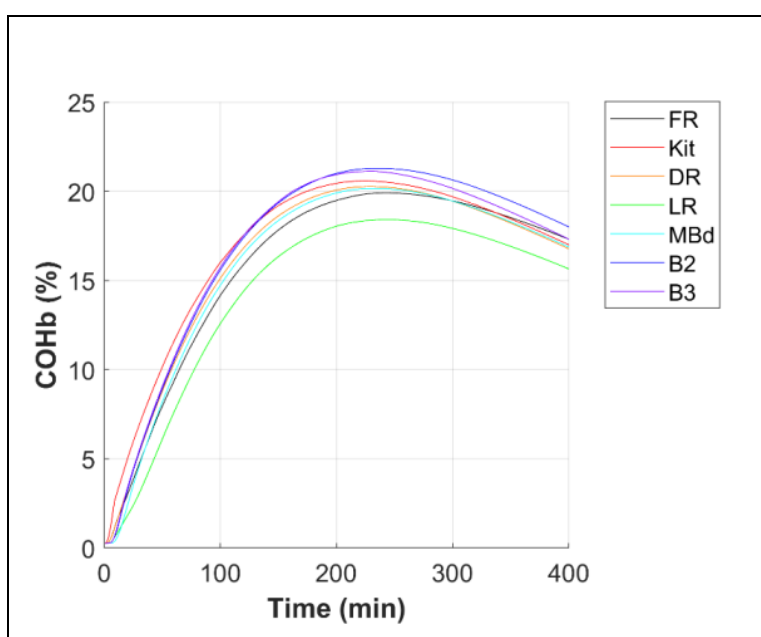

Figure 9e. $\mathrm{COHb}$ of simulated house occupants during Production Case 2 Test 1 - G65S G300.

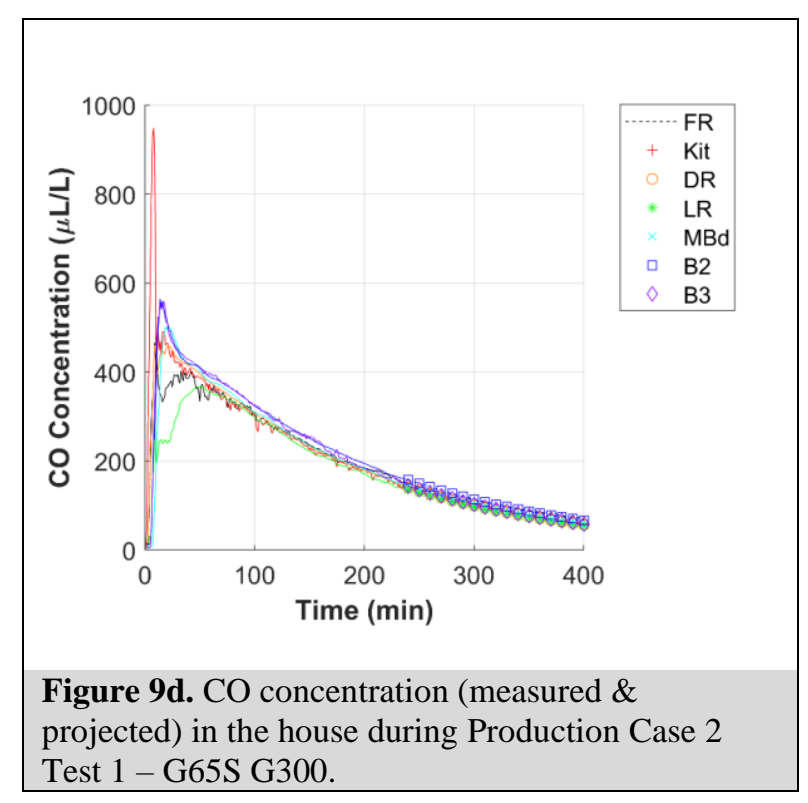

projected) in the house during Production Case 2 


\section{Production Case 2 Test 1 - G65C G300}

The following figures illustrate the results for Production Case 2 Test 1 . The G65C generator, which the manufacturer stated as being certified to PGMA G300, was fully fueled, positioned in the kitchen ( $30 \mathrm{~cm}$ from the master bedroom closet wall with the exhaust facing the dining room), and tested at $50 \%$ load $(3,250 \mathrm{~W})$. The kitchen window nearest to the generator was open $10 \mathrm{~cm}$. The generator's CO safety shutoff system activated to shut off the generator after approximately 23 min. Figure 10a shows the test house layout with generator location, generator exhaust direction, and sensor array locations. Figure 10b shows the $\mathrm{CO}$ concentrations measured in the kitchen (by the dedicated room sensor), by two sensors located on the kitchen-family room boundary (A1: height $183 \mathrm{~cm}, \mathrm{~A} 2$ : height $61 \mathrm{~cm}$ ), by the other two sensors located on the kitchendining room boundary (A3: height $183 \mathrm{~cm}$, A4: height $61 \mathrm{~cm}$ ), and by an electrochemical sensor measuring $\mathrm{CO}$ near the generator's $\mathrm{CO}$ safety shutoff sensor. The timeframe of the figure has been selected to show the degree of $\mathrm{CO}$ uniformity among these locations near the time of shutoff. Figure 10c shows the $\mathrm{CO}$ concentration measured in each room of the house over the test. Figure 10d shows the $\mathrm{CO}$ concentration in the house, with each room represented by a single line composed of both a 'solid-line' pattern (showing measured CO concentration) and a 'dotted-line with a symbol' pattern (showing projected $\mathrm{CO}$ concentration). Figure 10e shows the calculated $\mathrm{COHb}$ profiles of simulated house occupants in each room of the house.
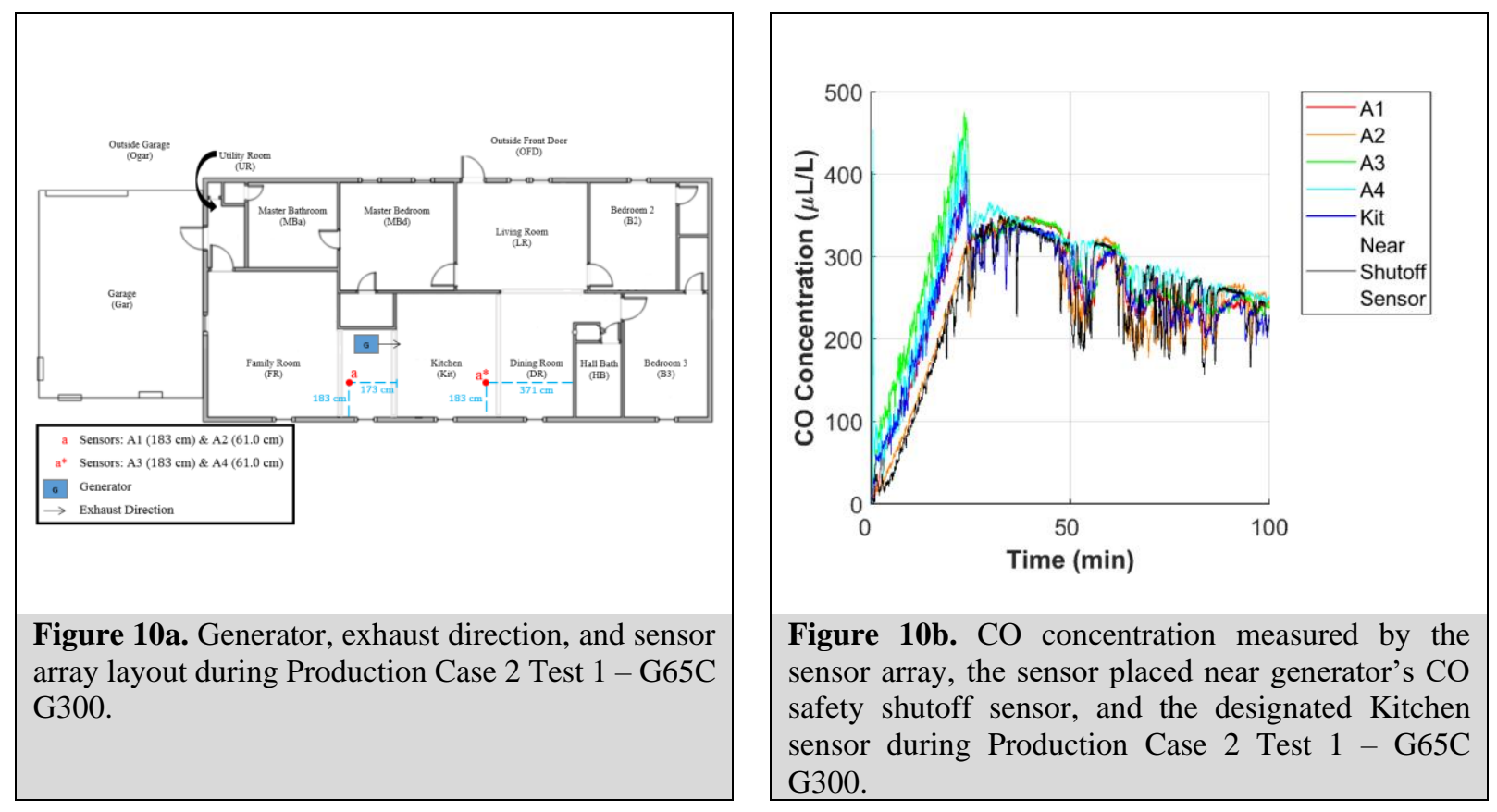


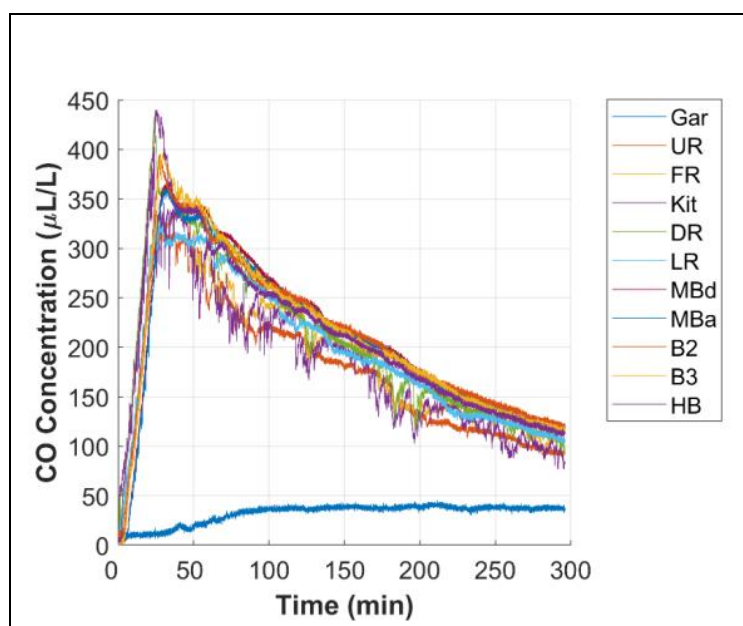

Figure 10c. $\mathrm{CO}$ concentration measured in each room of the house during Production Case 2 Test 1 - G65C G300.

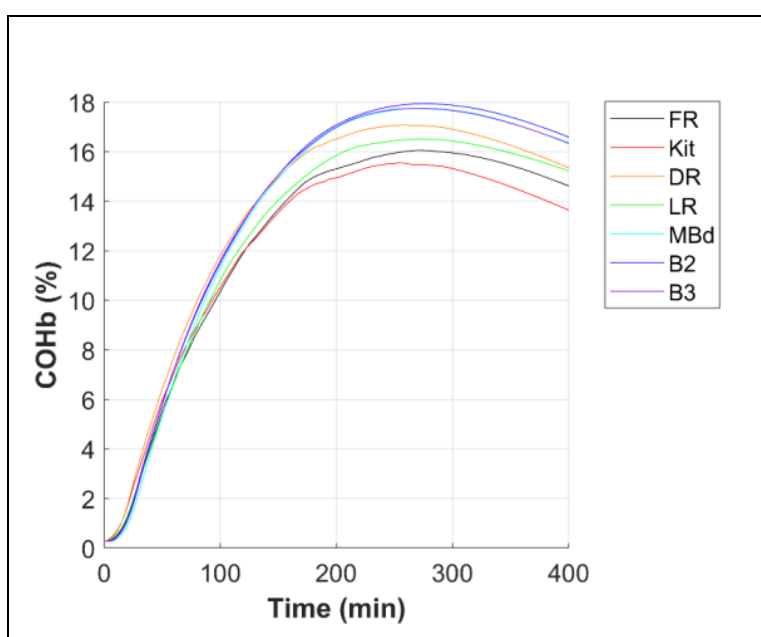

Figure 10e. $\mathrm{COHb}$ of simulated house occupants during Production Case 2 Test 1 - G65C G300.

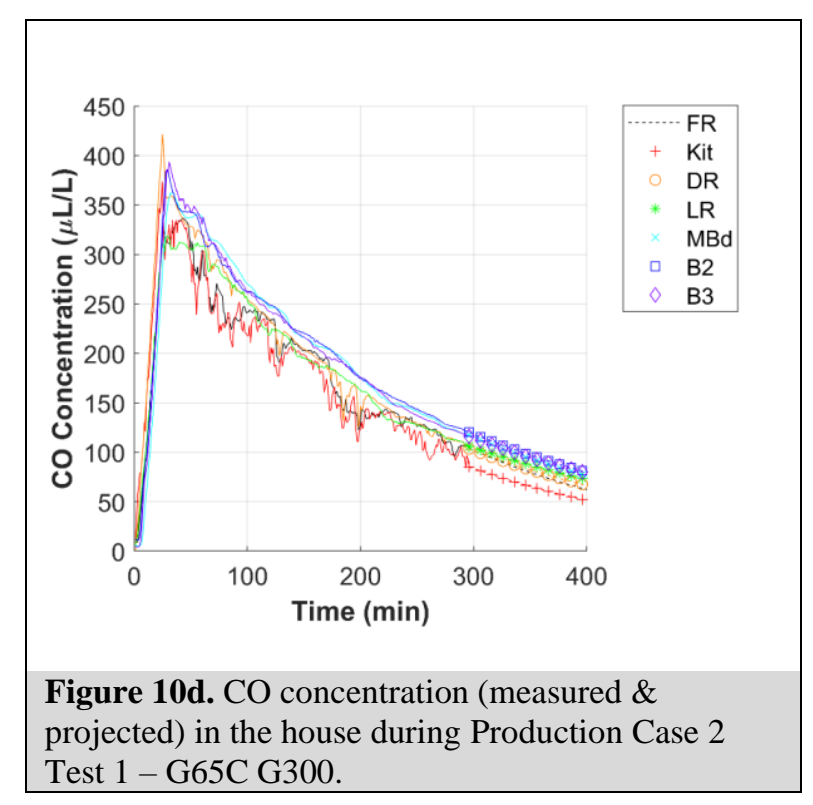

Figure 10d. CO concentration (measured \& projected) in the house during Production Case 2 Test 1 - G65C G300. 


\section{Production Case 2 Test 1 - G7S UL 2201}

The following figures illustrate the results for Production Case 2 Test 1. The G7S generator, which the manufacturer stated as being certified to UL 2201, was fully fueled, positioned in the kitchen (30 $\mathrm{cm}$ from the master bedroom closet wall with the exhaust facing the dining room), and tested at $50 \%$ load $(3,500 \mathrm{~W})$. The kitchen window nearest to the generator was open $10 \mathrm{~cm}$. The generator's $\mathrm{CO}$ safety shutoff system activated to shut off the generator after approximately $38 \mathrm{~min}$. Figure 11a shows the test house layout with generator location, generator exhaust direction, and sensor array locations. Figure 11b shows the $\mathrm{CO}$ concentrations measured in the kitchen (by the dedicated room sensor), by two sensors located on the kitchen-family room boundary (A1: height $183 \mathrm{~cm}, \mathrm{~A} 2$ : height $61 \mathrm{~cm}$ ), by the other two sensors located on the kitchendining room boundary (A3: height $183 \mathrm{~cm}, \mathrm{~A} 4$ : height $61 \mathrm{~cm}$ ), and by an electrochemical sensor measuring $\mathrm{CO}$ near the generator's $\mathrm{CO}$ safety shutoff sensor. The timeframe of the figure has been selected to show the degree of $\mathrm{CO}$ uniformity among these locations near the time of shutoff. Figure 11c shows the $\mathrm{CO}$ concentration measured in each room of the house over the test. Figure 11d shows the $\mathrm{CO}$ concentration in the house, with each room represented by a single line composed of both a 'solid-line' pattern (showing measured CO concentration) and a 'dotted-line with a symbol' pattern (showing projected CO concentration). Figure 11e shows the calculated $\mathrm{COHb}$ profiles of simulated house occupants in each room of the house.

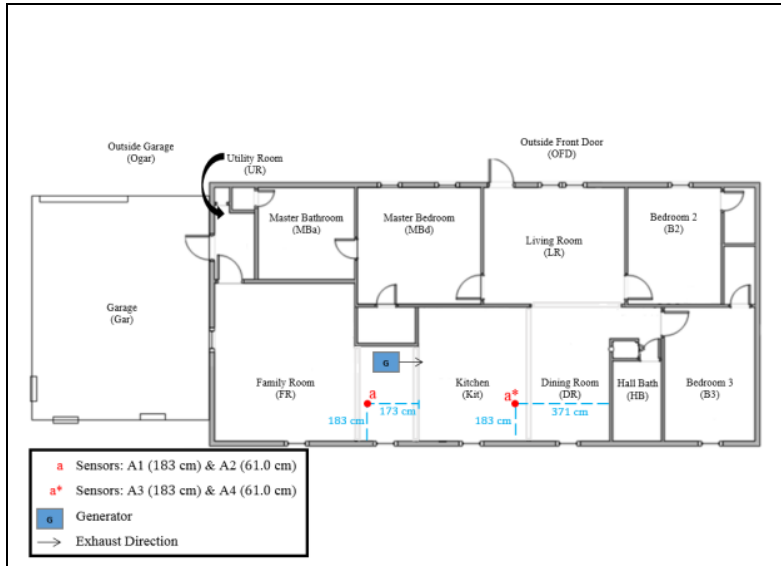

Figure 11a. Generator, exhaust direction, and sensor array layout during Production Case 2 Test 1 - G7S UL 2201.

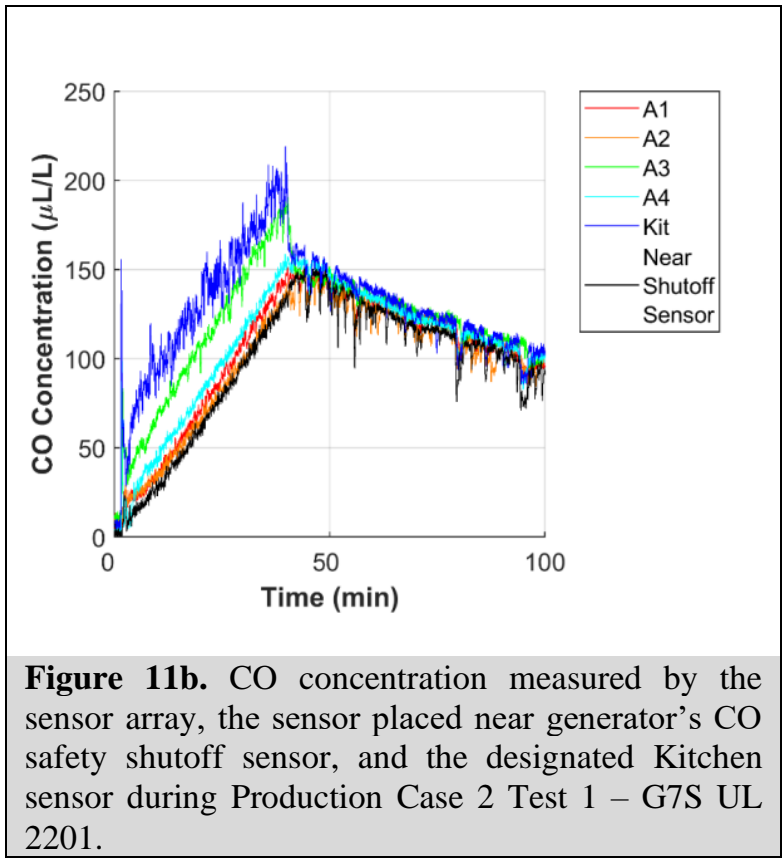




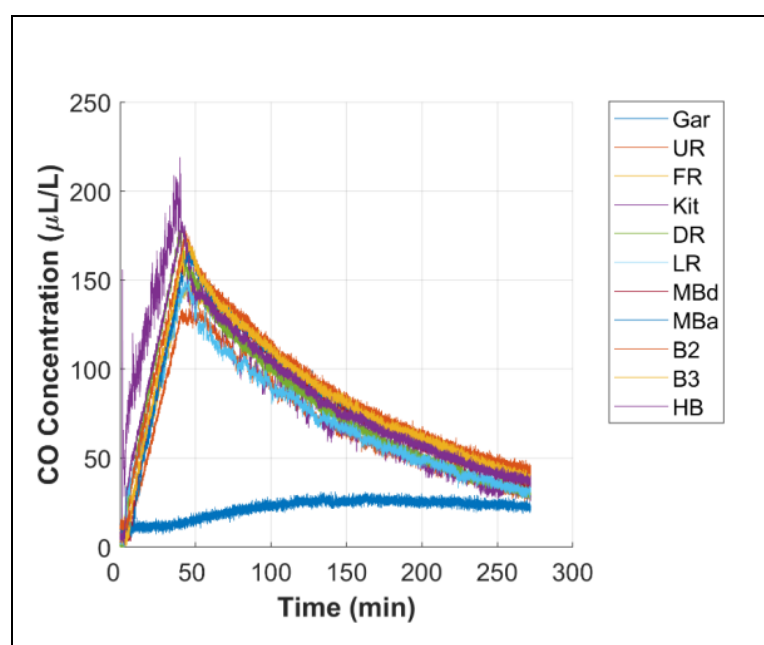

Figure 11c. $\mathrm{CO}$ concentration measured in each room of the house during Production Case 2 Test $1-$ G7S UL 2201.

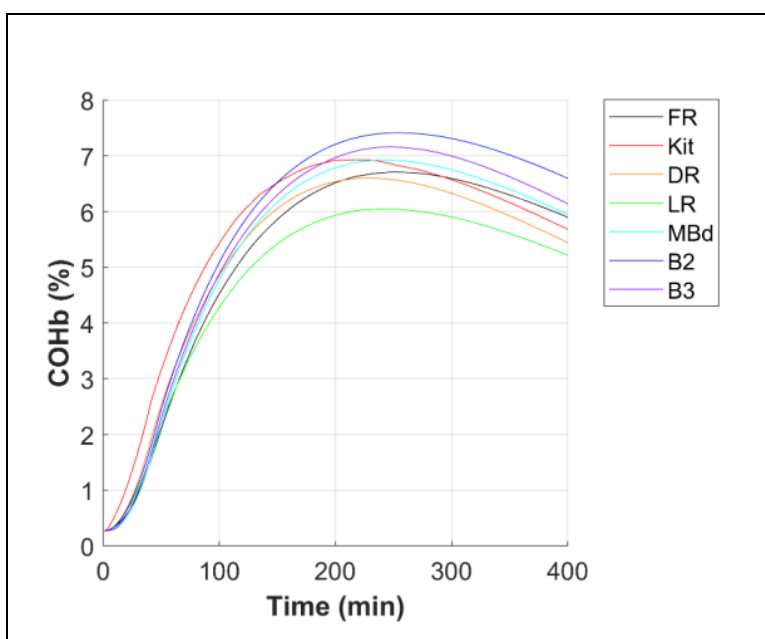

Figure 11e. $\mathrm{COHb}$ of simulated house occupants during Production Case 2 Test 1 - G7S UL 2201.

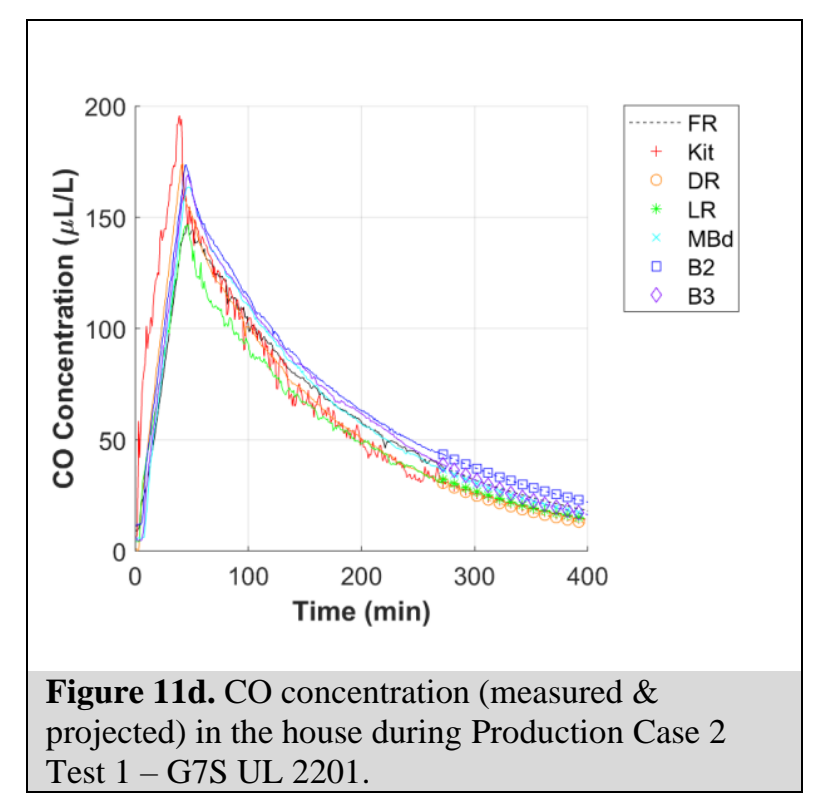

Figure 11d. CO concentration (measured \& projected) in the house during Production Case 2 Test 1 - G7S UL 2201. 


\section{Production Case 2 Test 1 - G85 G300}

The following figures illustrate the results for Production Case 2 Test 1. The G85 generator, which the manufacturer stated as being certified to PGMA G300, was fully fueled, positioned in the kitchen ( $30 \mathrm{~cm}$ from the master bedroom closet wall with the exhaust facing the dining room), and tested at $50 \%$ load $(3,125 \mathrm{~W})$. The kitchen window nearest to the generator was open $10 \mathrm{~cm}$. The generator's CO safety shutoff system activated to shut off the generator after approximately $3 \mathrm{~min}$. Figure 12a shows the test house layout with generator location, generator exhaust direction, and sensor array locations. Figure 12b shows the $\mathrm{CO}$ concentrations measured in the kitchen (by the dedicated room sensor), by two sensors located on the kitchen-family room boundary (A1: height $183 \mathrm{~cm}, \mathrm{A2}$ : height $61 \mathrm{~cm}$ ), by the other two sensors located on the kitchen-dining room boundary (A3: height $183 \mathrm{~cm}, \mathrm{~A} 4$ : height $61 \mathrm{~cm}$ ), and by an electrochemical sensor measuring $\mathrm{CO}$ near the generator's CO safety shutoff sensor. The timeframe of the figure has been selected to show the degree of $\mathrm{CO}$ uniformity among these locations near the time of shutoff. Figure 12c shows the $\mathrm{CO}$ concentration measured in each room of the house over the test. Figure 12d shows the CO concentration in the house, with each room represented by a single line composed of both a 'solidline' pattern (showing measured CO concentration) and a 'dotted-line with a symbol' pattern (showing projected $\mathrm{CO}$ concentration). Figure 12e shows the calculated $\mathrm{COHb}$ profiles of simulated house occupants in each room of the house.

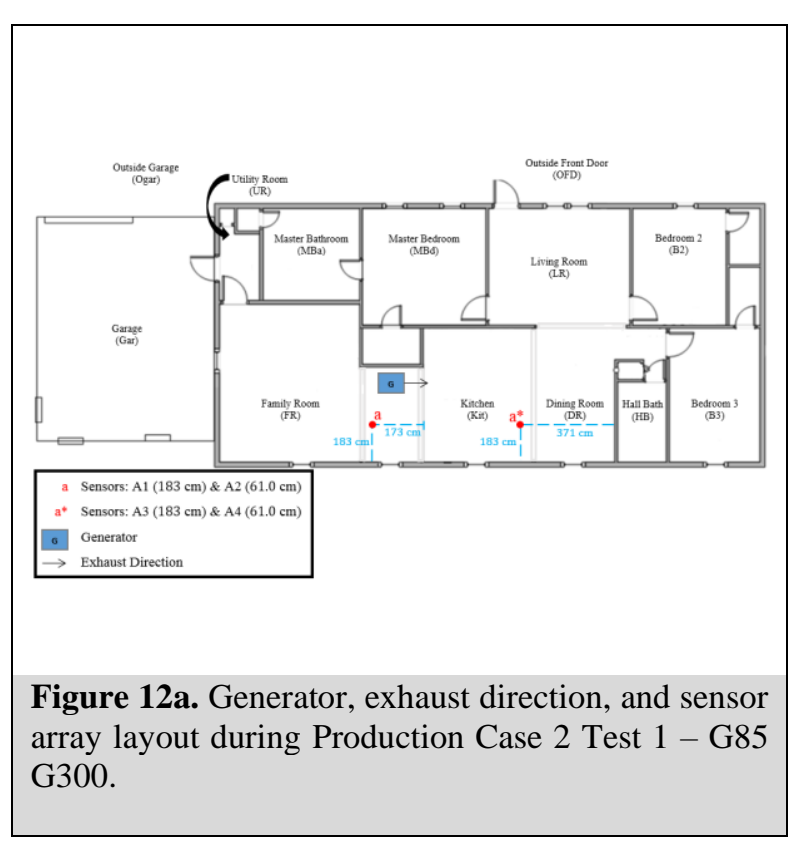

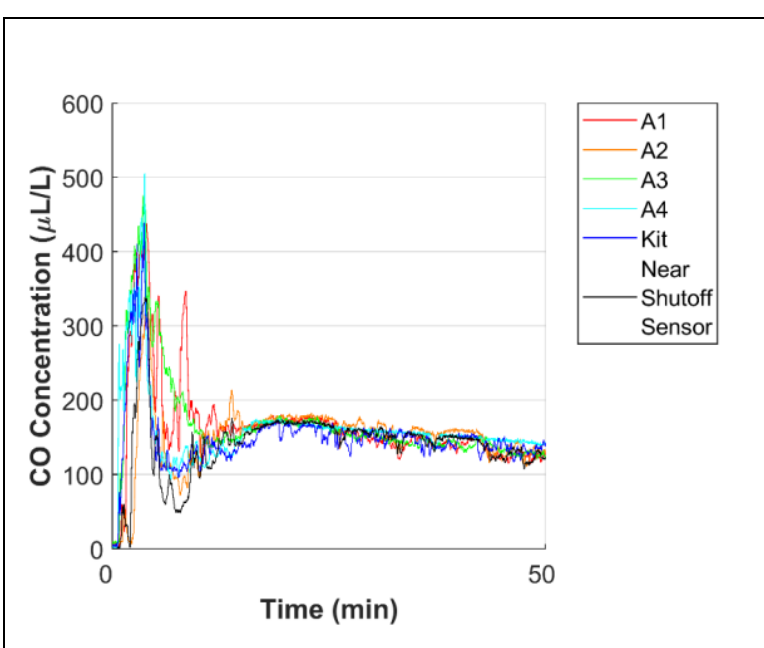

Figure 12b. $\mathrm{CO}$ concentration measured by the sensor array, the sensor placed near generator's CO safety shutoff sensor, and the designated Kitchen sensor during Production Case 2 Test 1 - G85 G300. 


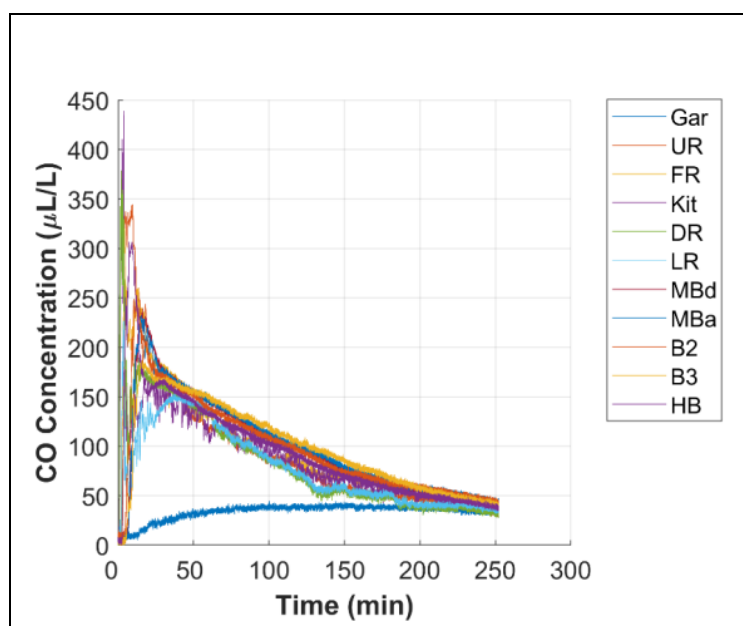

Figure 12c. $\mathrm{CO}$ concentration measured in each room of the house during Production Case 2 Test $1-$ G85 G300.

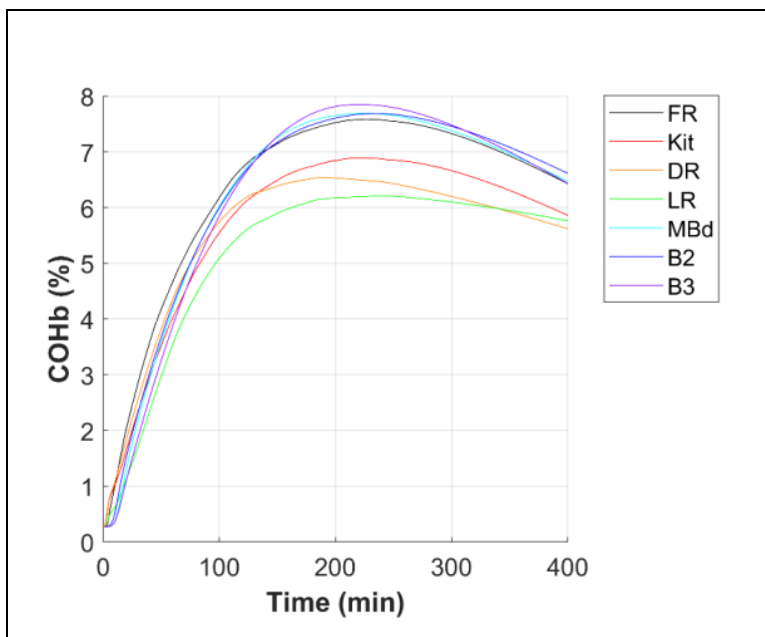

Figure 12e. $\mathrm{COHb}$ of simulated house occupants during Production Case 2 Test 1- G85 G300.

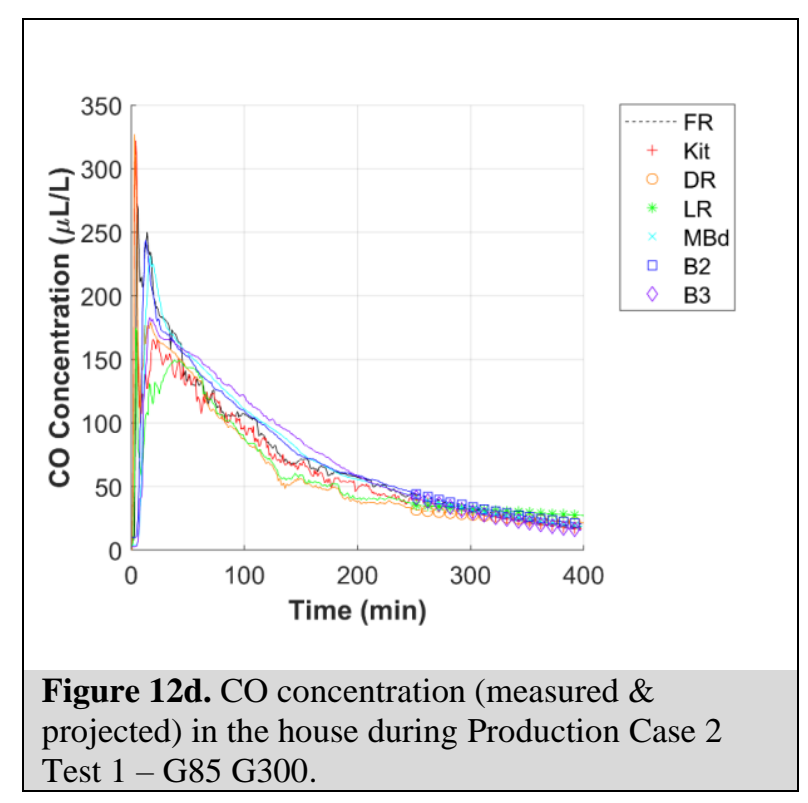

projected) in the house during Production Case 2 


\section{Production Case 3 Test 1 - G65S G300}

The following figures illustrate the results for Production Case 3 Test 1. The G65S generator, which the manufacturer stated as being certified to PGMA G300, was fully fueled, positioned in the kitchen (30 cm from the master bedroom closet wall with the exhaust facing the dining room), and tested at $10 \%$ load $(650 \mathrm{~W})$. The kitchen window nearest to the generator was open $10 \mathrm{~cm}$. The generator's CO safety shutoff system activated to shut off the generator after approximately $10 \mathrm{~min}$. Figure 13a shows the test house layout with generator location, generator exhaust direction, and sensor array locations. Figure 13b shows the $\mathrm{CO}$ concentrations measured in the kitchen (by the dedicated room sensor), by two sensors located on the kitchen-family room boundary (A1: height $183 \mathrm{~cm}, \mathrm{~A} 2$ : height $61 \mathrm{~cm}$ ), by the other two sensors located on the kitchendining room boundary (A3: height $183 \mathrm{~cm}, \mathrm{~A} 4$ : height $61 \mathrm{~cm}$ ), and by an electrochemical sensor measuring $\mathrm{CO}$ near the generator's $\mathrm{CO}$ safety shutoff sensor. The timeframe of the figure has been selected to show the degree of CO uniformity among these locations near the time of shutoff. Figure 13c shows the $\mathrm{CO}$ concentration measured in each room of the house over the test. Figure 13d shows the $\mathrm{CO}$ concentration in the house, with each room represented by a single line composed of both a 'solid-line' pattern (showing measured CO concentration) and a 'dotted-line with a symbol' pattern (showing projected CO concentration). Figure 13e shows the calculated $\mathrm{COHb}$ profiles of simulated house occupants in each room of the house.

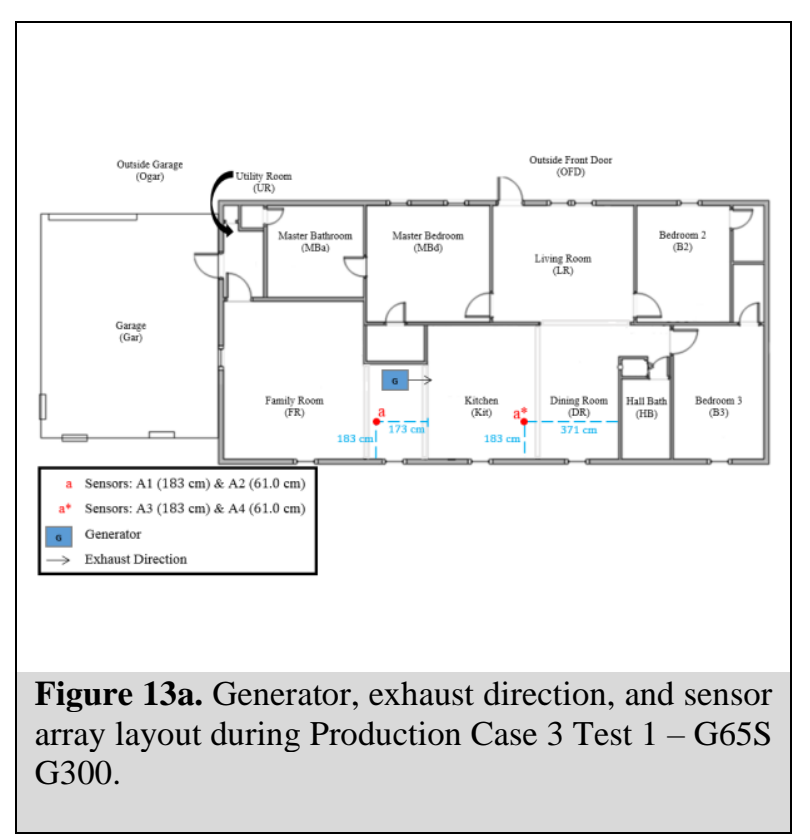

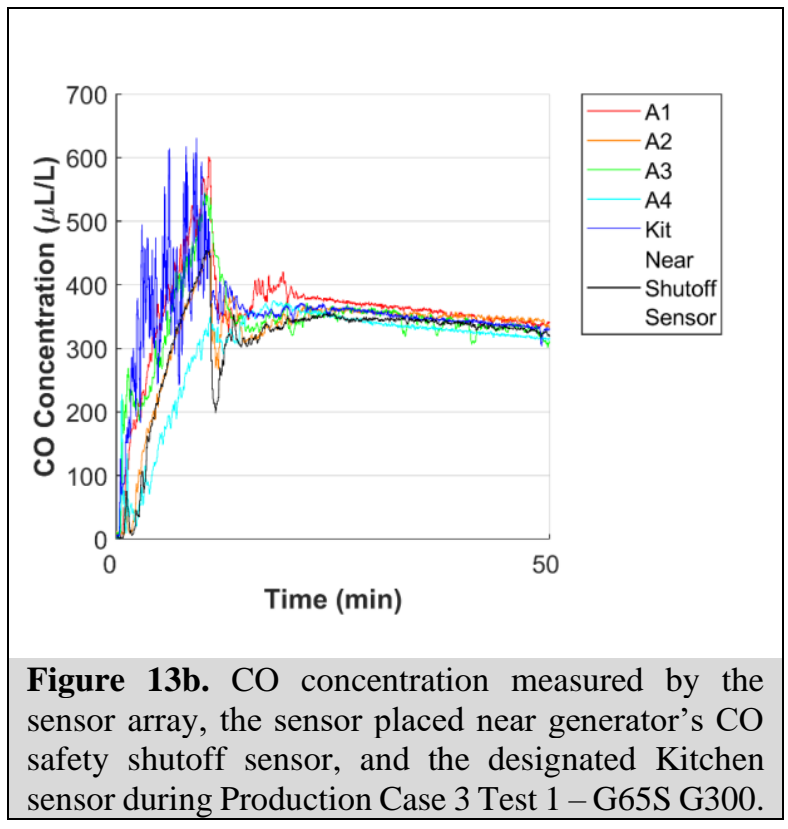




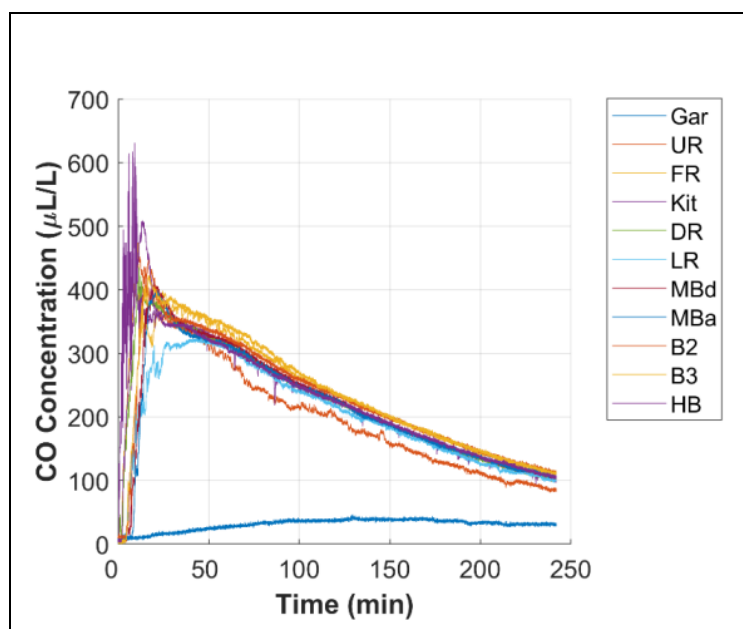

Figure 13c. $\mathrm{CO}$ concentration measured in each room of the house during Production Case 3 Test 1 - G65S G300.

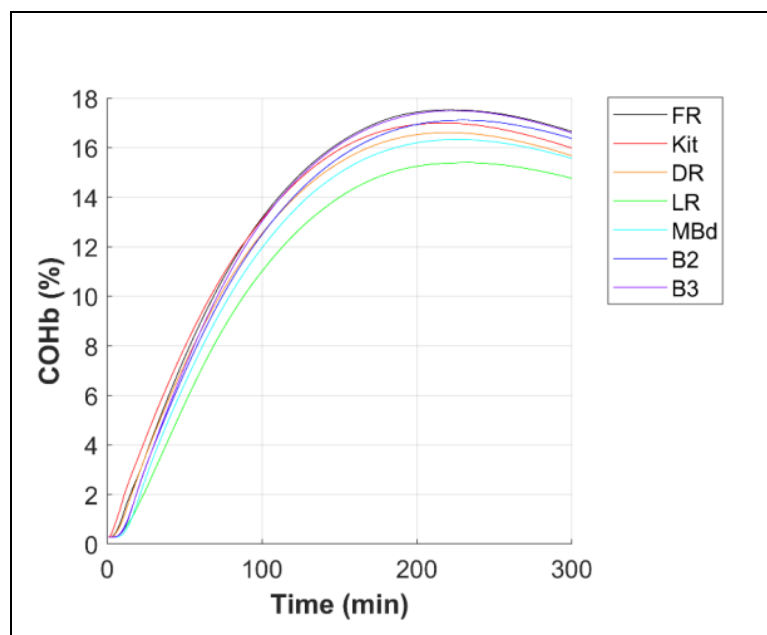

Figure 13e. $\mathrm{COHb}$ of simulated house occupants during Production Case 3 Test 1 - G65S G300.

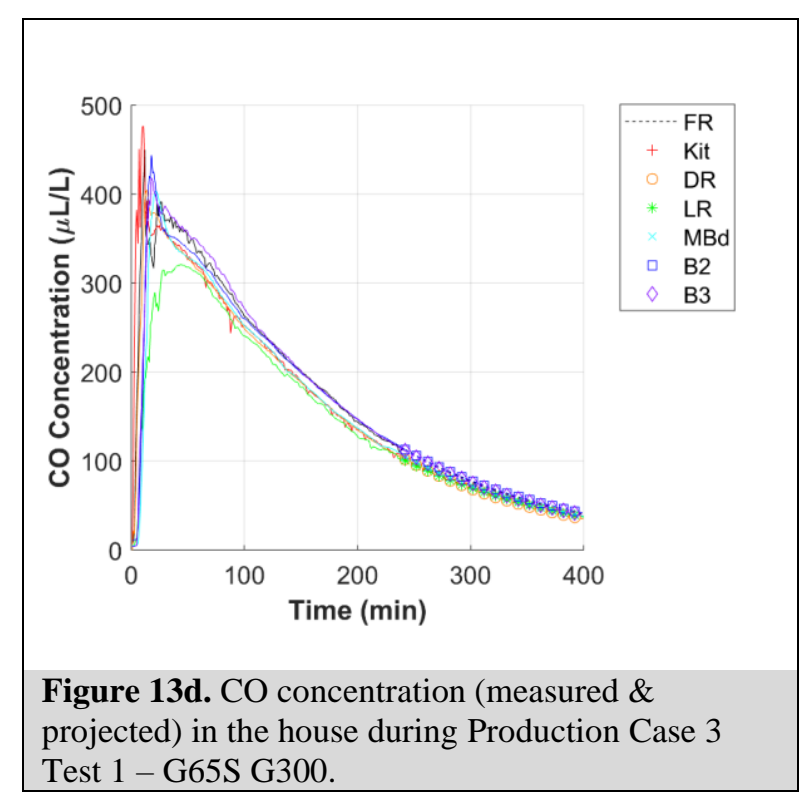

Figure 13d. CO concentration (measured \& projected) in the house during Production Case 3 Test 1 - G65S G300. 


\section{Production Case 3 Test 1 - G65C G300}

The following figures illustrate the results for Production Case 3 Test 1 . The G65C generator, which the manufacturer stated as being certified to PGMA G300, was fully fueled, positioned in the kitchen $(30 \mathrm{~cm}$ from the master bedroom closet wall with the exhaust facing the dining room), and tested at $10 \%$ load $(650 \mathrm{~W})$. The kitchen window nearest to the generator was open $10 \mathrm{~cm}$. The generator's CO safety shutoff system activated to shut off the generator after approximately $171 \mathrm{~min}$. Figure 14a shows the test house layout with generator location, generator exhaust direction, and sensor array locations. Figure 14b shows the $\mathrm{CO}$ concentrations measured in the kitchen (by the dedicated room sensor), by two sensors located on the kitchen-family room boundary (A1: height $183 \mathrm{~cm}, \mathrm{~A} 2$ : height $61 \mathrm{~cm}$ ), by the other two sensors located on the kitchendining room boundary (A3: height $183 \mathrm{~cm}, \mathrm{~A} 4$ : height $61 \mathrm{~cm}$ ), and by an electrochemical sensor measuring $\mathrm{CO}$ near the generator's $\mathrm{CO}$ safety shutoff sensor. The timeframe of the figure has been selected to show the degree of $\mathrm{CO}$ uniformity among these locations near the time of shutoff. Figure 14c shows the $\mathrm{CO}$ concentration measured in each room of the house over the test. Figure 14d shows the $\mathrm{CO}$ concentration in the house, with each room represented by a single line composed of both a 'solid-line' pattern (showing measured CO concentration) and a 'dotted-line with a symbol' pattern (showing projected $\mathrm{CO}$ concentration). Figure 14e shows the calculated $\mathrm{COHb}$ profiles of simulated house occupants in each room of the house.
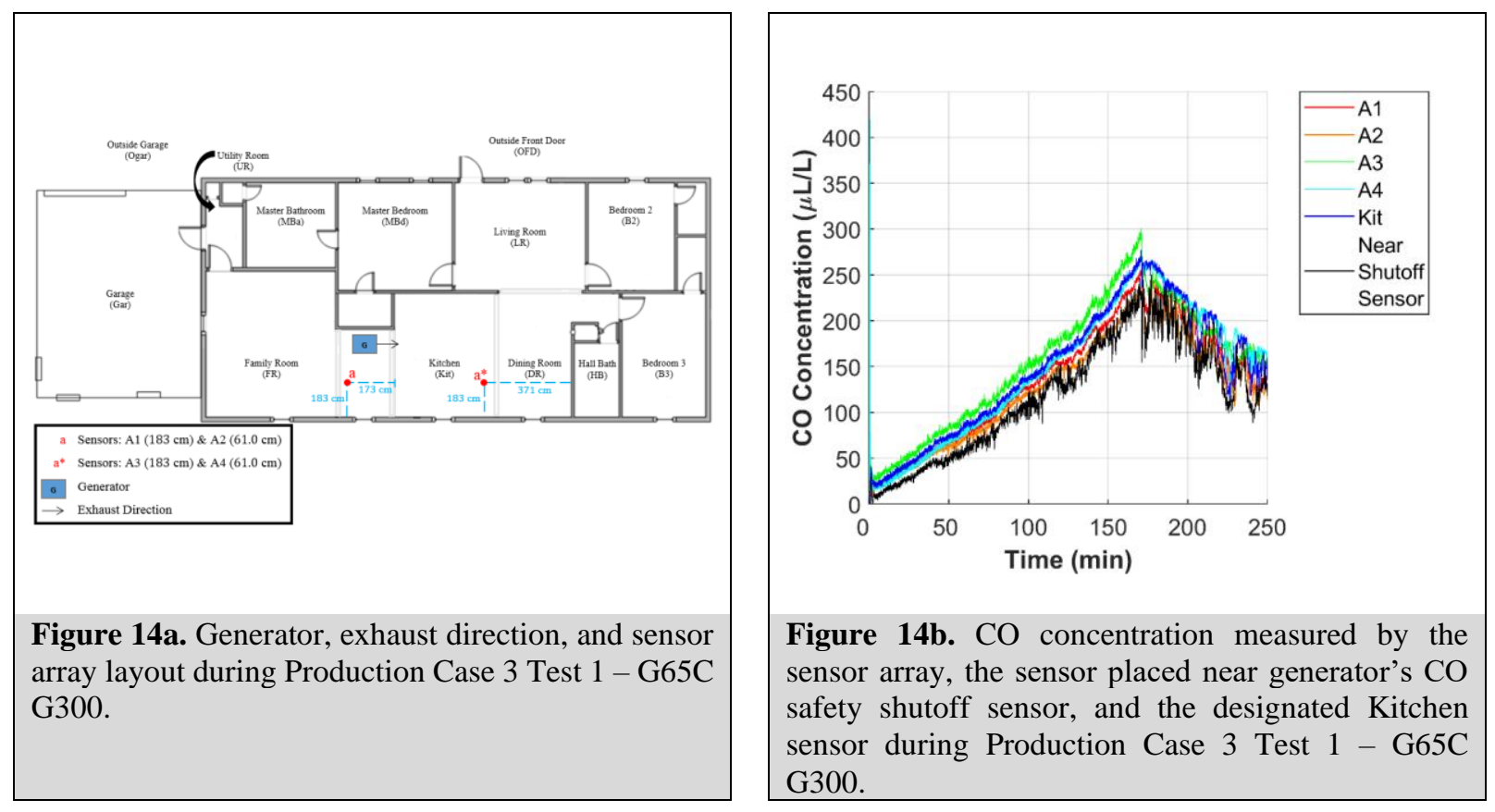


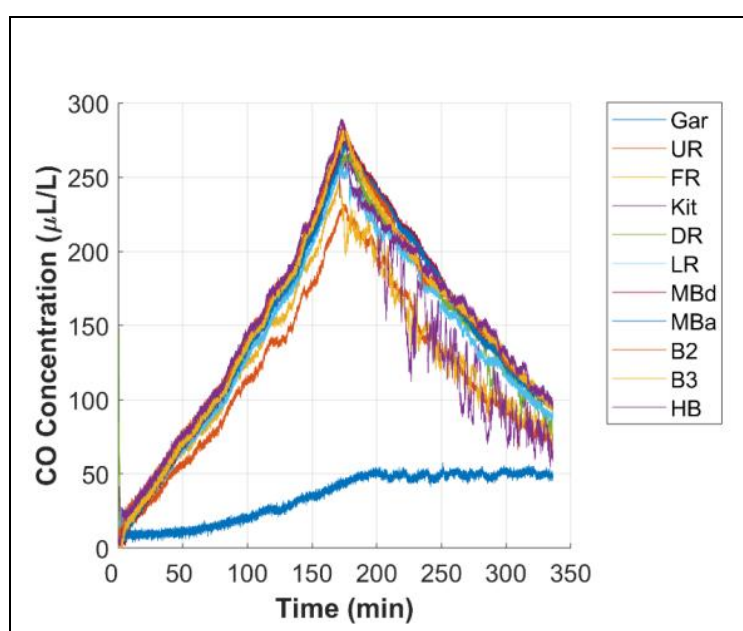

Figure 14c. $\mathrm{CO}$ concentration measured in each room of the house during Production Case 3 Test 1 - G65C G300.

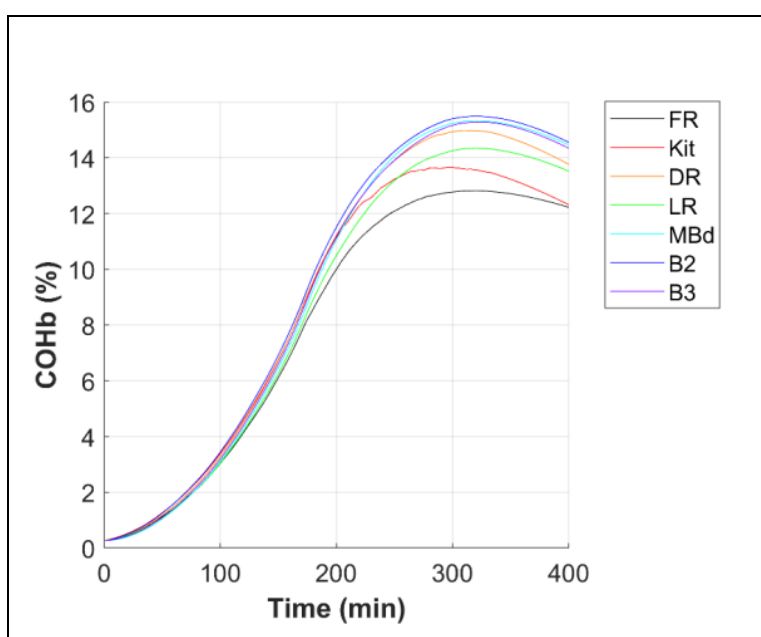

Figure 14e. $\mathrm{COHb}$ of simulated house occupants during Production Case 3 Test 1 - G65C G300.

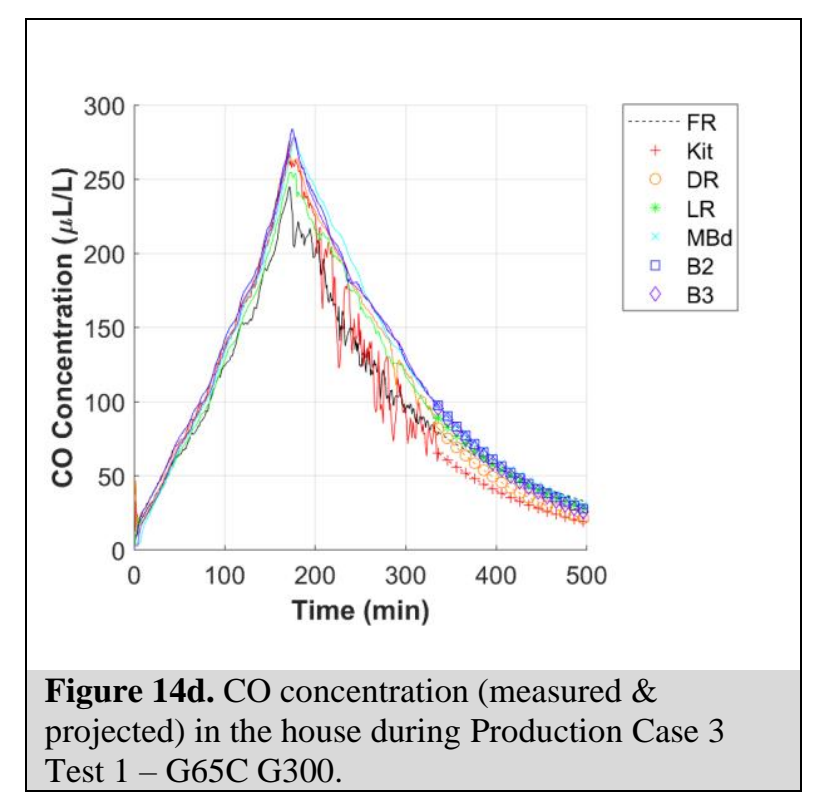

Figure 14d. CO concentration (measured \& projected) in the house during Production Case 3 Test 1 - G65C G300. 


\section{Production Case 3 Test 1 - G7S UL 2201}

The following figures illustrate the results for Production Case 3 Test 1. The G7S generator, which the manufacturer stated as being certified to UL 2201, was fully fueled, positioned in the kitchen (30 $\mathrm{cm}$ from the master bedroom closet wall with the exhaust facing the dining room), and tested at $10 \%$ load $(700 \mathrm{~W})$. The kitchen window nearest to the generator was open $10 \mathrm{~cm}$. The generator's CO safety shutoff system was not activated, and the generator was manually shut down after approximately $294 \mathrm{~min}$ due to high temperatures in the house (approaching $50^{\circ} \mathrm{C}$ ). Figure 15a shows the test house layout with generator location, generator exhaust direction, and sensor array locations. Figure 15b shows the $\mathrm{CO}$ concentrations measured in the kitchen (by the dedicated room sensor), by two sensors located on the kitchen-family room boundary (A1: height $183 \mathrm{~cm}, \mathrm{~A} 2$ : height $61 \mathrm{~cm}$ ), by the other two sensors located on the kitchen-dining room boundary (A3: height $183 \mathrm{~cm}, \mathrm{~A} 4$ : height $61 \mathrm{~cm}$ ), and by an electrochemical sensor measuring $\mathrm{CO}$ near the generator's $\mathrm{CO}$ safety shutoff sensor. The figure shows the degree of $\mathrm{CO}$ uniformity among these locations near the time of shutdown. Figure 15c shows the $\mathrm{CO}$ concentration measured in each room of the house over the test. Figure 15d shows the calculated $\mathrm{COHb}$ profiles of simulated house occupants in each room of the house.
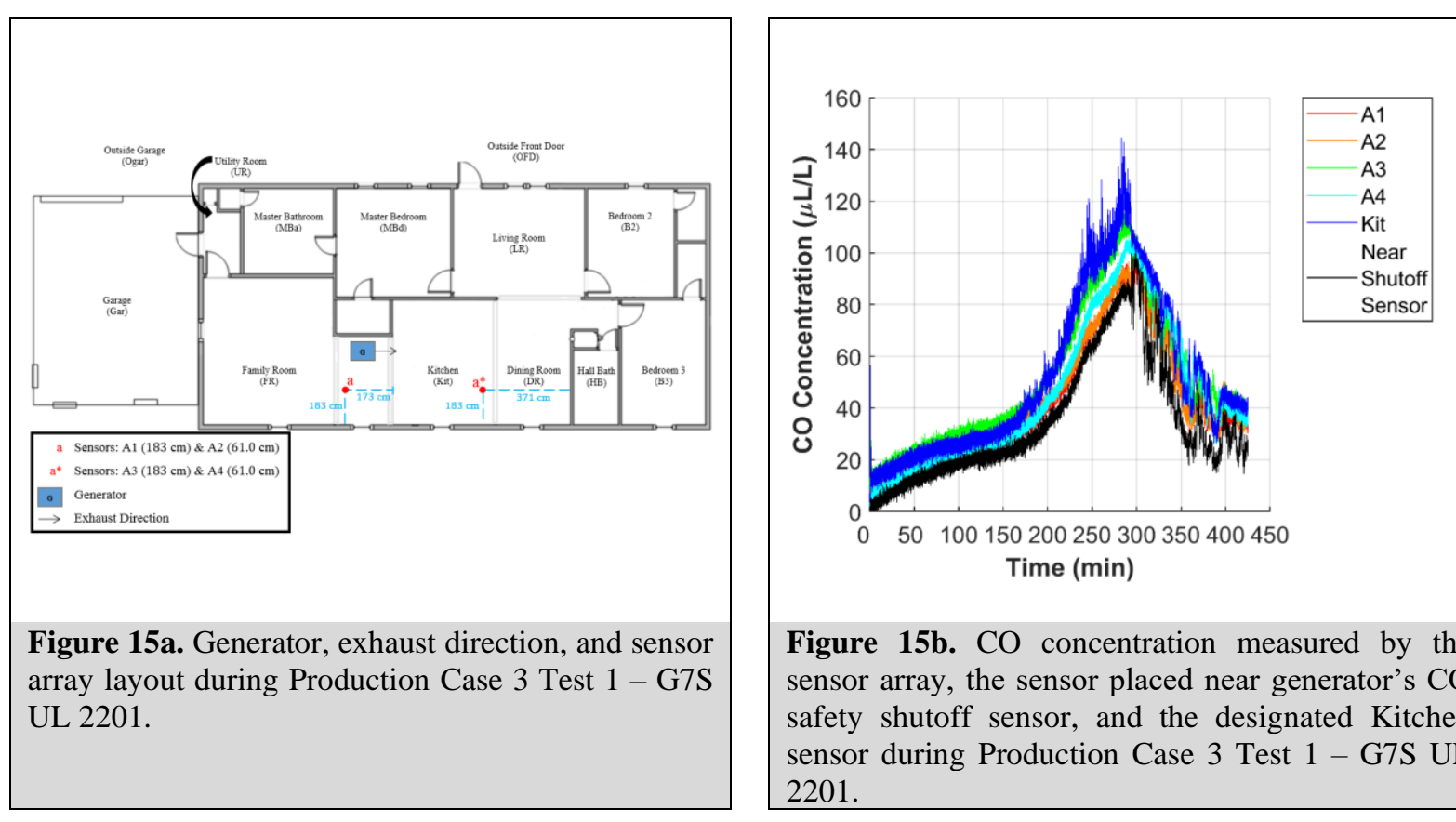

Figure 15b. $\mathrm{CO}$ concentration measured by the sensor array, the sensor placed near generator's CO safety shutoff sensor, and the designated Kitchen sensor during Production Case 3 Test 1 - G7S UL 2201. 

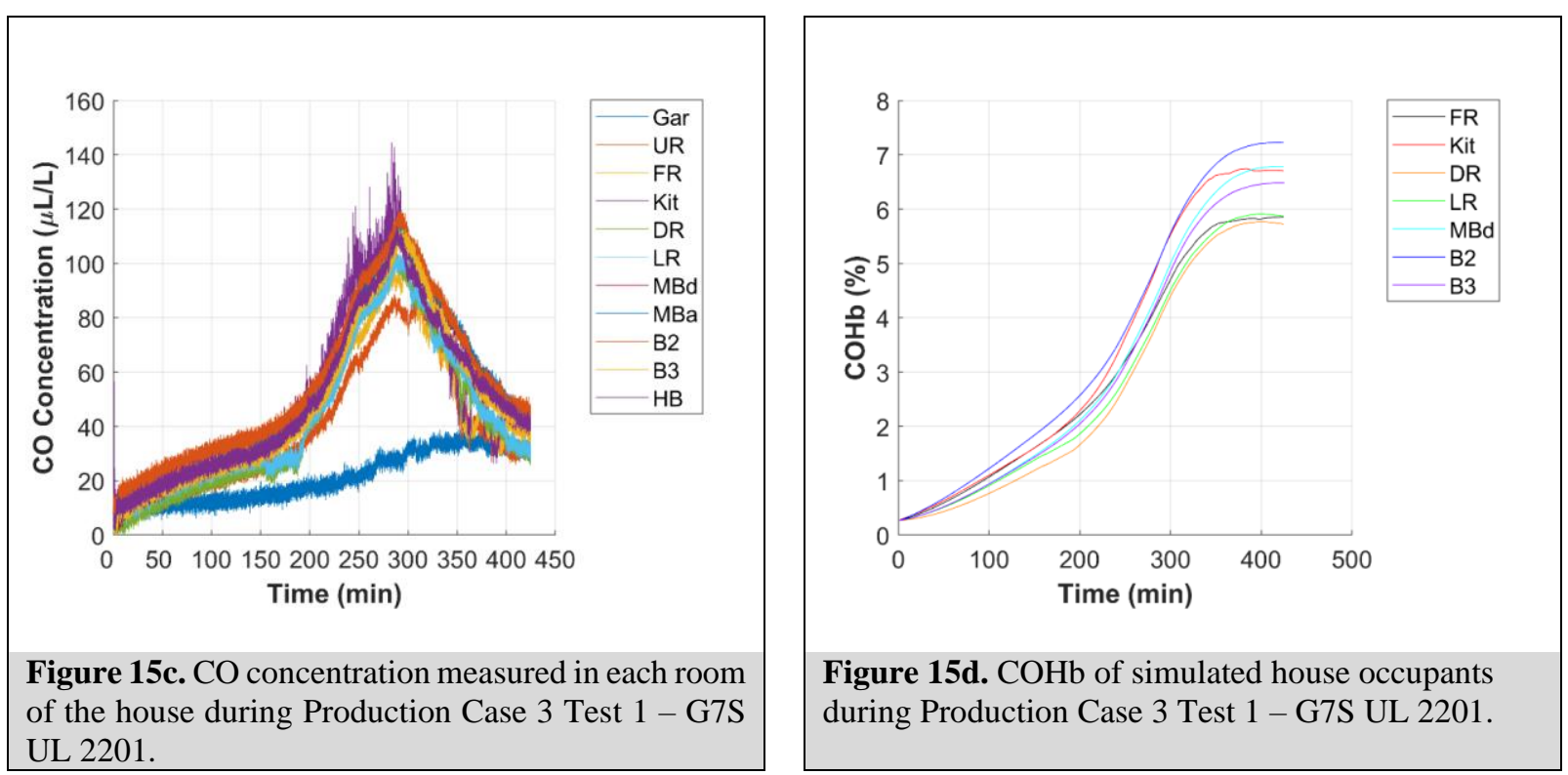


\section{Production Case 3 Test 1 - G85 G300}

The following figures illustrate the results for Production Case 3 Test 1. The G85 generator, which the manufacturer stated as being certified to PGMA G300, was fully fueled, positioned in the kitchen ( $30 \mathrm{~cm}$ from the master bedroom closet wall with the exhaust facing the dining room), and tested at $10 \%$ load $(625 \mathrm{~W})$. The kitchen window nearest to the generator was open $10 \mathrm{~cm}$. The generator's CO safety shutoff system activated to shut off the generator after approximately 4 min. Figure 16a shows the test house layout with generator location, generator exhaust direction, and sensor array locations. Figure 16b shows the $\mathrm{CO}$ concentrations measured in the kitchen (by the dedicated room sensor), by two sensors located on the kitchen-family room boundary (A1: height $183 \mathrm{~cm}, \mathrm{A2}$ : height $61 \mathrm{~cm}$ ), by the other two sensors located on the kitchen-dining room boundary (A3: height $183 \mathrm{~cm}, \mathrm{~A} 4$ : height $61 \mathrm{~cm}$ ), and by an electrochemical sensor measuring $\mathrm{CO}$ near the generator's CO safety shutoff sensor. The timeframe of the figure has been selected to show the degree of $\mathrm{CO}$ uniformity among these locations near the time of shutoff. Figure 16c shows the $\mathrm{CO}$ concentration measured in each room of the house over the test. Figure 16d shows the CO concentration in the house, with each room represented by a single line composed of both a 'solidline' pattern (showing measured CO concentration) and a 'dotted-line with a symbol' pattern (showing projected $\mathrm{CO}$ concentration). Figure 16e shows the calculated $\mathrm{COHb}$ profiles of simulated house occupants in each room of the house.

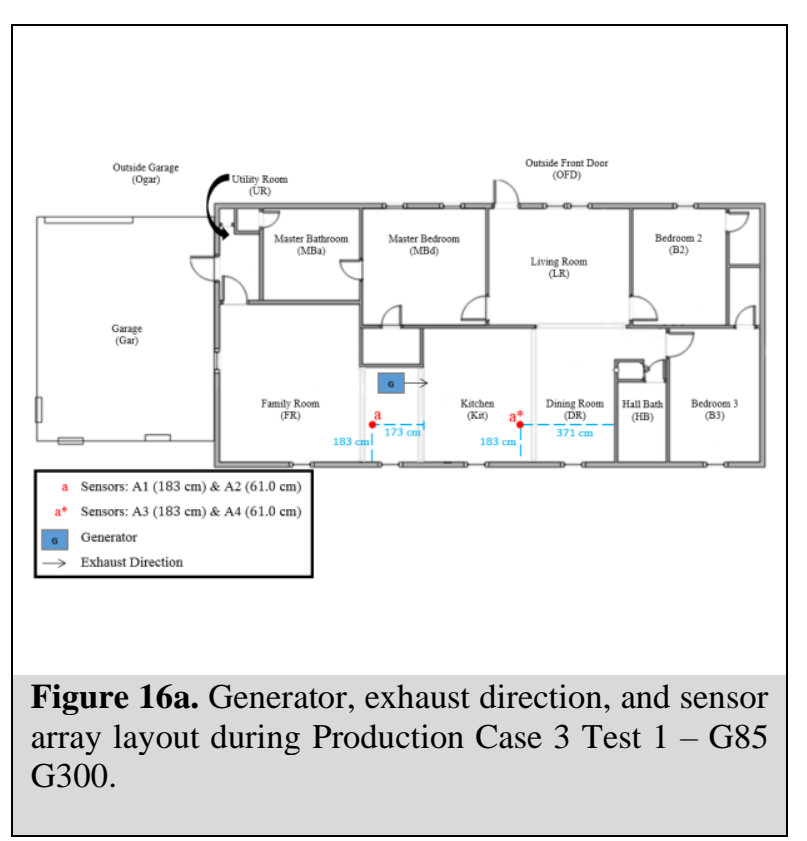

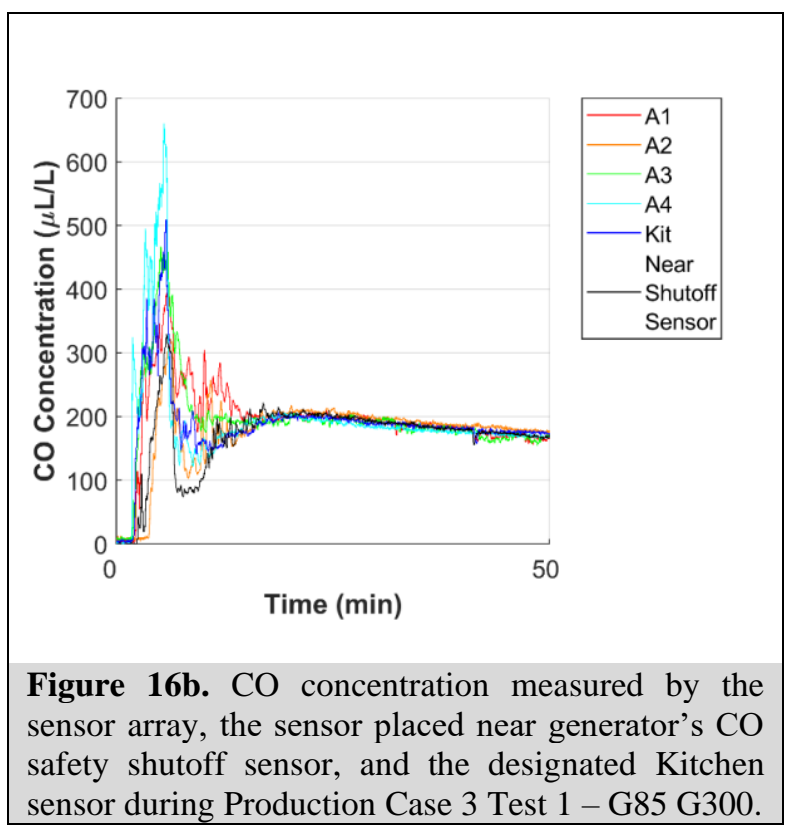




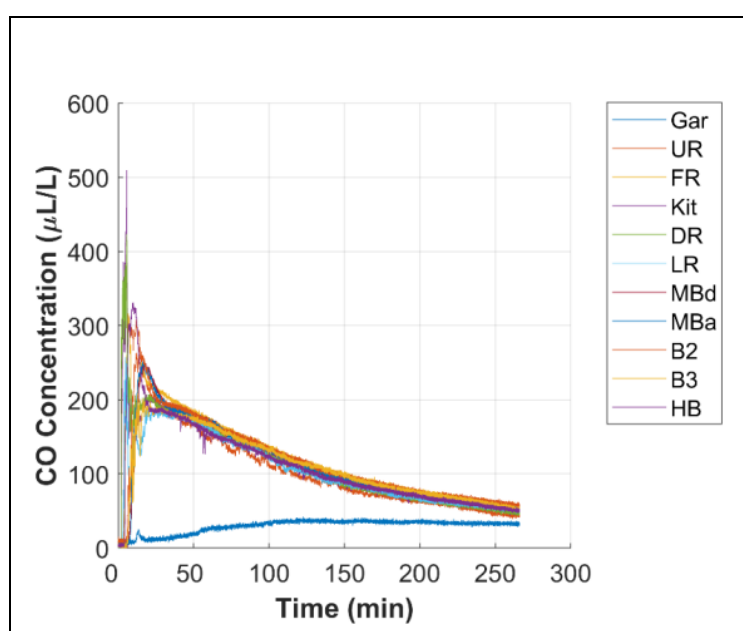

Figure 16c. $\mathrm{CO}$ concentration measured in each room of the house during Production Case 3 Test $1-$ G85 G300.

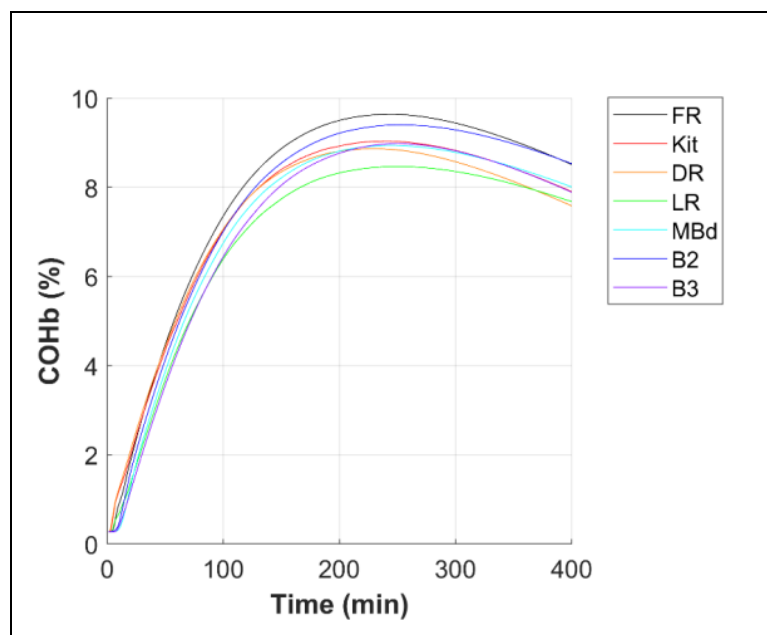

Figure 16e. $\mathrm{COHb}$ of simulated house occupants during Production Case 3 Test 1- G85 G300.

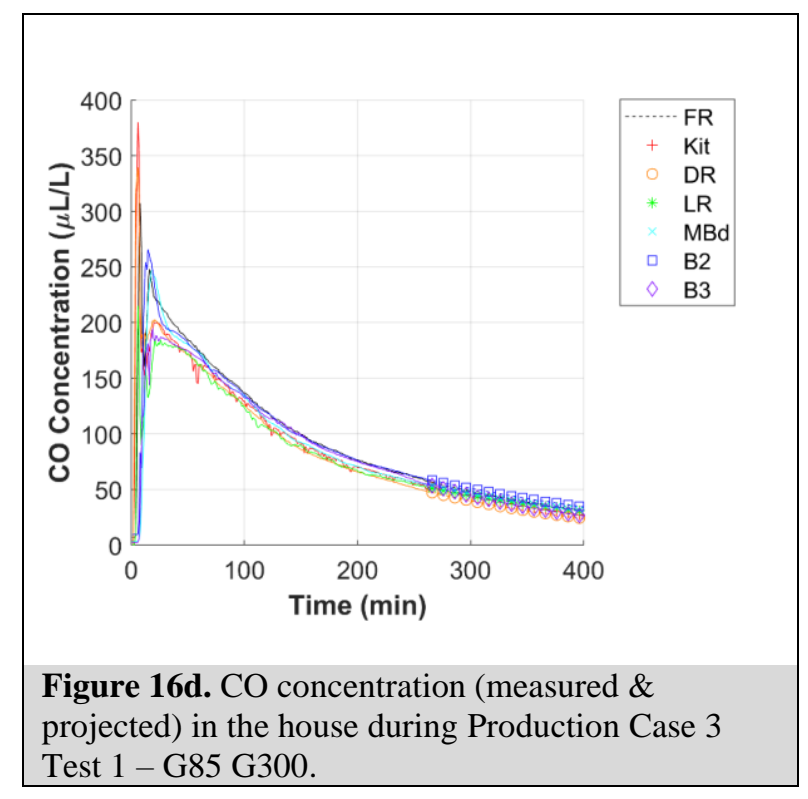

Test 1 - G85 G300. 


\section{Generator Location: Garage}

Table 2 summarizes the results for all tests performed with a generator located in the test house garage. The details are discussed below and shown in Figures 17 through 36. For these tests, the designated Garage sensor was set at the G300 standard's test height (3 cm to $5 \mathrm{~cm}$ above the centerline of the top of the generator) to evaluate the difference between this location and the onboard sensor location. An additional electrochemical sensor was set at the UL 2201 standard's test height $(30 \mathrm{~cm}$ above the centerline of the top of the generator) to evaluate the difference between this location and the onboard sensor location.

\begin{tabular}{|c|c|c|c|c|c|c|c|c|c|c|c|c|}
\hline $\begin{array}{l}\text { Generator } \\
\text { Location }\end{array}$ & Generator & Load & $\begin{array}{c}\text { PCase \# / } \\
\text { Test \# }\end{array}$ & $\begin{array}{l}\text { Voluntary } \\
\text { Standard }\end{array}$ & $\begin{array}{l}\text { Avg Temp } \\
\text { Out } \\
\text { (C) }\end{array}$ & $\begin{array}{c}\text { Avg } \\
\text { Wind } \\
\text { Speed } \\
(\mathrm{m} / \mathrm{s})\end{array}$ & $\begin{array}{c}\text { Peak CO } \\
\text { in House } \\
\text { and Garage } \\
\quad(\mu \mathrm{L} / \mathrm{L})\end{array}$ & $\begin{array}{c}\text { Concentration } \\
\text { @ Shutoff + } \\
(\mu \mathrm{L} / \mathrm{L})\end{array}$ & $\begin{array}{c}\text { Shutoff Ratio } \\
\text { (Zone Avg: } \\
\text { Near Shutoff Sensor) }\end{array}$ & $\begin{array}{c}\text { Range of } \\
\text { Peak COHb } \\
\text { Values H } \\
(\%)\end{array}$ & $\begin{array}{c}\text { Ventilation HH } \\
\text { (W=window open, } \\
\mathrm{D}=\text { door open) }\end{array}$ & $\begin{array}{c}\begin{array}{c}\text { Shutoff } \\
\text { Activation }\end{array} \\
(\mathrm{min})\end{array}$ \\
\hline \multirow{20}{*}{\begin{tabular}{|l} 
Garage \\
(Gar)
\end{tabular}} & G65S & 100 & $4 / 1$ & G300 & 18.5 & 1.7 & 721 & 566 & 1.08 & 4 to 7 & \multirow[t]{12}{*}{$\mathrm{D}$ (int. person) $-10 \mathrm{~cm}$} & $\approx 3$ \\
\hline & G65C & 100 & $4 / 1$ & G300 & 12.5 & 2.7 & 545 & 254 & 1.10 & $<5$ & & $\approx 1$ \\
\hline & G7S & 100 & $4 / 1$ & UL2201 & 16.3 & 2.5 & 197 & 177 & 1.09 & $<5$ & & $\approx 15$ \\
\hline & G85 & 100 & $4 / 1$ & G300 & 12.9 & 2.1 & 370 & 251 & 1.22 & 4 to 6 & & $\approx 2$ \\
\hline & G65S & 50 & $5 / 1$ & G300 & 20.5 & 1.2 & 628 & 533 & 1.09 & 6 to 9 & & $\approx 4$ \\
\hline & G65C & 50 & $5 / 1$ & G300 & 15.0 & 3.2 & 466 & 436 & 1.05 & $<5$ & & $\approx 12$ \\
\hline & G7S & 50 & $5 / 1$ & UL2201 & 18.2 & 3.4 & 225 & 211 & 1.04 & $<5$ & & $\approx 14$ \\
\hline & G85 & 50 & $5 / 1$ & G300 & 14.9 & 2.5 & 396 & 293 & 1.14 & $<5$ & & $\approx 3$ \\
\hline & G65S & 10 & $6 / 1$ & G300 & 12.6 & 4.0 & 569 & 543 & 1.01 & $<5$ & & $\approx 5$ \\
\hline & G65C & 10 & $6 / 1$ & G300 & 15.6 & 4.4 & 261 & 244 & 1.04 & 4 to 7 & & $\approx 58$ \\
\hline & G7S & 10 & $6 / 1$ & UL2201 & 18.8 & 3.2 & 115 & 98 & 1.17 & 5 to 7 & & $\approx 166$ \\
\hline & G85 & 10 & $6 / 1$ & G300 & 5.3 & 3.6 & 504 & 437 & 1.01 & 4 to 6 & & $\approx 4$ \\
\hline & G65S & 100 & $7 / 1$ & G300 & 9.8 & 2.5 & 547 & - & - & 27 to 37 & \multirow{8}{*}{\begin{tabular}{|c|}
$\mathrm{D}$ (int. person) $-10 \mathrm{~cm}$ \\
$\mathrm{D}$ (garage bay) - fully
\end{tabular}} & $\approx 329 \mathrm{HH}$ \\
\hline & G65C & 100 & $7 / 1$ & G300 & 12.8 & 3.5 & 471 & 200 & 1.01 & $<5$ & & $\approx 2$ \\
\hline & G7S & 100 & $7 / 1$ & UL2201 & 7.7 & 1.2 & 124 & - & - & $<5$ & & $\approx 225 \mathrm{HHH}$ \\
\hline & G85 & 100 & $7 / 1$ & G300 & 10.0 & 1.9 & 511 & 346 & 1.34 & $<5$ & & $\approx 8$ \\
\hline & G65S & 50 & $8 / 1$ & G300 & 10.2 & 3.3 & 267 & - & - & 5 to 8 & & $\approx 467 \mathrm{H11H}$ \\
\hline & G65C & 50 & $8 / 1$ & G300 & 15.7 & 2.1 & 96 & - & - & 5 to 8 & & $\approx 320 \mathrm{HH}$ \\
\hline & G7S & 50 & $8 / 1$ & UL2201 & 6.7 & 3.2 & 44 & - & - & $<5$ & & $\approx 357 \mathrm{H11H}$ \\
\hline & G85 & 50 & $8 / 1$ & G300 & 10.5 & 4.7 & 395 & - & - & 20 to 26 & & $\approx 468 \mathrm{H} 11 \mathrm{H}$ \\
\hline
\end{tabular}

†Measured by the NDIR channel placed near the sensor of onboard shutoff system.

HPeak $\mathrm{COHb}$ Values are for house zones only.

HVentilation Note: Unless specified otherwise, during the test - all exterior doors are closed, all interior doors are fully open, and all windows are closed.

HH Shutoff not activated, generator ran out of fuel

HIH Shutoff not activated, generator manually shut down due to low levels of $\mathrm{CO}$ in the house and anticipated long runtime before generator running out of fuel

H11+ Shutoff not activated, generator manually shut down due to reaching peak $\mathrm{COHb}$ in the house

Table 2. Summary of test results for Garage (Gar) tests 


\section{Production Case 4 Test 1 - G65S G300}

The following figures illustrate the results for Production Case 4 Test 1. The G65S generator, which the manufacturer stated as being certified to PGMA G300, was fully fueled, positioned in the garage (centered, with the exhaust facing towards the family room), and tested at $100 \%$ load $(6,500 \mathrm{~W})$. The interior person door (from garage to utility room) was open $10 \mathrm{~cm}$ and both the exterior person door (from garage to backyard) and the garage bay door were closed. The generator's CO safety shutoff system activated to shut off the generator after approximately $3 \mathrm{~min}$. Figure 17a shows the test house layout with generator location, generator exhaust direction, and sensor array locations. Figure 17b shows the $\mathrm{CO}$ concentrations measured in the garage by the G300 sensor (placed 3 to $5 \mathrm{~cm}$ above the approximate center of the generator's top surface), by the sensor array placed in the garage located as shown in Figure 17a (A1, A3, A5, and A7: height $183 \mathrm{~cm}$; A2, A4, A6 and A8: height $61 \mathrm{~cm}$ ), and by the NDIR analyzer sample line measuring CO concentrations near the generator's CO safety shutoff sensor. All array sensors set to a height of $183 \mathrm{~cm}$ are illustrated as orange lines whereas the array sensors set to a height of $61 \mathrm{~cm}$ are illustrated as turquoise lines. The timeframe of the figure has been selected to show the degree of $\mathrm{CO}$ uniformity among these locations near the time of shutoff. Figure 17c shows the CO concentration measured in each room of the house over the test. Figure 17d shows the CO concentration in the house, with each room represented by a single line composed of both a 'solidline' pattern (showing measured CO concentration) and a 'dotted-line with a symbol' pattern (showing projected $\mathrm{CO}$ concentration). Figure 17e shows the calculated $\mathrm{COHb}$ profiles of simulated house occupants in each room of the house.

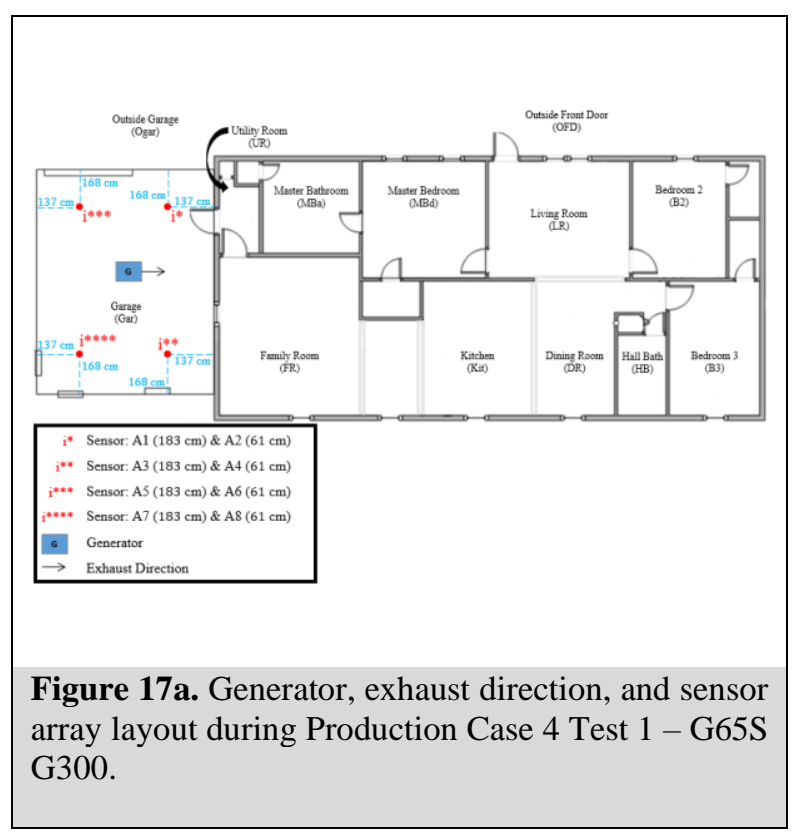

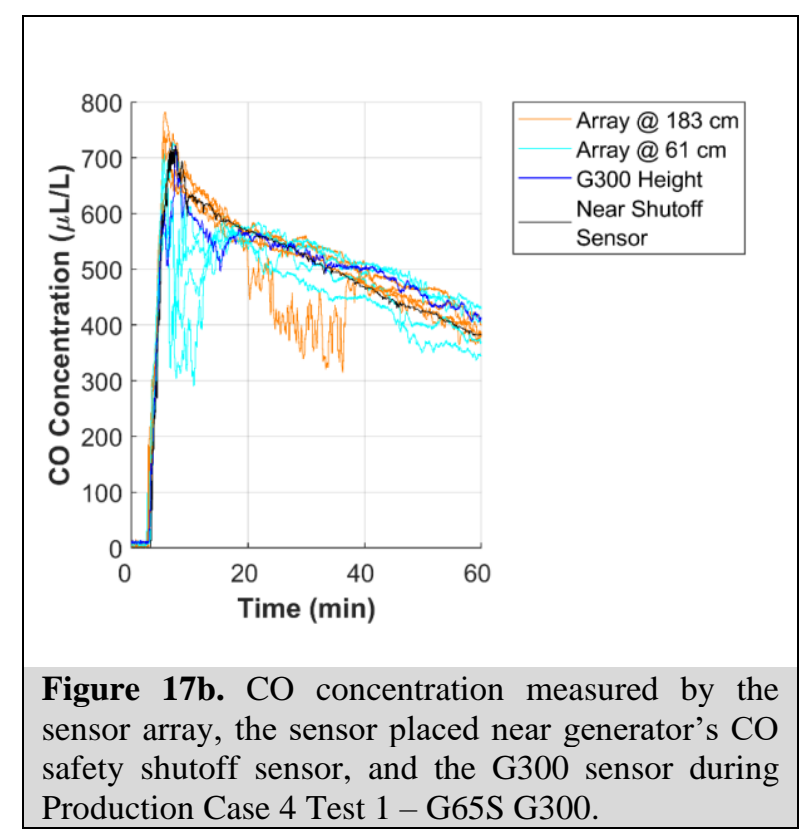




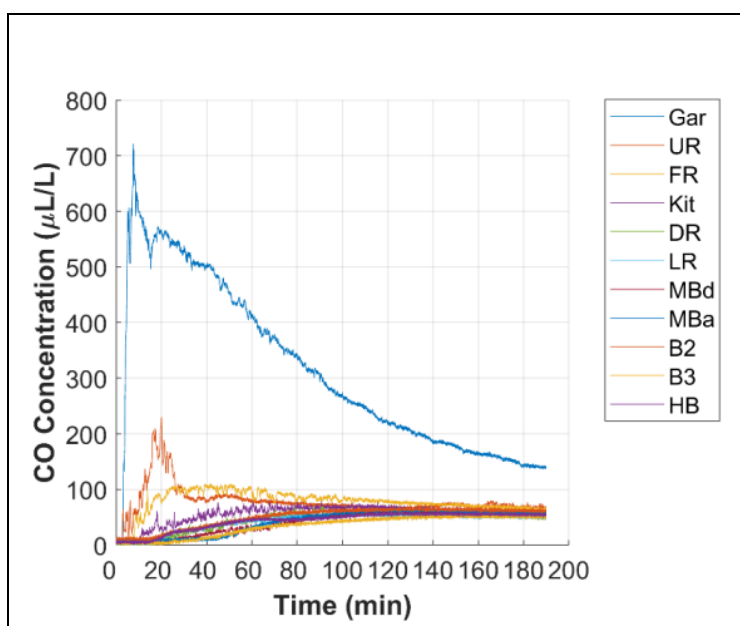

Figure 17c. $\mathrm{CO}$ concentration measured in each room of the house during Production Case 4 Test $1-$ G65S G300.

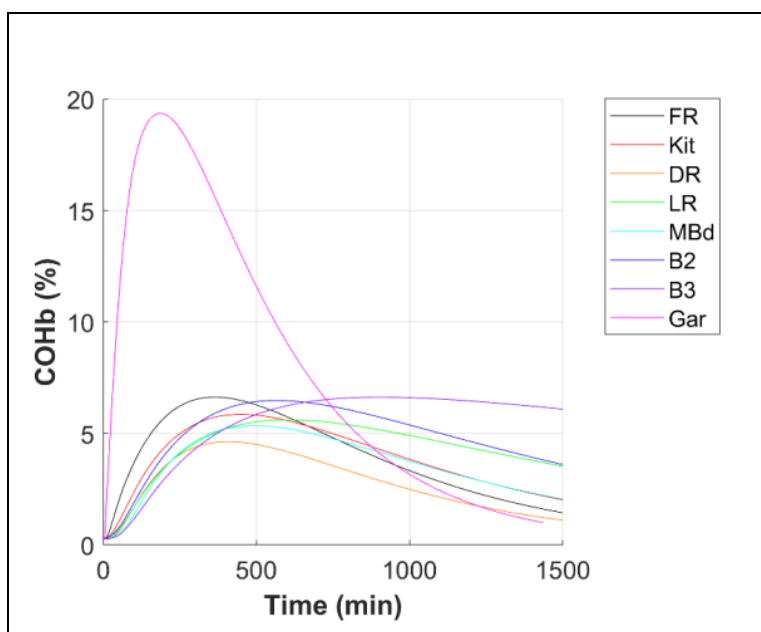

Figure 17e. $\mathrm{COHb}$ of simulated house occupants during Production Case 4 Test 1 - G65S G300.

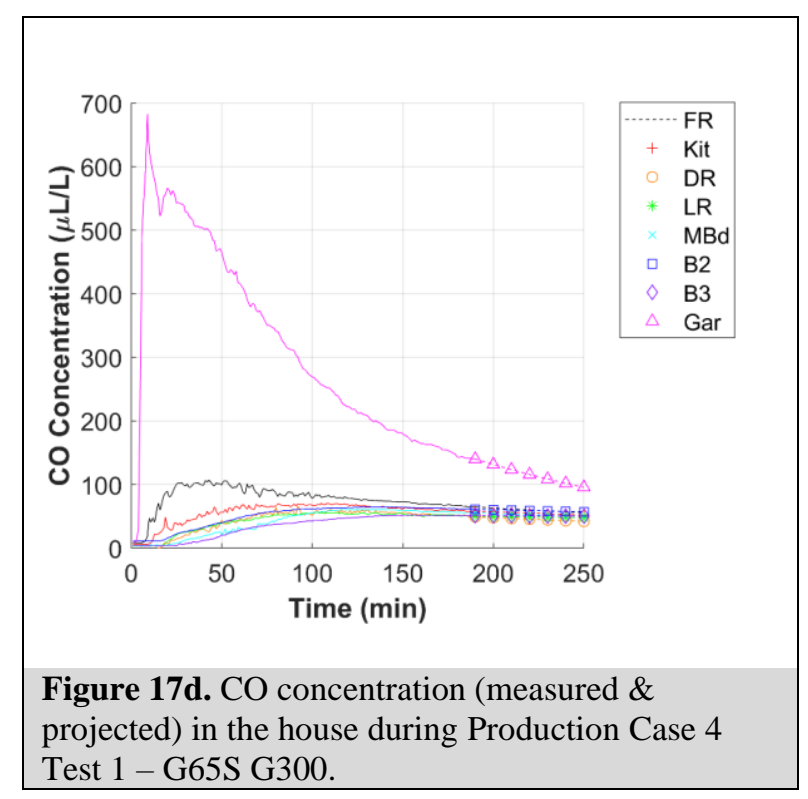

Figure 17d. CO concentration (measured \& projected) in the house during Production Case 4 Test 1 - G65S G300. 


\section{Production Case 4 Test 1 - G65C G300}

The following figures illustrate the results for Production Case 4 Test 1 . The G65C generator, which the manufacturer stated as being certified to PGMA G300, was fully fueled, positioned in the garage (centered, with the exhaust facing towards the family room), and tested at $100 \%$ load $(6,500 \mathrm{~W})$. The interior person door (from garage to utility room) was open $10 \mathrm{~cm}$ and both the exterior person door (from garage to backyard) and the garage bay door were closed. The generator's CO safety shutoff system activated to shut off the generator after approximately $1 \mathrm{~min}$. Figure 18a shows the test house layout with generator location, generator exhaust direction, and sensor array locations. Figure 18b shows the $\mathrm{CO}$ concentrations measured in the garage by the G300 sensor (placed 3 to $5 \mathrm{~cm}$ above the approximate center of the generator's top surface), by the UL sensor (placed $30 \mathrm{~cm}$ above the approximate center of the generator's top surface), by the sensor array placed in the garage located as shown in Figure 18a (A1, A3, A5, and A7: height 183 $\mathrm{cm}$; A2, A4, A6 and A8: height $61 \mathrm{~cm}$ ), and by the NDIR analyzer sample line measuring CO near the generator's CO safety shutoff sensor. All array sensors set to a height of $183 \mathrm{~cm}$ are illustrated as orange lines whereas the array sensors set to a height of $61 \mathrm{~cm}$ are illustrated as turquoise lines. The timeframe of the figure has been selected to show the degree of $\mathrm{CO}$ uniformity among these locations near the time of shutoff. Figure 18c shows the $\mathrm{CO}$ concentration measured in each room of the house over the test. Figure 18d shows the calculated $\mathrm{COHb}$ profiles of simulated house occupants in each room of the house.

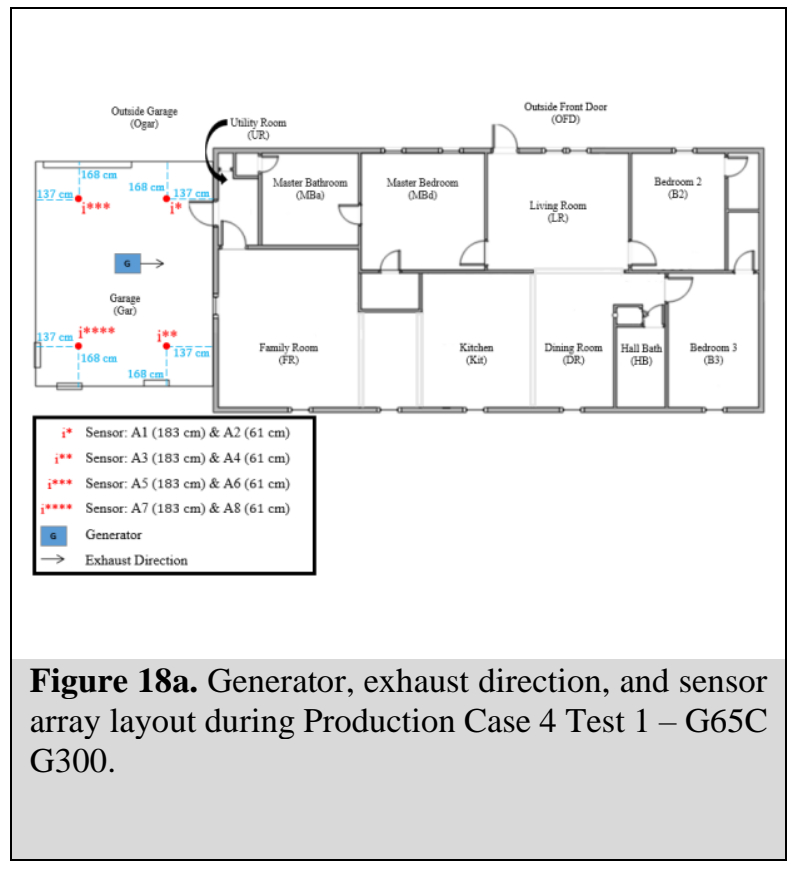

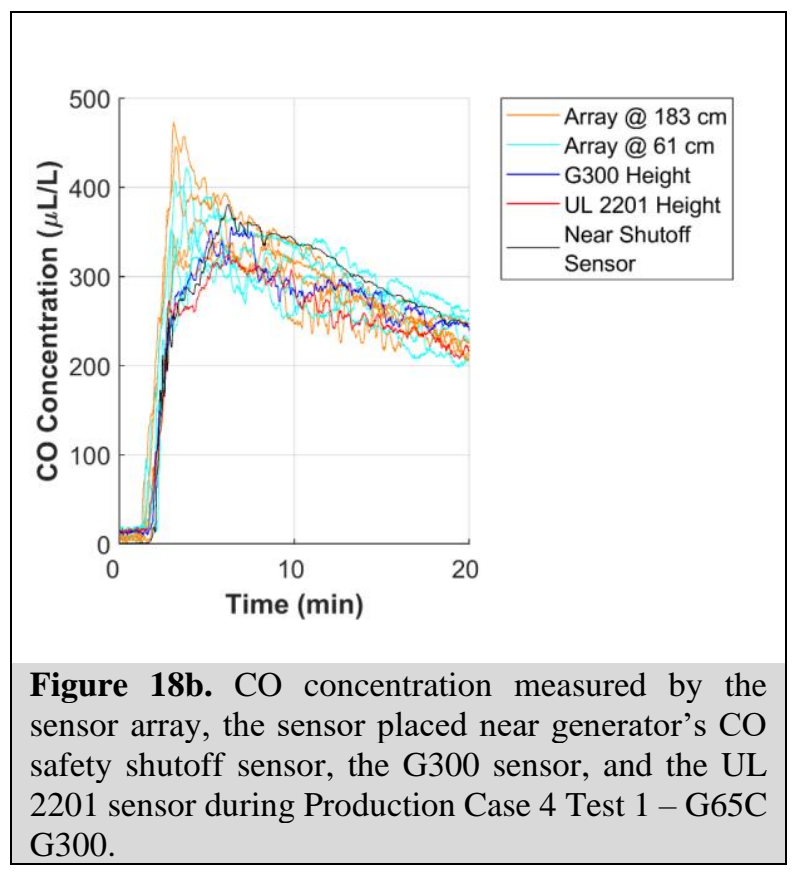




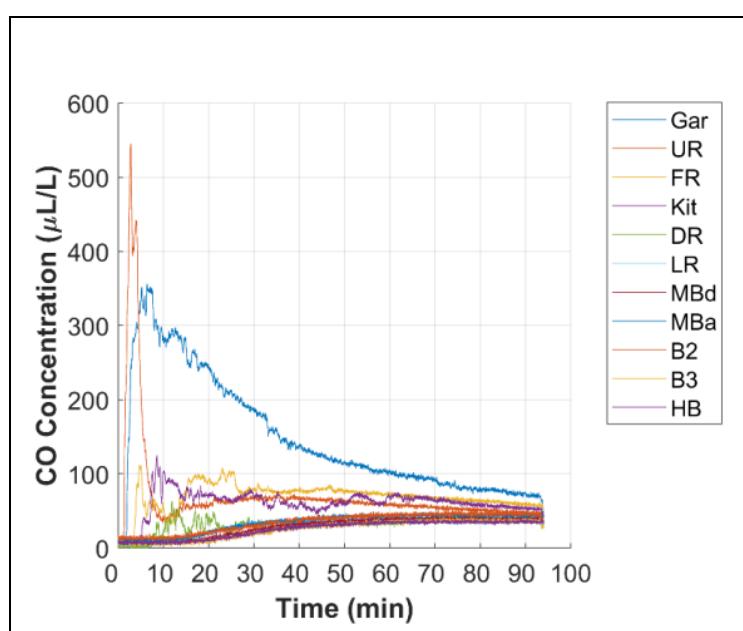

Figure 18c. $\mathrm{CO}$ concentration measured in each room of the house during Production Case 4 Test 1 - G65C G300.

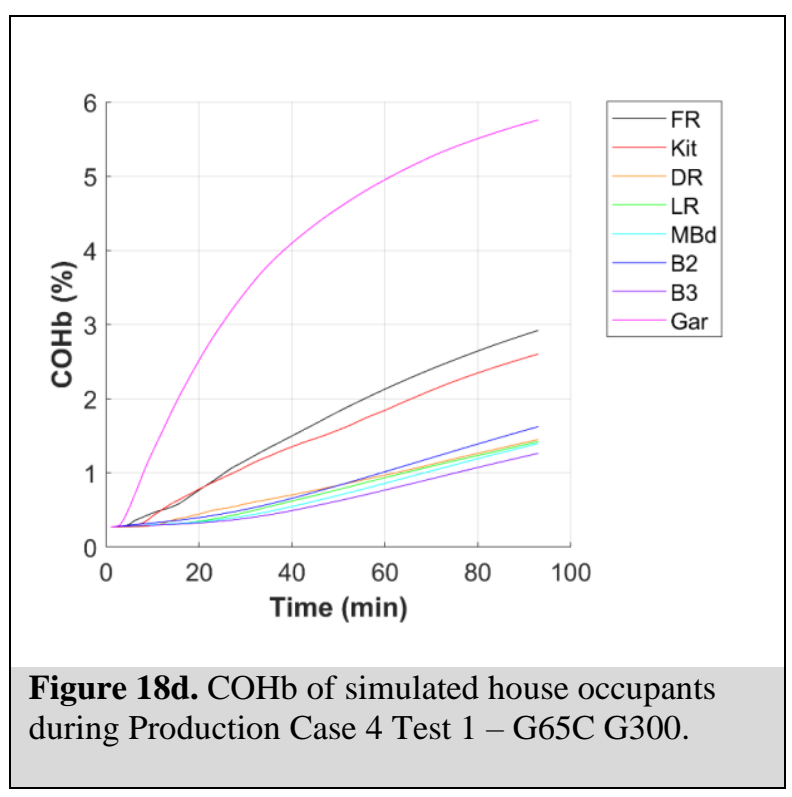

Figure 18d. $\mathrm{COHb}$ of simulated house occupants during Production Case 4 Test 1 - G65C G300. 


\section{Production Case 4 Test 1 - G7S UL 2201}

The following figures illustrate the results for Production Case 4 Test 1. The G7S generator, which the manufacturer stated as being certified to UL 2201, was fully fueled, positioned in the garage (centered, with the exhaust facing towards the family room), and tested at $100 \%$ load $(7,000 \mathrm{~W})$. The interior person door (from garage to utility room) was open $10 \mathrm{~cm}$ and both the exterior person door (from garage to backyard) and the garage bay door were closed. The generator's CO safety shutoff system activated to shut off the generator after approximately 15 min. Figure 19a shows the test house layout with generator location, generator exhaust direction, and sensor array locations. Figure 19b shows the $\mathrm{CO}$ concentrations measured in the garage by the G300 sensor (placed 3 to $5 \mathrm{~cm}$ above the approximate center of the generator's top surface), by the UL sensor (placed $30 \mathrm{~cm}$ above the approximate center of the generator's top surface), by the sensor array placed in the garage located as shown in Figure 19a (A1, A3, A5, and A7: height $183 \mathrm{~cm}$; A2, A4, A6 and A8: height $61 \mathrm{~cm}$ ), and by the NDIR analyzer sample line measuring CO near the generator's CO safety shutoff sensor. All array sensors set to a height of $183 \mathrm{~cm}$ are illustrated as orange lines whereas the array sensors set to a height of $61 \mathrm{~cm}$ are illustrated as turquoise lines. The timeframe of the figure has been selected to show the degree of $\mathrm{CO}$ uniformity among these locations near the time of shutoff. Figure 19c shows the $\mathrm{CO}$ concentration measured in each room of the house over the test. Figure 19d shows the $\mathrm{CO}$ concentration in the house, with each room represented by a single line composed of both a 'solid-line' pattern (showing measured CO concentration) and a 'dotted-line with a symbol' pattern (showing projected CO concentration). Figure 19e shows the calculated $\mathrm{COHb}$ profiles of simulated house occupants in each room of the house.
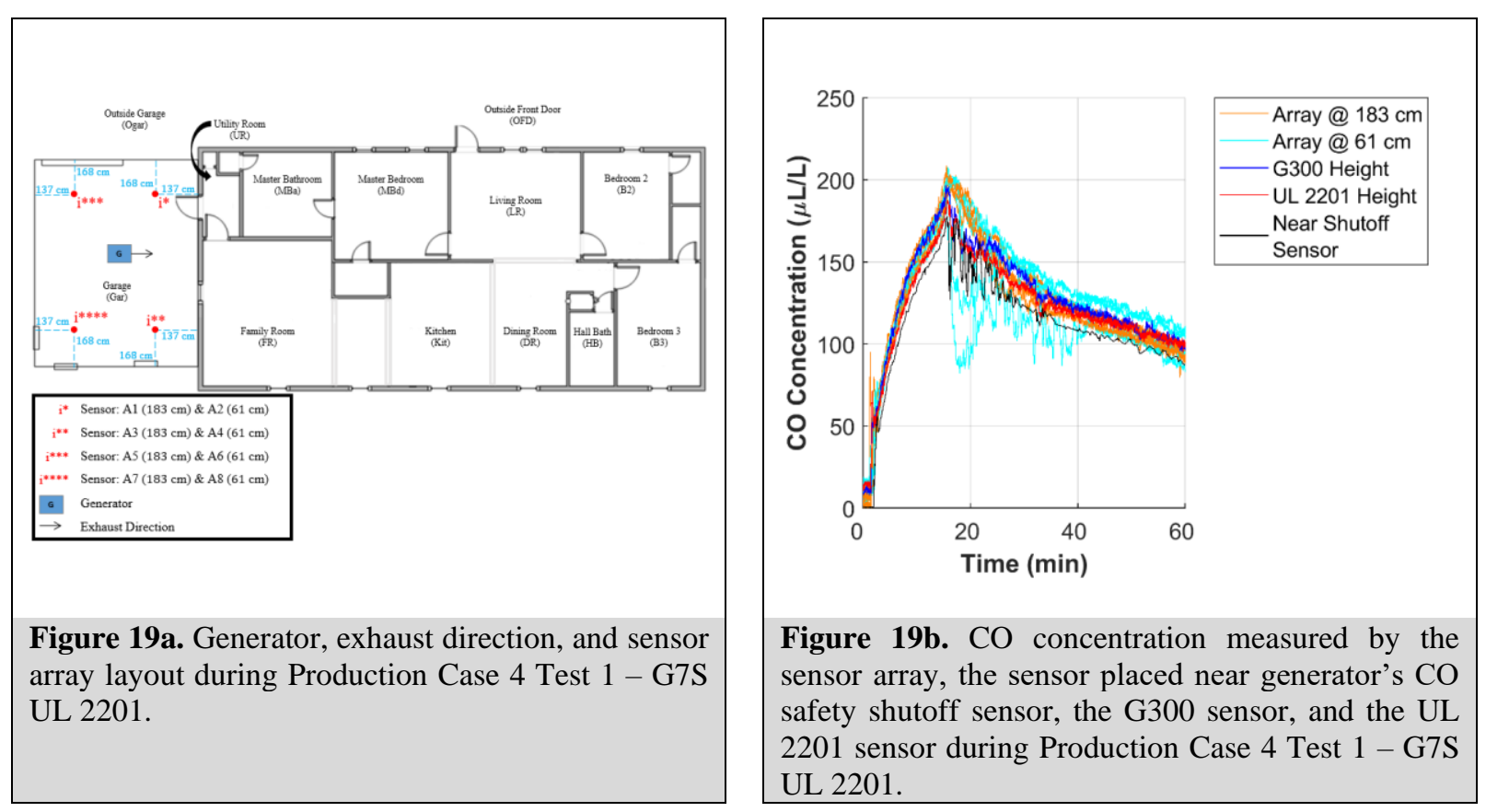

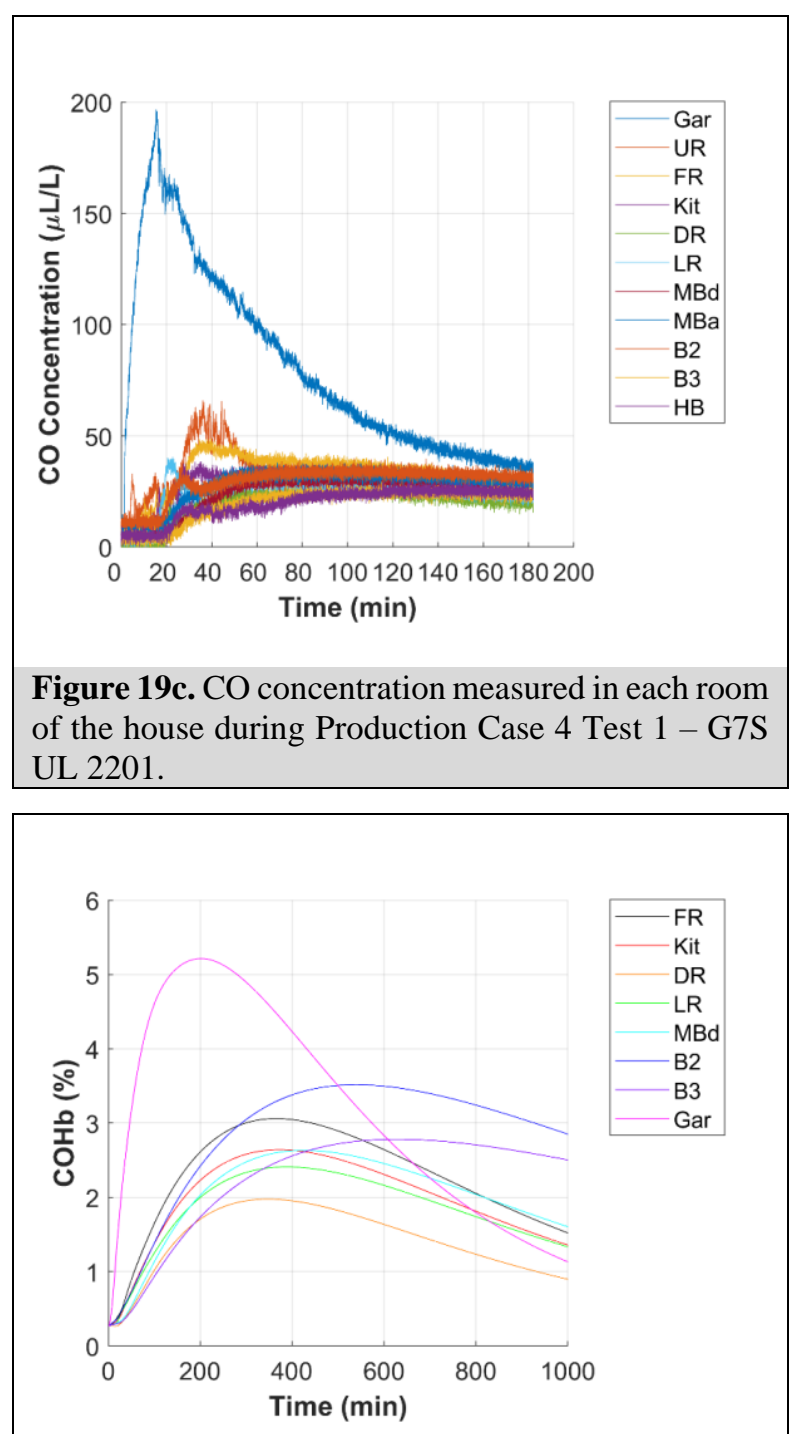

Figure 19e. $\mathrm{COHb}$ of simulated house occupants during Production Case 4 Test 1 - G7S UL 2201.

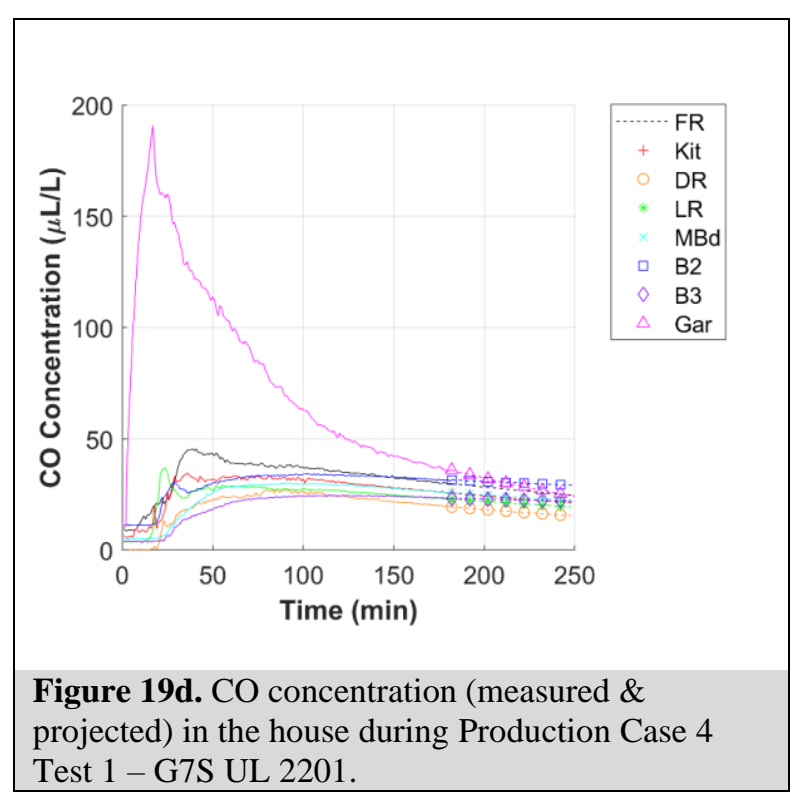

projected) in the house during Production Case 4 


\section{Production Case 4 Test 1 - G85 G300}

The following figures illustrate the results for Production Case 4 Test 1. The G85 generator, which the manufacturer stated as being certified to PGMA G300, was fully fueled, positioned in the garage (centered, with the exhaust facing towards the family room), and tested at $100 \%$ load $(6,250 \mathrm{~W})$. The interior person door (from garage to utility room) was open $10 \mathrm{~cm}$ and both the exterior person door (from garage to backyard) and the garage bay door were closed. The generator's CO safety shutoff system activated to shut off the generator after approximately $2 \mathrm{~min}$. Figure 20a shows the test house layout with generator location, generator exhaust direction, and sensor array locations. Figure 20b shows the $\mathrm{CO}$ concentrations measured in the garage by the G300 sensor (placed 3 to $5 \mathrm{~cm}$ above the approximate center of the generator's top surface), by the UL sensor (placed $30 \mathrm{~cm}$ above the approximate center of the generator's top surface), by the sensor array placed in the garage located as shown in Figure 20a (A1, A3, A5, and A7: height 183 $\mathrm{cm} ; \mathrm{A} 2, \mathrm{~A} 4, \mathrm{~A} 6$ and A8: height $61 \mathrm{~cm}$ ), and by the NDIR analyzer sample line measuring CO near the generator's CO safety shutoff sensor. All array sensors set to a height of $183 \mathrm{~cm}$ are illustrated as orange lines whereas the array sensors set to a height of $61 \mathrm{~cm}$ are illustrated as turquoise lines. The timeframe of the figure has been selected to show the degree of $\mathrm{CO}$ uniformity among these locations near the time of shutoff. Figure 20c shows the $\mathrm{CO}$ concentration measured in each room of the house over the test. Figure 20d shows the $\mathrm{CO}$ concentration in the house, with each room represented by a single line composed of both a 'solid-line' pattern (showing measured CO concentration) and a 'dotted-line with a symbol' pattern (showing projected CO concentration). Figure 20e shows the calculated $\mathrm{COHb}$ profiles of simulated house occupants in each room of the house.
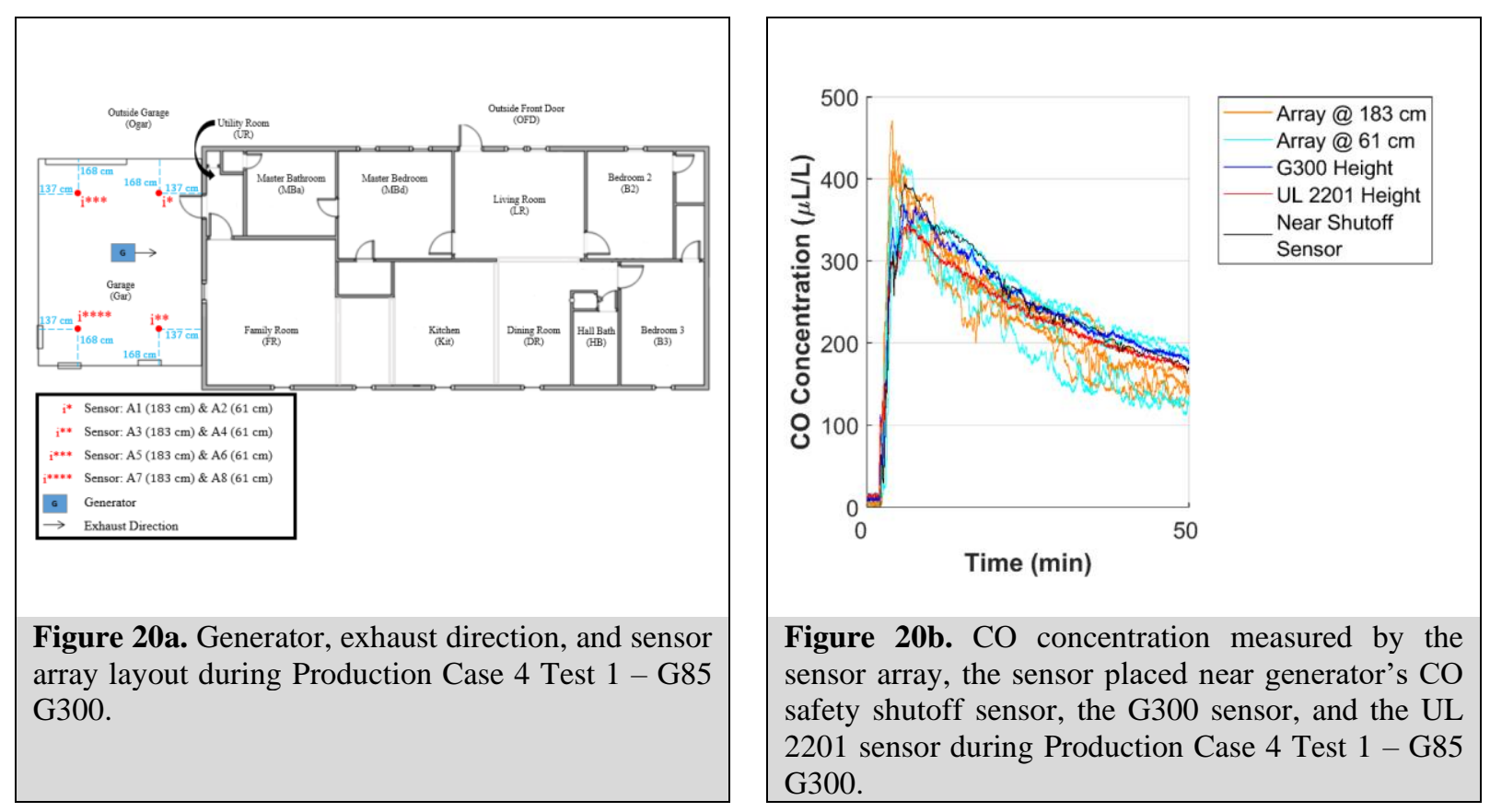


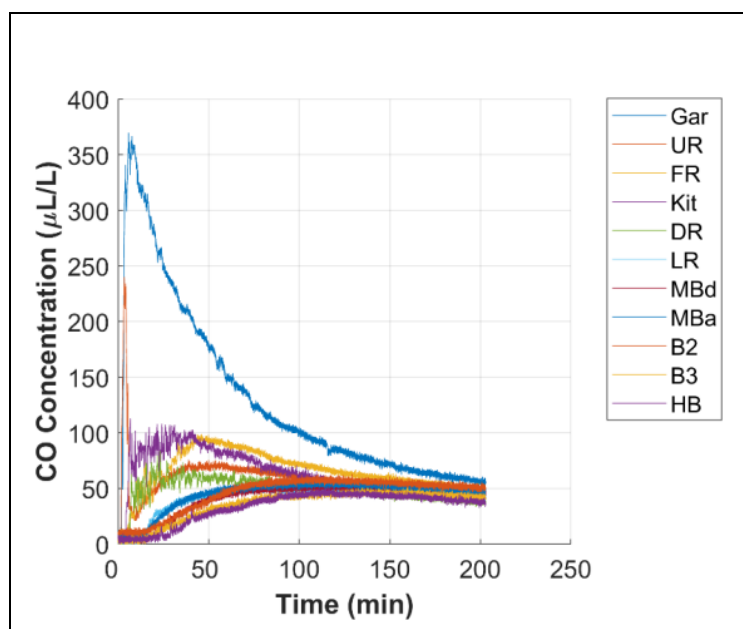

Figure 20c. $\mathrm{CO}$ concentration measured in each room of the house during Production Case 4 Test 1 - G85 G300.

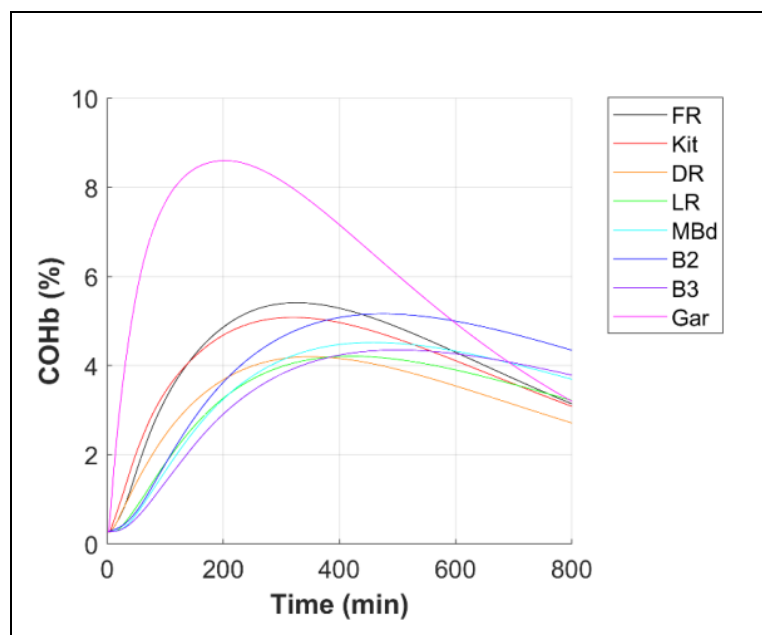

Figure 20e. $\mathrm{COHb}$ of simulated house occupants during Production Case 4 Test 1- G85 G300.

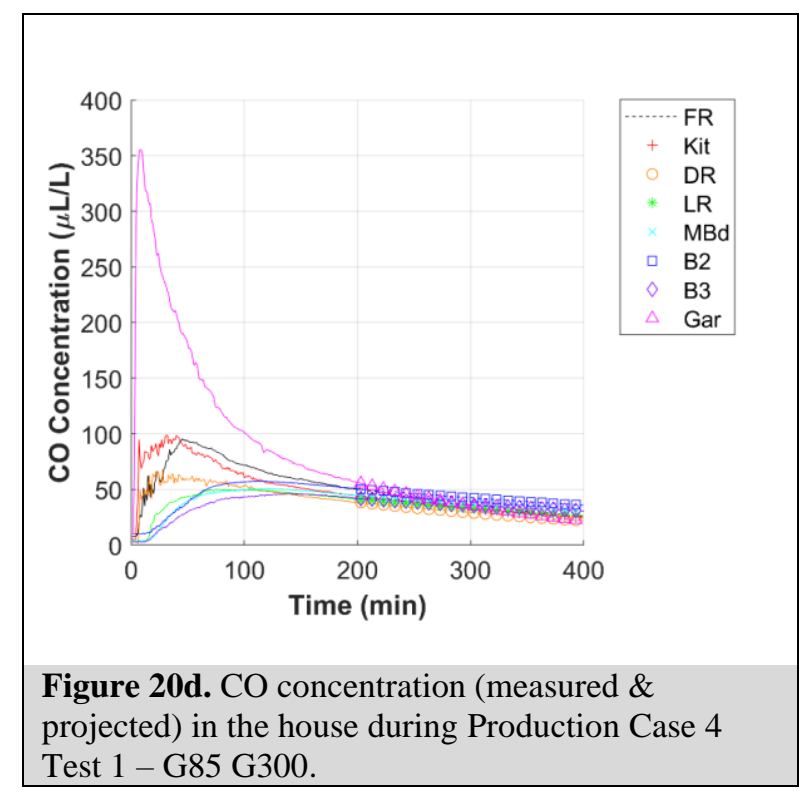

Figure 20d. CO concentration (measured \& projected) in the house during Production Case 4 Test 1 - G85 G300. 


\section{Production Case 5 Test 1 - G65S G300}

The following figures illustrate the results for Production Case 5 Test 1 . The G65S generator, which the manufacturer stated as being certified to PGMA G300, was fully fueled, positioned in the garage (centered, with the exhaust facing towards the family room), and tested at $50 \%$ load $(3,250 \mathrm{~W})$. The interior person door (from garage to utility room) was open $10 \mathrm{~cm}$ and both the exterior person door (from garage to backyard) and the garage bay door were closed. The generator's CO safety shutoff system activated to shut off the generator after approximately $4 \mathrm{~min}$. Figure 21a shows the test house layout with generator location, generator exhaust direction, and sensor array locations. Figure 21b shows the $\mathrm{CO}$ concentrations measured in the garage by the G300 sensor (placed 3 to $5 \mathrm{~cm}$ above the approximate center of the generator's top surface), by the UL sensor (placed $30 \mathrm{~cm}$ above the approximate center of the generator's top surface), by the sensor array placed in the garage located as shown in Figure 21a (A1, A3, A5, and A7: height 183 $\mathrm{cm}$; A2, A4, A6 and A8: height $61 \mathrm{~cm}$ ), and by the NDIR analyzer sample line measuring CO near the generator's CO safety shutoff sensor. All array sensors set to a height of $183 \mathrm{~cm}$ are illustrated as orange lines whereas the array sensors set to a height of $61 \mathrm{~cm}$ are illustrated as turquoise lines. The timeframe of the figure has been selected to show the degree of $\mathrm{CO}$ uniformity among these locations near the time of shutoff. Figure 21c shows the $\mathrm{CO}$ concentration measured in each room of the house over the test. Figure 21d shows the $\mathrm{CO}$ concentration in the house, with each room represented by a single line composed of both a 'solid-line' pattern (showing measured CO concentration) and a 'dotted-line with a symbol' pattern (showing projected CO concentration). Figure 21e shows the calculated $\mathrm{COHb}$ profiles of simulated house occupants in each room of the house.
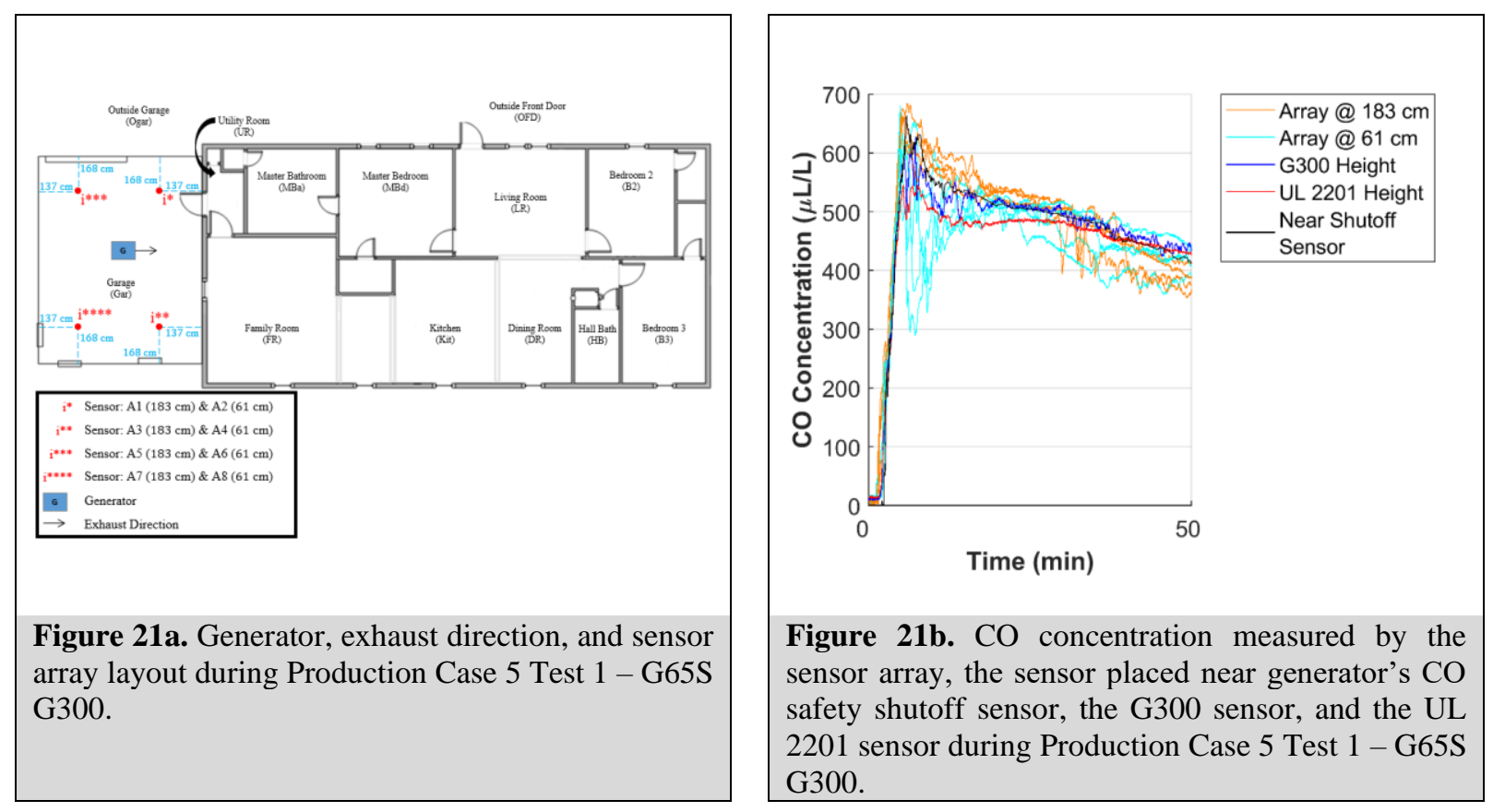


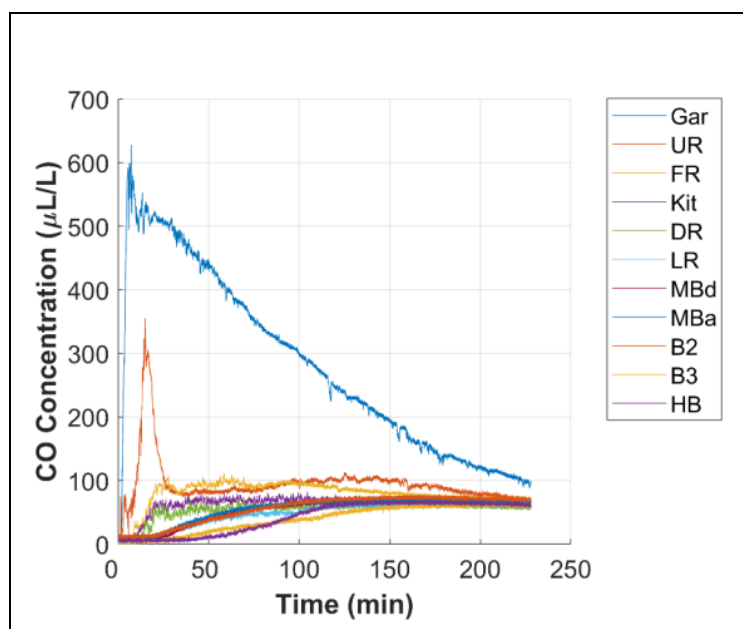

Figure 21c. $\mathrm{CO}$ concentration measured in each room of the house during Production Case 5 Test 1 - G65S G300.

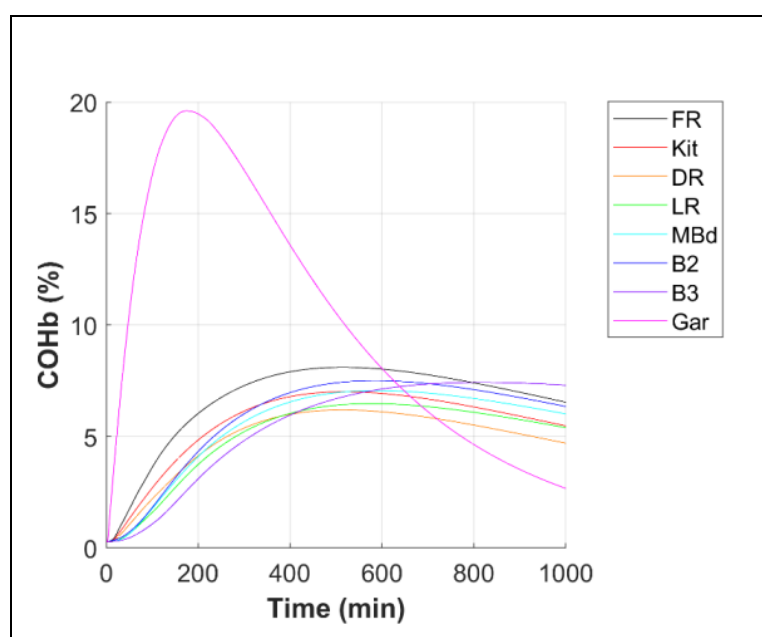

Figure 21e. $\mathrm{COHb}$ of simulated house occupants during Production Case 5 Test 1 - G65S G300.

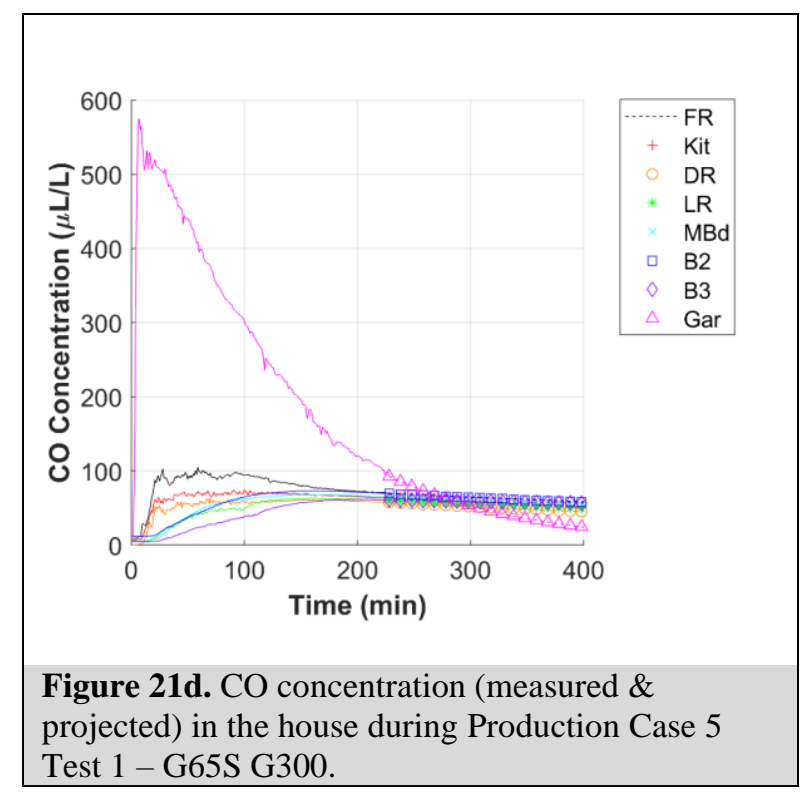

\section{Test 1 - G65S G300.}




\section{Production Case 5 Test 1 - G65C G300}

The following figures illustrate the results for Production Case 5 Test 1 . The G65C generator, which the manufacturer stated as being certified to PGMA G300, was fully fueled, positioned in the garage (centered, with the exhaust facing towards the family room), and tested at $50 \%$ load $(3,250 \mathrm{~W})$. The interior person door (from garage to utility room) was open $10 \mathrm{~cm}$ and both the exterior person door (from garage to backyard) and the garage bay door were closed. The generator's CO safety shutoff system activated to shut off the generator after approximately $12 \mathrm{~min}$. Figure 22a shows the test house layout with generator location, generator exhaust direction, and sensor array locations. Figure 22b shows the $\mathrm{CO}$ concentrations measured in the garage by the G300 sensor (placed 3 to $5 \mathrm{~cm}$ above the approximate center of the generator's top surface), by the UL sensor (placed $30 \mathrm{~cm}$ above the approximate center of the generator's top surface), by the sensor array placed in the garage located as shown in Figure 22a (A1, A3, A5, and A7: height $183 \mathrm{~cm}$; A2, A4, A6 and A8: height $61 \mathrm{~cm}$ ), and by the NDIR analyzer sample line measuring $\mathrm{CO}$ near the generator's CO safety shutoff sensor. All array sensors set to a height of $183 \mathrm{~cm}$ are illustrated as orange lines whereas the array sensors set to a height of $61 \mathrm{~cm}$ are illustrated as turquoise lines. The timeframe of the figure has been selected to show the degree of $\mathrm{CO}$ uniformity among these locations near the time of shutoff. Figure 22c shows the CO concentration measured in each room of the house over the test. Figure 22d shows the CO concentration in the house, with each room represented by a single line composed of both a 'solidline' pattern (showing measured CO concentration) and a 'dotted-line with a symbol' pattern (showing projected $\mathrm{CO}$ concentration). Figure 22e shows the calculated $\mathrm{COHb}$ profiles of simulated house occupants in each room of the house.
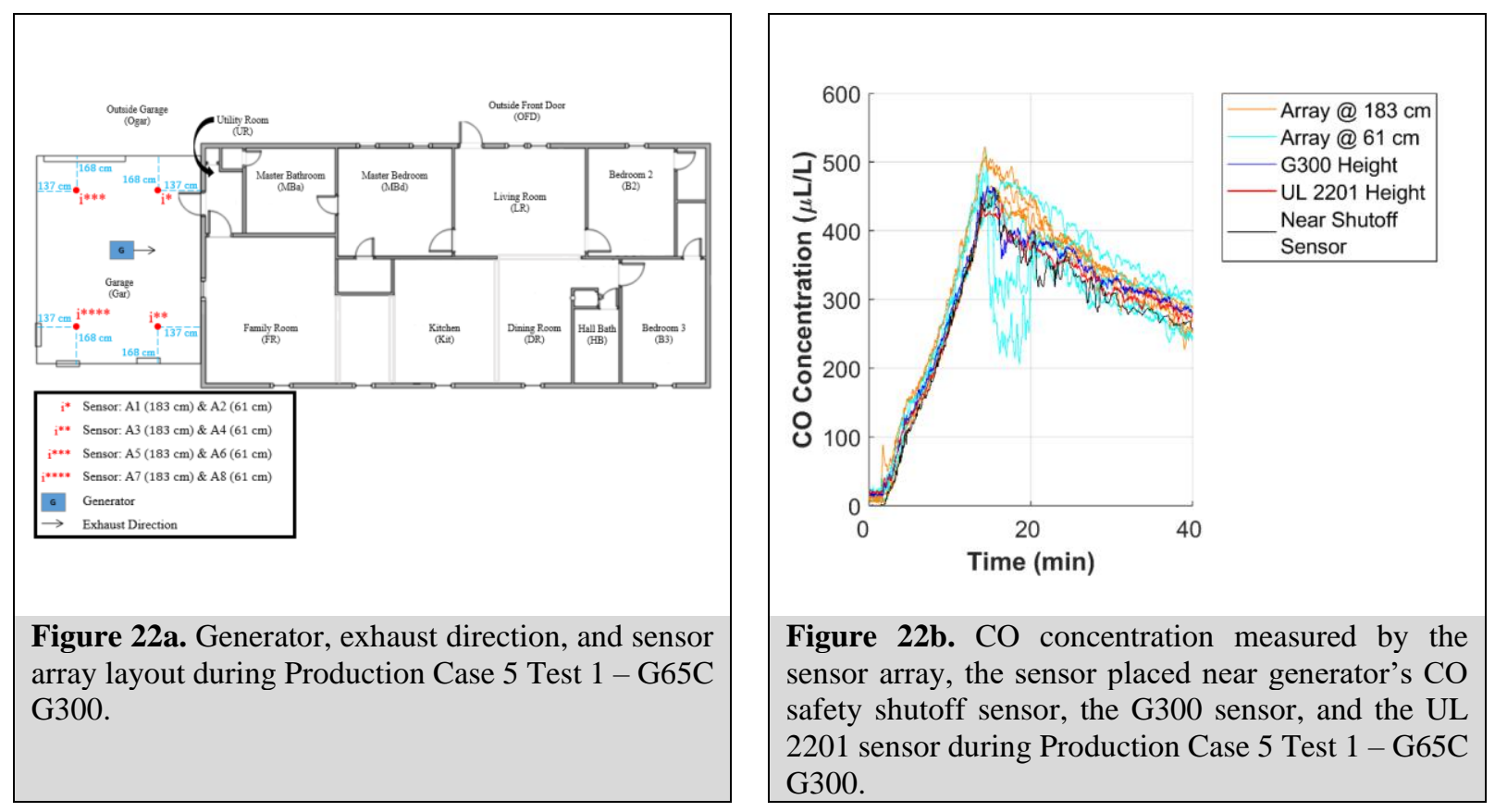


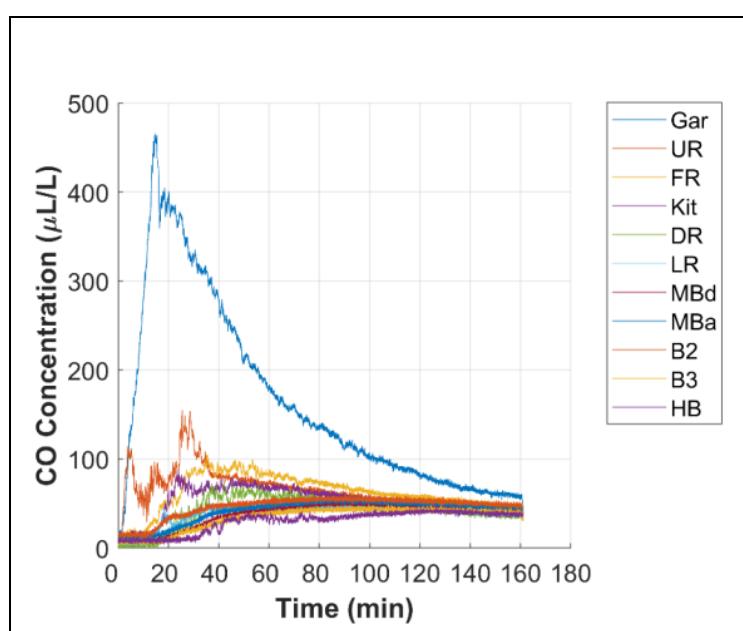

Figure 22c. $\mathrm{CO}$ concentration measured in each room of the house during Production Case 5 Test 1 - G65C G300.

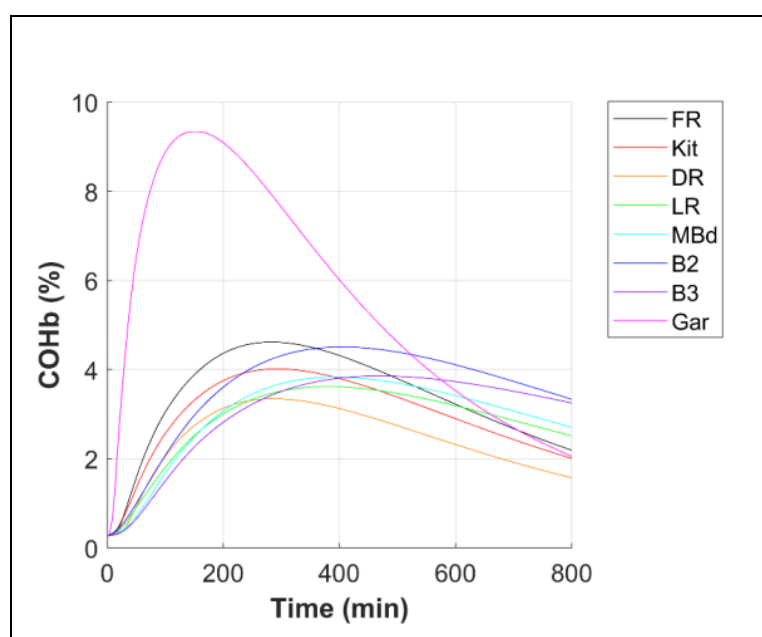

Figure 22e. $\mathrm{COHb}$ of simulated house occupants during Production Case 5 Test 1 - G65C G300.

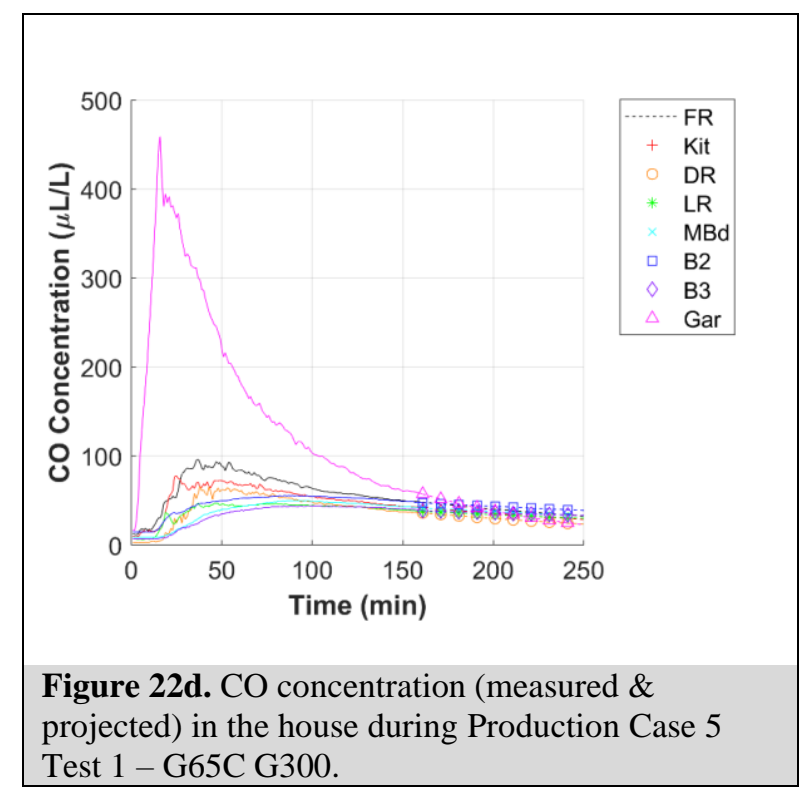

Figure 22d. CO concentration (measured \& projected) in the house during Production Case 5 Test 1 - G65C G300. 


\section{Production Case 5 Test 1 - G7S UL 2201}

The following figures illustrate the results for Production Case 5 Test 1. The G7S generator, which the manufacturer stated as being certified to UL 2201, was fully fueled, positioned in the garage (centered, with the exhaust facing towards the family room), and tested at $50 \%$ load $(3,500 \mathrm{~W})$. The interior person door (from garage to utility room) was open $10 \mathrm{~cm}$ and both the exterior person door (from garage to backyard) and the garage bay door were closed. The generator's CO safety shutoff system activated to shut off the generator after approximately 14 min. Figure 23a shows the test house layout with generator location, generator exhaust direction, and sensor array locations. Figure 23b shows the $\mathrm{CO}$ concentrations measured in the garage by the G300 sensor (placed 3 to $5 \mathrm{~cm}$ above the approximate center of the generator's top surface), by the UL sensor (placed $30 \mathrm{~cm}$ above the approximate center of the generator's top surface), by the sensor array placed in the garage located as shown in Figure 23a (A1, A3, A5, and A7: height $183 \mathrm{~cm}$; A2, A4, A6 and A8: height $61 \mathrm{~cm}$ ), and by the NDIR analyzer sample line measuring CO near the generator's CO safety shutoff sensor. All array sensors set to a height of $183 \mathrm{~cm}$ are illustrated as orange lines whereas the array sensors set to a height of $61 \mathrm{~cm}$ are illustrated as turquoise lines. The timeframe of the figure has been selected to show the degree of $\mathrm{CO}$ uniformity among these locations near the time of shutoff. Figure 23c shows the $\mathrm{CO}$ concentration measured in each room of the house over the test. Figure 23d shows the $\mathrm{CO}$ concentration in the house, with each room represented by a single line composed of both a 'solid-line' pattern (showing measured CO concentration) and a 'dotted-line with a symbol' pattern (showing projected CO concentration). Figure 23e shows the calculated $\mathrm{COHb}$ profiles of simulated house occupants in each room of the house.
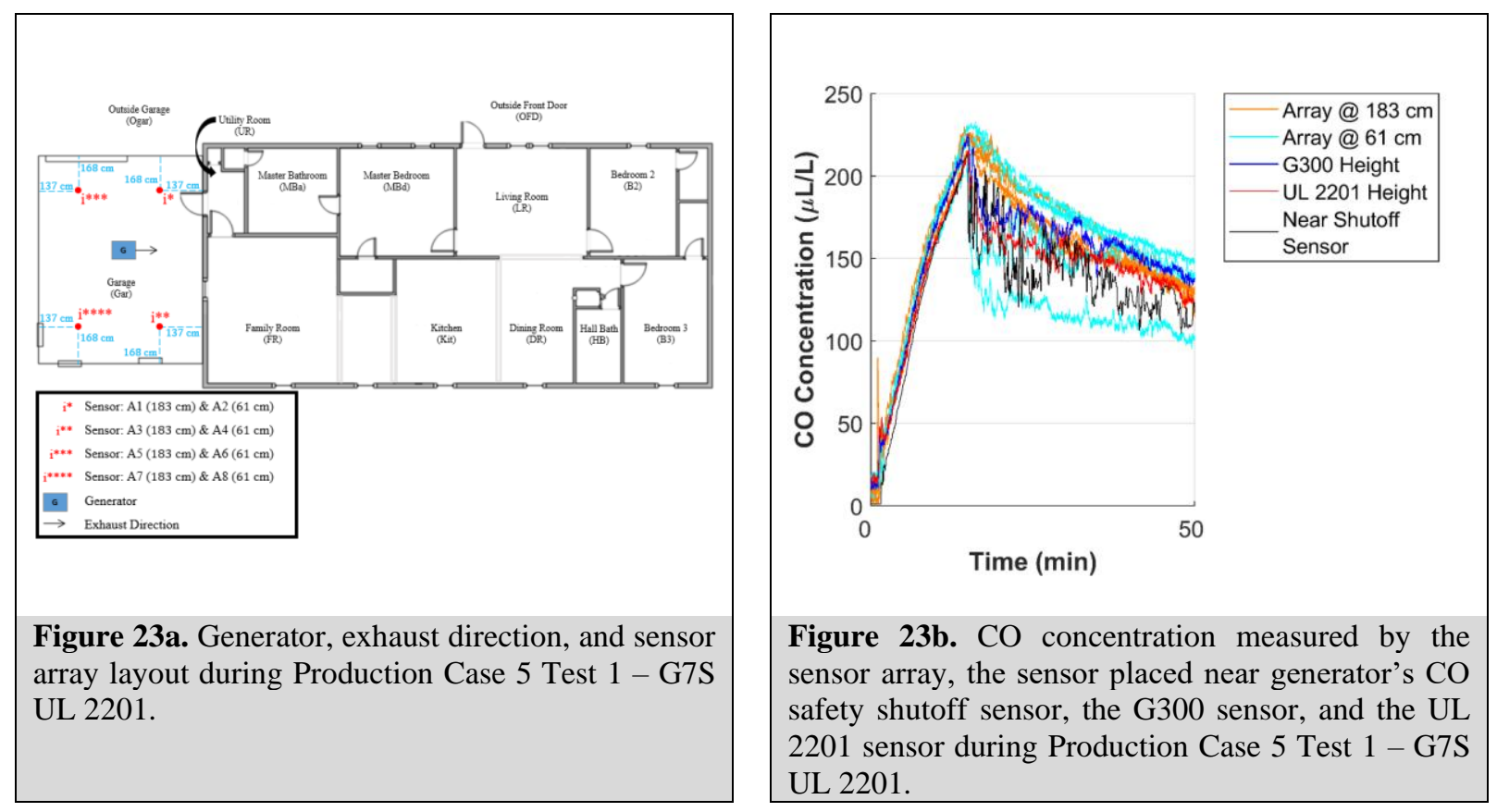


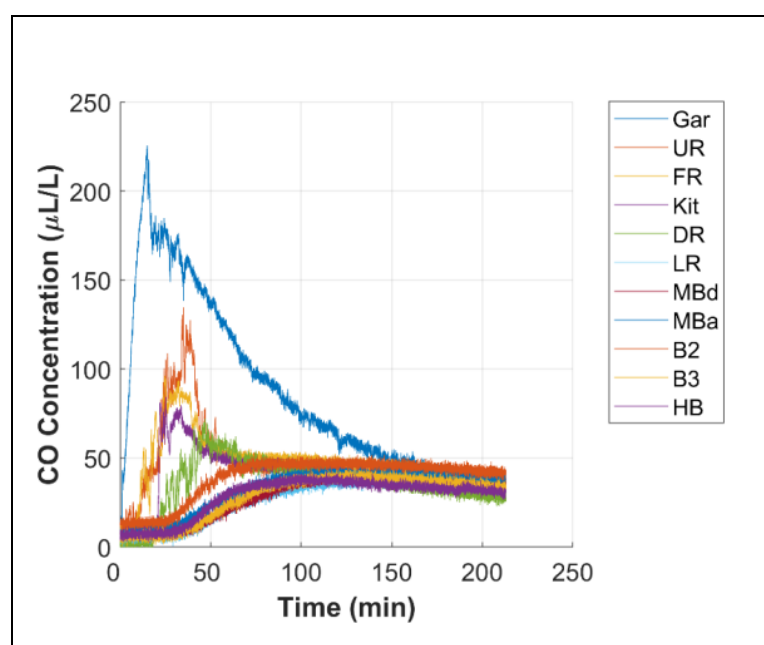

Figure 23c. $\mathrm{CO}$ concentration measured in each room of the house during Production Case 5 Test $1-$ G7S UL 2201.

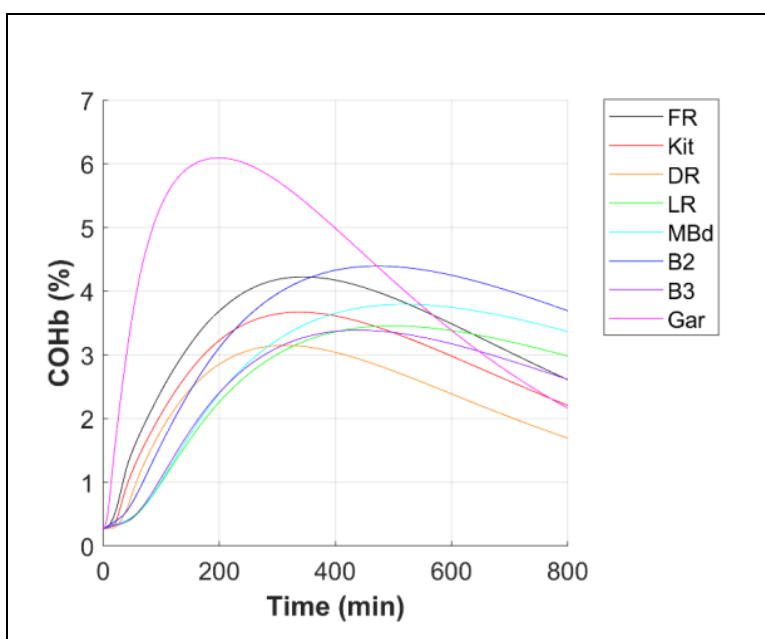

Figure 23e. $\mathrm{COHb}$ of simulated house occupants during Production Case 5 Test 1 - G7S UL 2201.

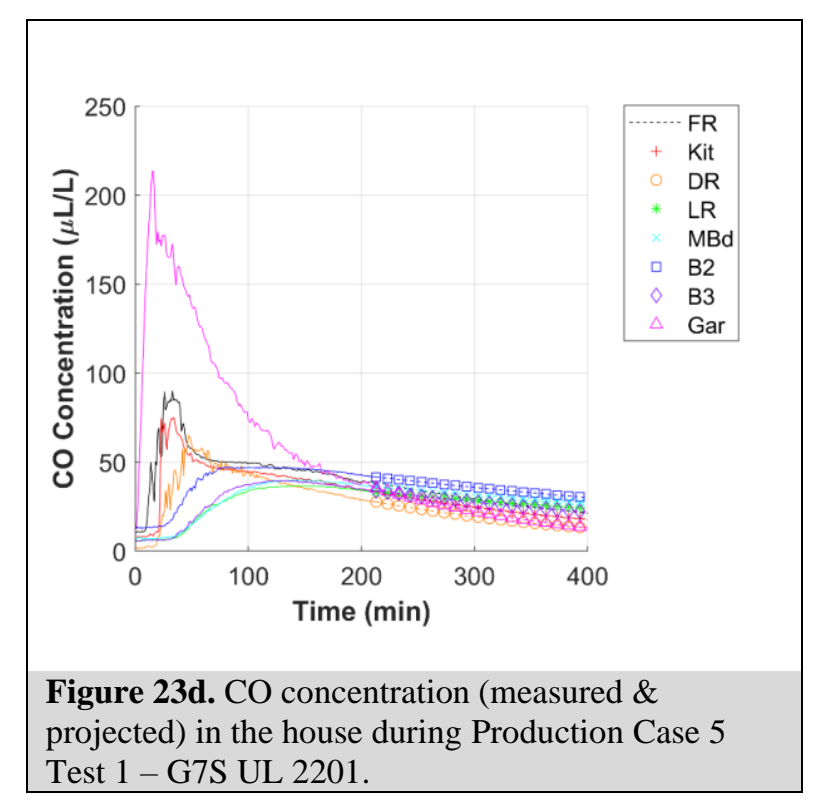

Figure 23d. CO concentration (measured \& projected) in the house during Production Case 5 Test 1 - G7S UL 2201. 


\section{Production Case 5 Test 1 - G85 G300}

The following figures illustrate the results for Production Case 5 Test 1. The G85 generator, which the manufacturer stated as being certified to PGMA G300, was fully fueled, positioned in the garage (centered, with the exhaust facing towards the family room), and tested at $50 \%$ load $(3,125$ $\mathrm{W}$ ). The interior person door (from garage to utility room) was open $10 \mathrm{~cm}$ and both the exterior person door (from garage to backyard) and the garage bay door were closed. The generator's CO safety shutoff system activated to shut off the generator after approximately $3 \mathrm{~min}$. Figure 24a shows the test house layout with generator location, generator exhaust direction, and sensor array locations. Figure 24b shows the $\mathrm{CO}$ concentrations measured in the garage by the G300 sensor (placed 3 to $5 \mathrm{~cm}$ above the approximate center of the generator's top surface), by the UL sensor (placed $30 \mathrm{~cm}$ above the approximate center of the generator's top surface), by the sensor array placed in the garage located as shown in Figure 24a (A1, A3, A5, and A7: height $183 \mathrm{~cm}$; A2, A4, A6 and A8: height $61 \mathrm{~cm}$ ), and by the NDIR analyzer sample line measuring CO near the generator's CO safety shutoff sensor. All array sensors set to a height of $183 \mathrm{~cm}$ are illustrated as orange lines whereas the array sensors set to a height of $61 \mathrm{~cm}$ are illustrated as turquoise lines. The timeframe of the figure has been selected to show the degree of $\mathrm{CO}$ uniformity among these locations near the time of shutoff. Figure $24 \mathbf{c}$ shows the $\mathrm{CO}$ concentration measured in each room of the house over the test. Figure 24d shows the $\mathrm{CO}$ concentration in the house, with each room represented by a single line composed of both a 'solid-line' pattern (showing measured CO concentration) and a 'dotted-line with a symbol' pattern (showing projected CO concentration). Figure 24e shows the calculated $\mathrm{COHb}$ profiles of simulated house occupants in each room of the house.
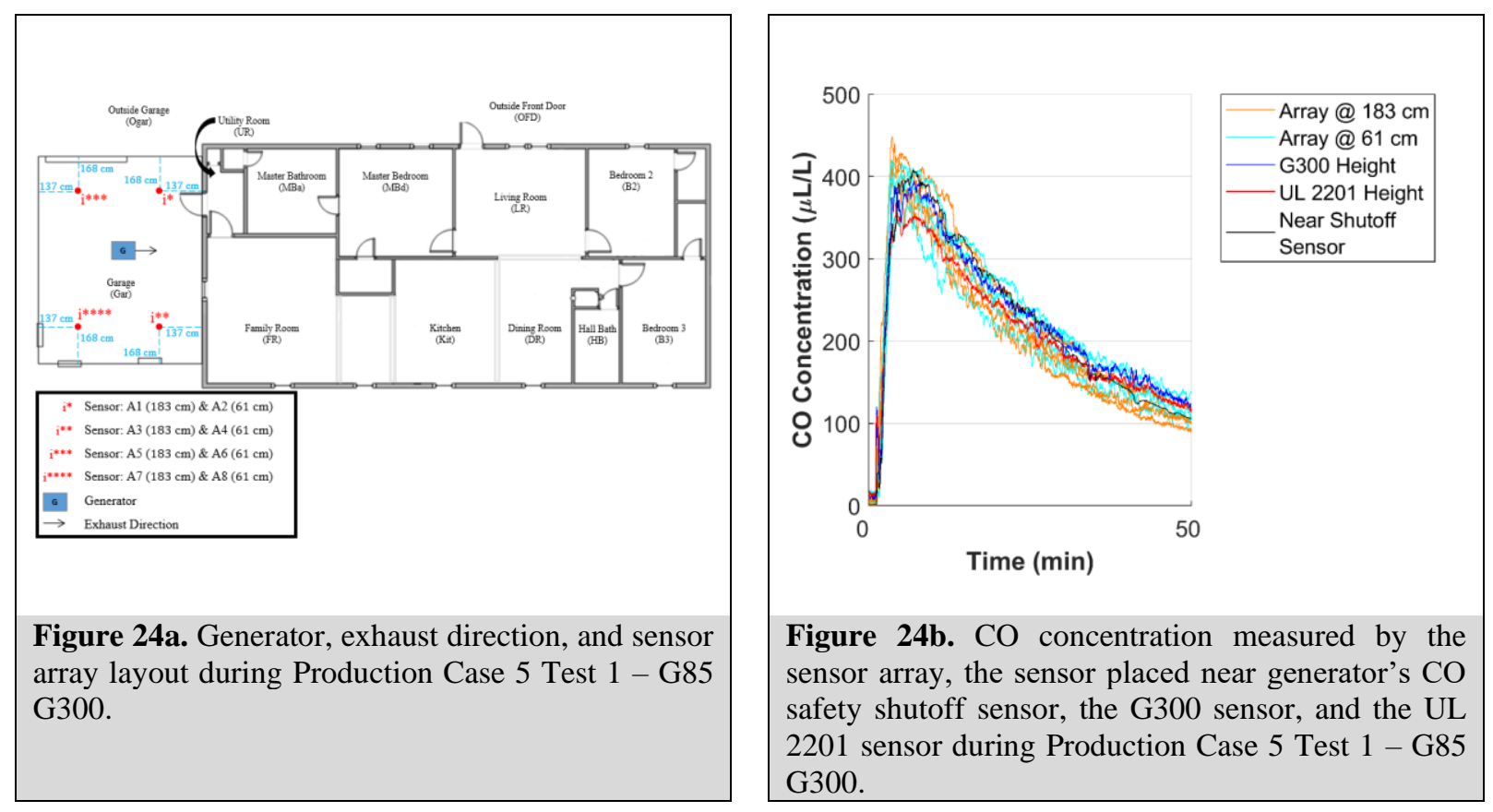


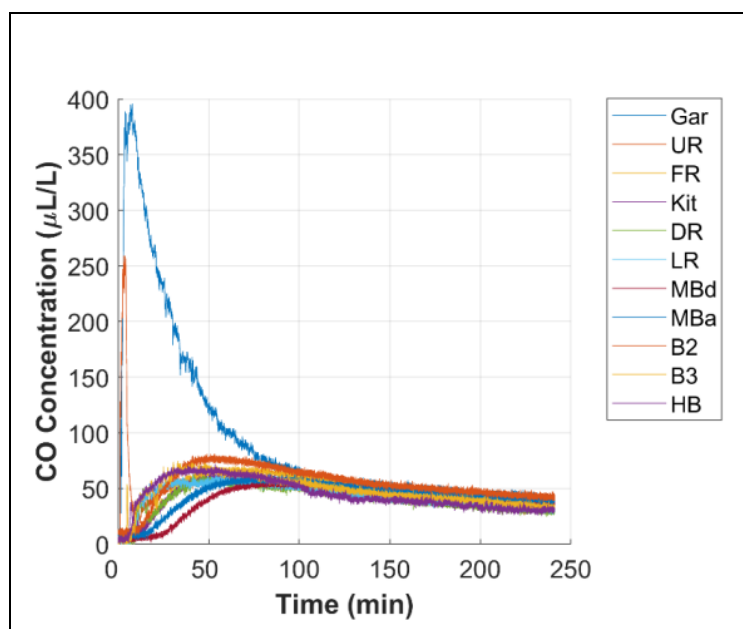

Figure 24c. $\mathrm{CO}$ concentration measured in each room of the house during Production Case 5 Test $1-$ G85 G300.

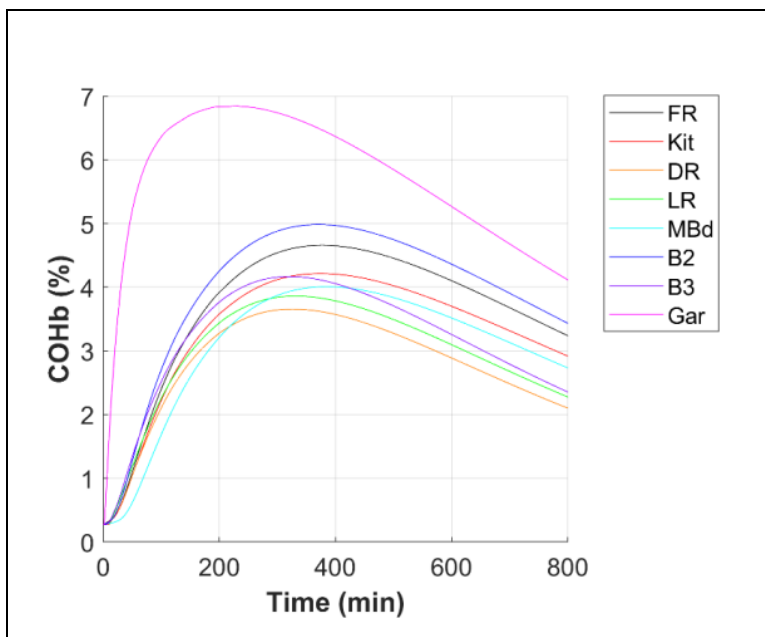

Figure 24e. $\mathrm{COHb}$ of simulated house occupants during Production Case 5 Test 1- G85 G300.

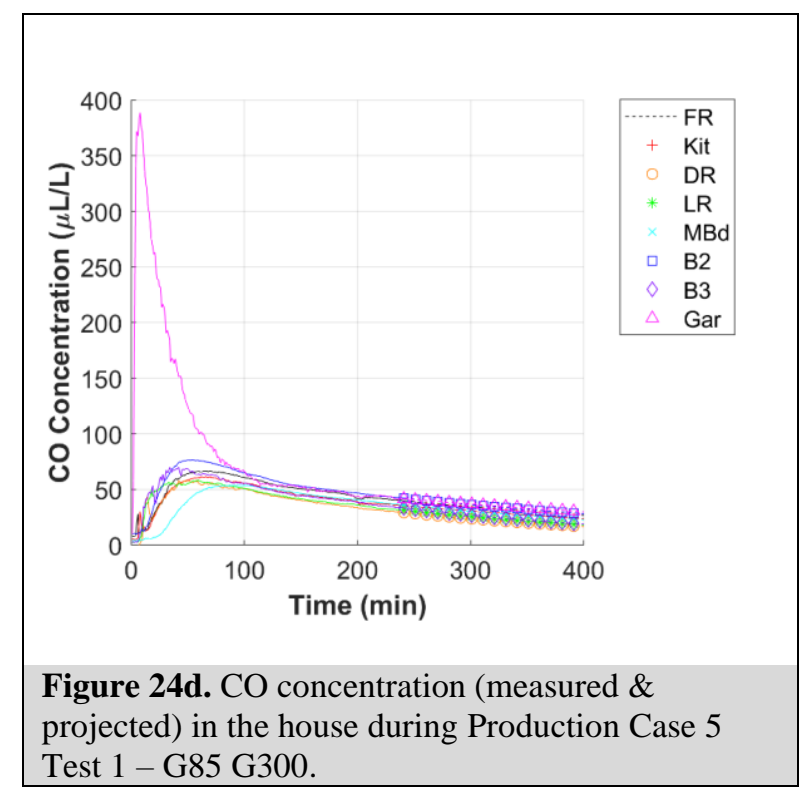

Figure 24d. CO concentration (measured \& projected) in the house during Production Case 5 Test 1 - G85 G300. 


\section{Production Case 6 Test 1 - G65S G300}

The following figures illustrate the results for Production Case 6 Test 1. The G65S generator, which the manufacturer stated as being certified to PGMA G300, was fully fueled, positioned in the garage (centered, with the exhaust facing towards the family room), and tested at $10 \%$ load $(650 \mathrm{~W})$. The interior person door (from garage to utility room) was open $10 \mathrm{~cm}$ and both the exterior person door (from garage to backyard) and the garage bay door were closed. The generator's CO safety shutoff system activated to shut off the generator after approximately $5 \mathrm{~min}$. Figure 25a shows the test house layout with generator location, generator exhaust direction, and sensor array locations. Figure 25b shows the $\mathrm{CO}$ concentrations measured in the garage by the G300 sensor (placed 3 to $5 \mathrm{~cm}$ above the approximate center of the generator's top surface), by the UL sensor (placed $30 \mathrm{~cm}$ above the approximate center of the generator's top surface), by the sensor array placed in the garage located as shown in Figure 25a (A1, A3, A5, and A7: height 183 $\mathrm{cm}$; A2, A4, A6 and A8: height $61 \mathrm{~cm}$ ), and by the NDIR analyzer sample line measuring CO near the generator's CO safety shutoff sensor. All array sensors set to a height of $183 \mathrm{~cm}$ are illustrated as orange lines whereas the array sensors set to a height of $61 \mathrm{~cm}$ are illustrated as turquoise lines. The timeframe of the figure has been selected to show the degree of $\mathrm{CO}$ uniformity among these locations near the time of shutoff. Figure 25c shows the $\mathrm{CO}$ concentration measured in each room of the house over the test. Figure 25d shows the $\mathrm{CO}$ concentration in the house, with each room represented by a single line composed of both a 'solid-line' pattern (showing measured CO concentration) and a 'dotted-line with a symbol' pattern (showing projected CO concentration). Figure 25e shows the calculated $\mathrm{COHb}$ profiles of simulated house occupants in each room of the house.
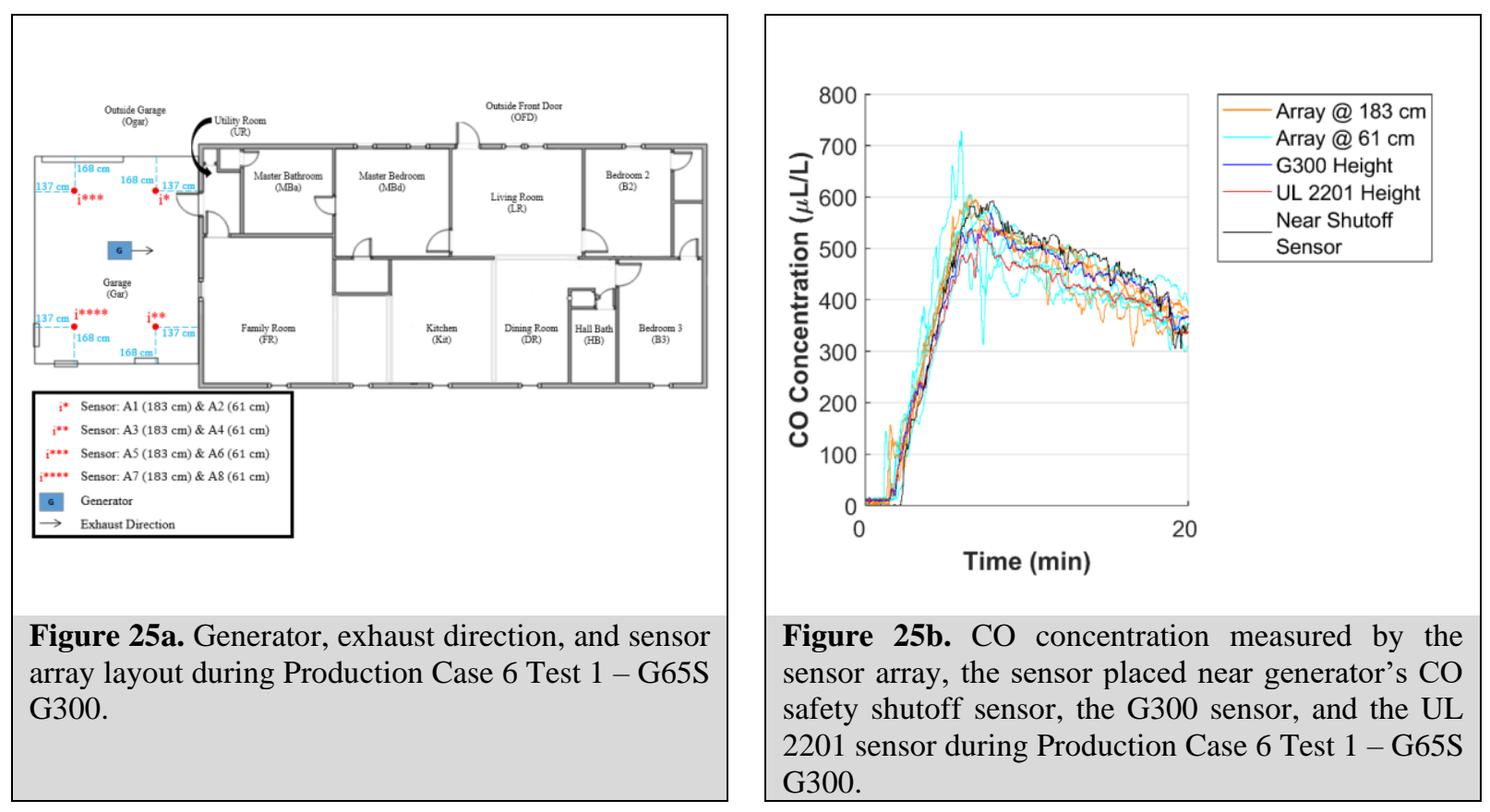


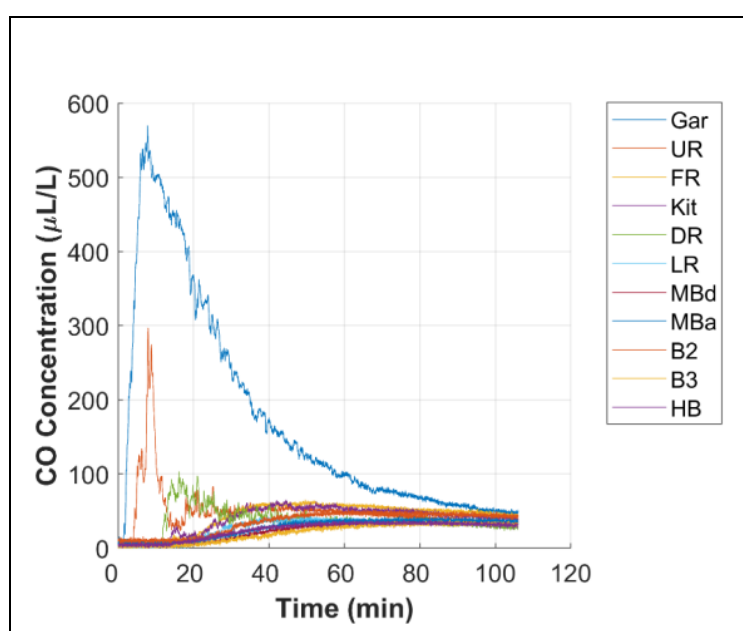

Figure 25c. $\mathrm{CO}$ concentration measured in each room of the house during Production Case 6 Test $1-$ G65S G300.

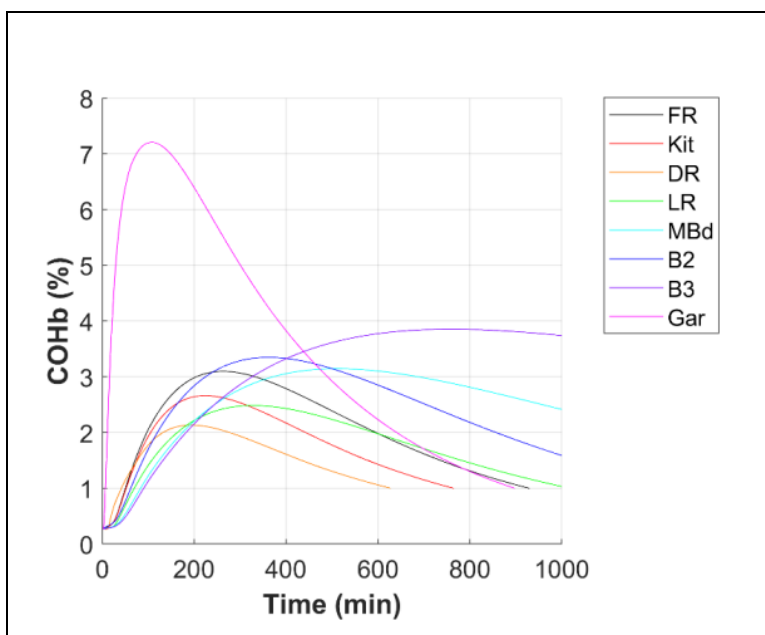

Figure 25e. $\mathrm{COHb}$ of simulated house occupants during Production Case 6 Test 1 - G65S G300.

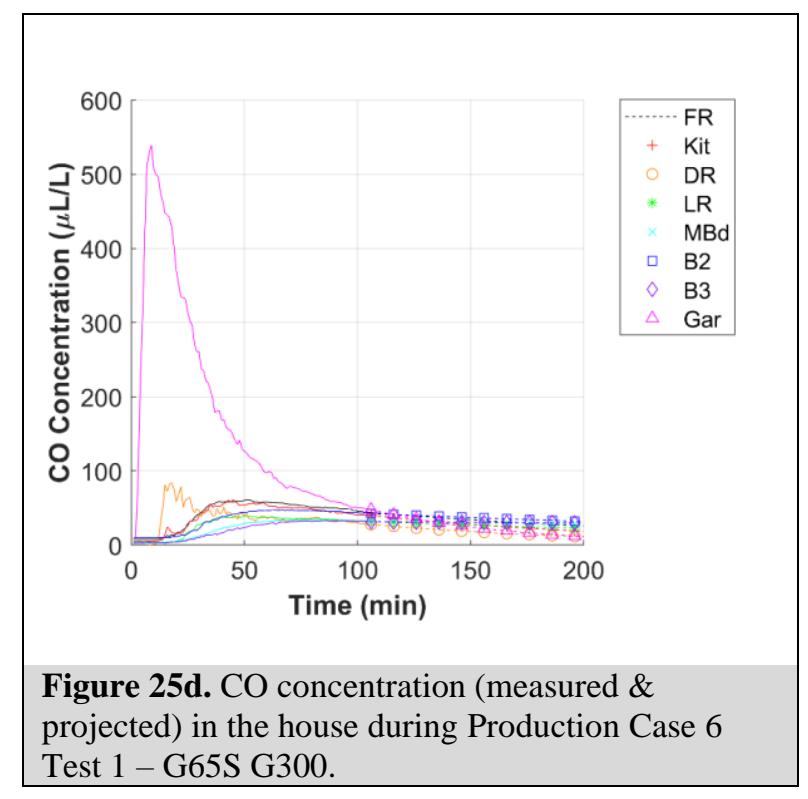

projected) in the house during Production Case 6 


\section{Production Case 6 Test 1 - G65C G300}

The following figures illustrate the results for Production Case 6 Test 1 . The G65C generator, which the manufacturer stated as being certified to PGMA G300, was fully fueled, positioned in the garage (centered, with the exhaust facing towards the family room), and tested at $10 \%$ load $(650 \mathrm{~W})$. The interior person door (from garage to utility room) was open $10 \mathrm{~cm}$ and both the exterior person door (from garage to backyard) and the garage bay door were closed. The generator's CO safety shutoff system activated to shut off the generator after approximately $58 \mathrm{~min}$. Figure 26a shows the test house layout with generator location, generator exhaust direction, and sensor array locations. Figure 26b shows the $\mathrm{CO}$ concentrations measured in the garage by the G300 sensor (placed 3 to $5 \mathrm{~cm}$ above the approximate center of the generator's top surface), by the UL sensor (placed $30 \mathrm{~cm}$ above the approximate center of the generator's top surface), by the sensor array placed in the garage located as shown in Figure 26a (A1, A3, A5, and A7: height $183 \mathrm{~cm}$; A2, A4, A6 and A8: height $61 \mathrm{~cm}$ ), and by the NDIR analyzer sample line measuring $\mathrm{CO}$ near the generator's CO safety shutoff sensor. All array sensors set to a height of $183 \mathrm{~cm}$ are illustrated as orange lines whereas the array sensors set to a height of $61 \mathrm{~cm}$ are illustrated as turquoise lines. The timeframe of the figure has been selected to show the degree of $\mathrm{CO}$ uniformity among these locations near the time of shutoff. Figure 26c shows the CO concentration measured in each room of the house over the test. Figure 26d shows the CO concentration in the house, with each room represented by a single line composed of both a 'solidline' pattern (showing measured CO concentration) and a 'dotted-line with a symbol' pattern (showing projected $\mathrm{CO}$ concentration). Figure 26e shows the calculated $\mathrm{COHb}$ profiles of simulated house occupants in each room of the house.
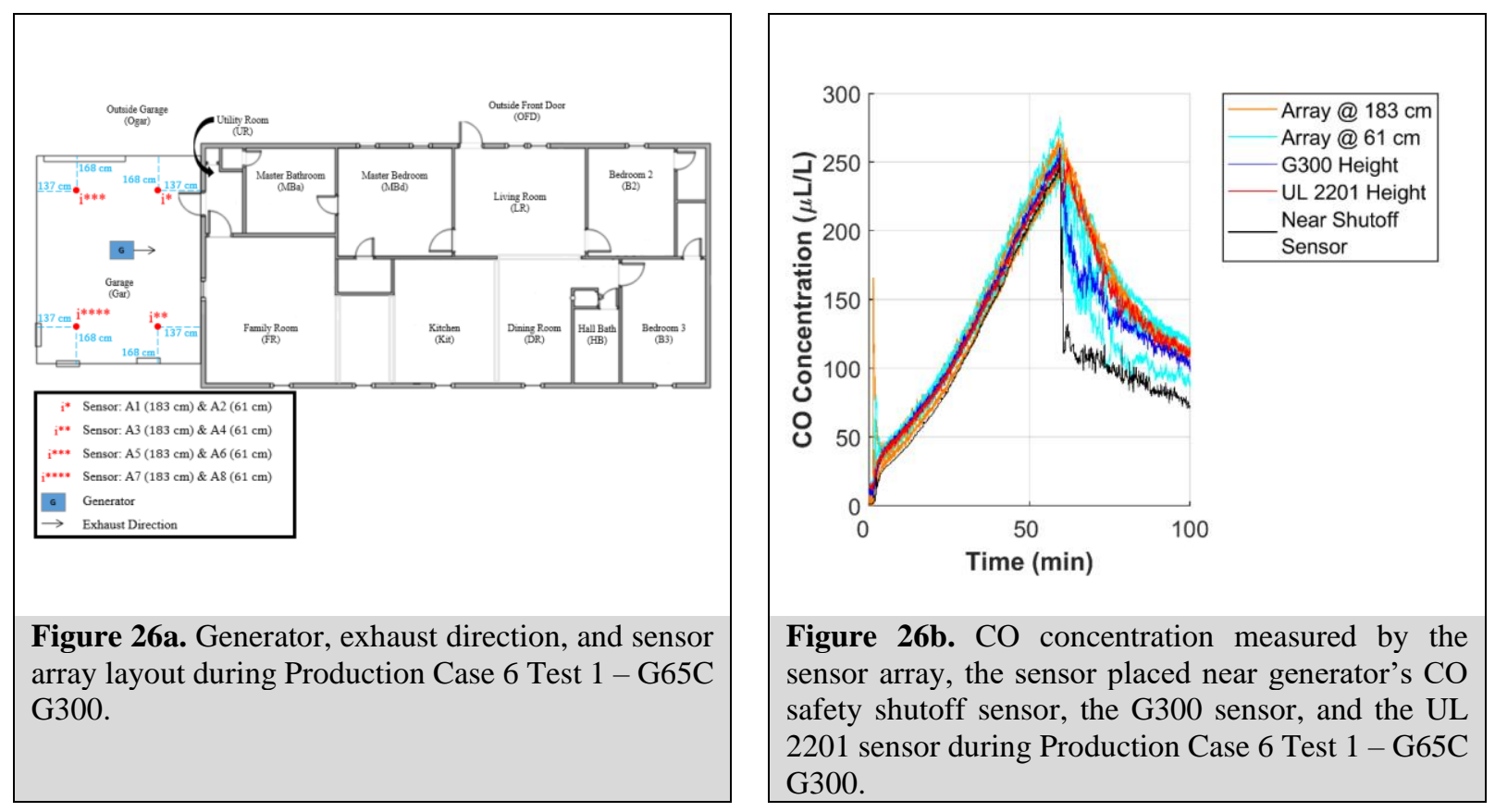


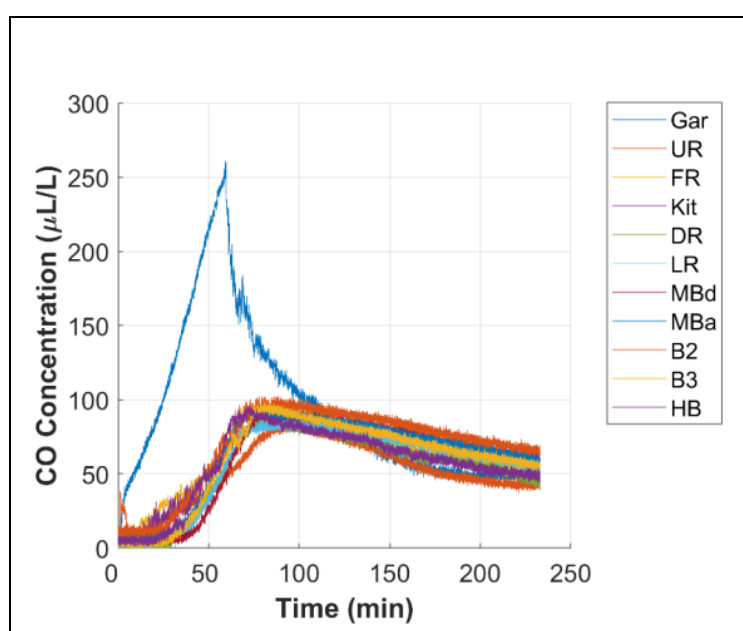

Figure 26c. $\mathrm{CO}$ concentration measured in each room of the house during Production Case 6 Test 1 - G65C G300.

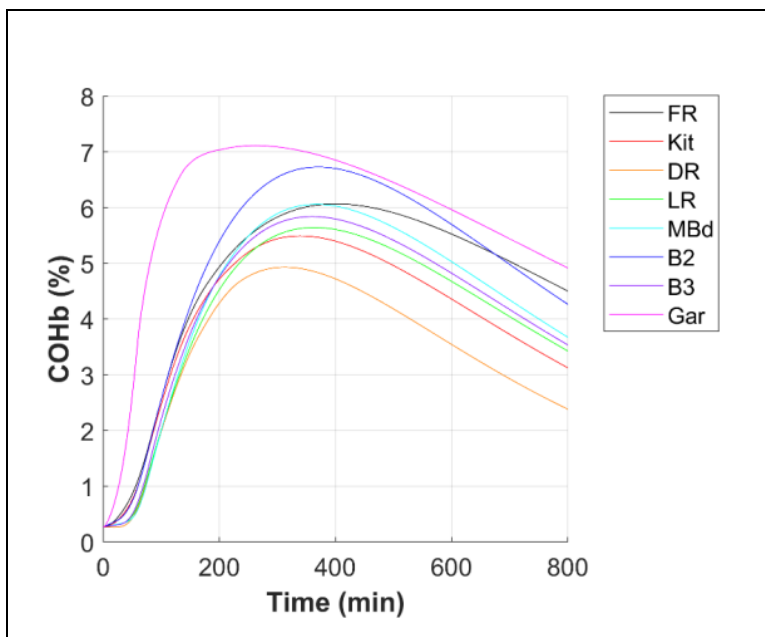

Figure 26e. $\mathrm{COHb}$ of simulated house occupants during Production Case 6 Test 1 - G65C G300.

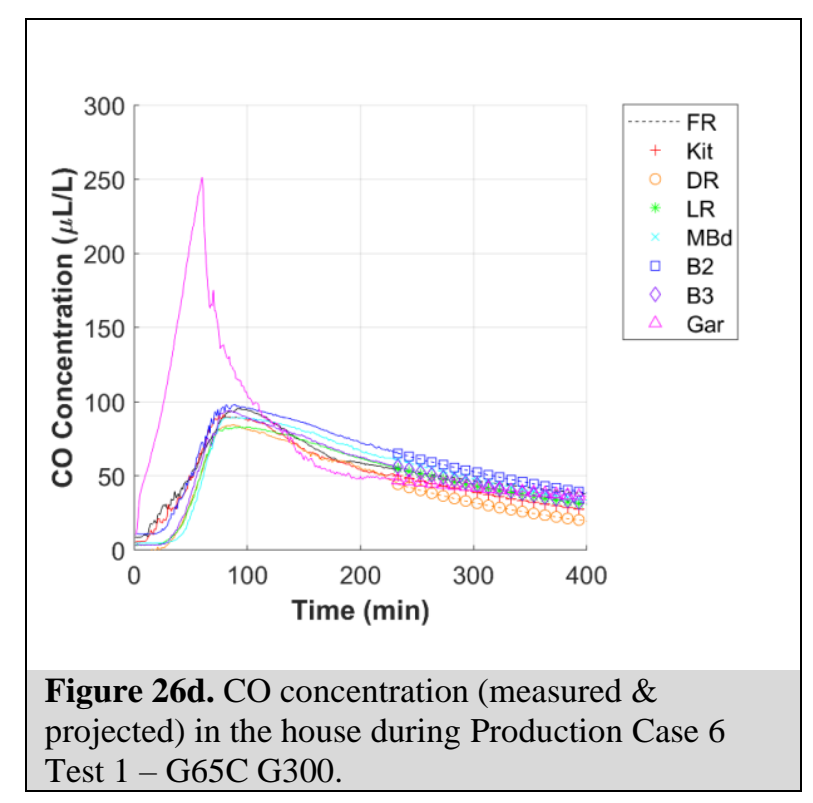

Figure 26d. CO concentration (measured \& projected) in the house during Production Case 6 Test 1 - G65C G300. 


\section{Production Case 6 Test 1 - G7S UL 2201}

The following figures illustrate the results for Production Case 6 Test 1. The G7S generator, which the manufacturer stated as being certified to UL 2201, was fully fueled, positioned in the garage (centered, with the exhaust facing towards the family room), and tested at $10 \%$ load $(700 \mathrm{~W})$. The interior person door (from garage to utility room) was open $10 \mathrm{~cm}$ and both the exterior person door (from garage to backyard) and the garage bay door were closed. The generator's CO safety shutoff system activated to shut off the generator after approximately $166 \mathrm{~min}$. Figure 27a shows the test house layout with generator location, generator exhaust direction, and sensor array locations. Figure 27b shows the $\mathrm{CO}$ concentrations measured in the garage by the G300 sensor (placed 3 to $5 \mathrm{~cm}$ above the approximate center of the generator's top surface), by the UL sensor (placed $30 \mathrm{~cm}$ above the approximate center of the generator's top surface), by the sensor array placed in the garage located as shown in Figure 27a (A1, A3, A5, and A7: height $183 \mathrm{~cm}$; A2, A4, A6 and A8: height $61 \mathrm{~cm}$ ), and by the NDIR analyzer sample line measuring CO near the generator's CO safety shutoff sensor. All array sensors set to a height of $183 \mathrm{~cm}$ are illustrated as orange lines whereas the array sensors set to a height of $61 \mathrm{~cm}$ are illustrated as turquoise lines. The timeframe of the figure has been selected to show the degree of $\mathrm{CO}$ uniformity among these locations near the time of shutoff. Figure 27c shows the $\mathrm{CO}$ concentration measured in each room of the house over the test. Figure 27d shows the $\mathrm{CO}$ concentration in the house, with each room represented by a single line composed of both a 'solid-line' pattern (showing measured CO concentration) and a 'dotted-line with a symbol' pattern (showing projected CO concentration). Figure 27e shows the calculated $\mathrm{COHb}$ profiles of simulated house occupants in each room of the house.
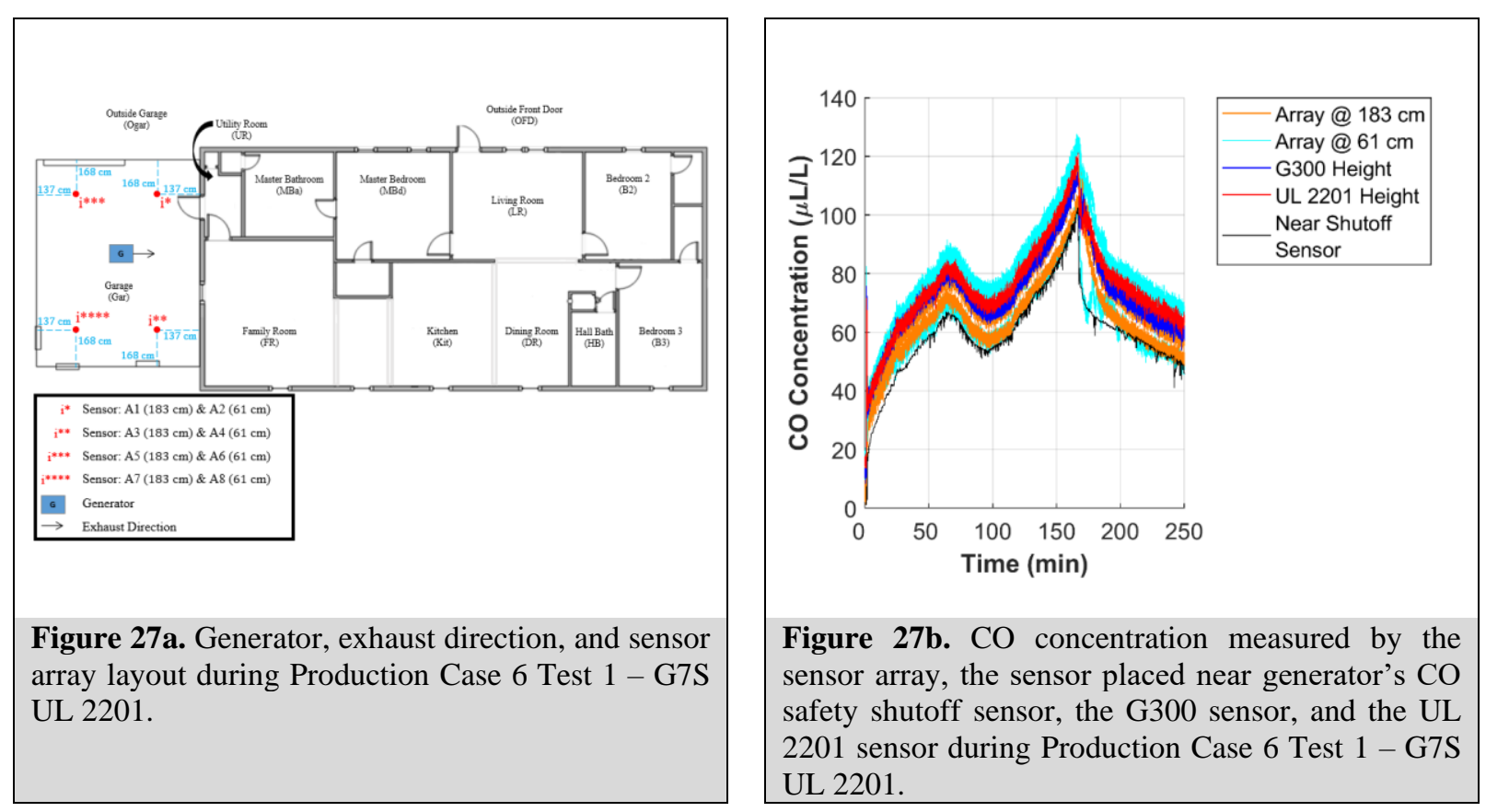


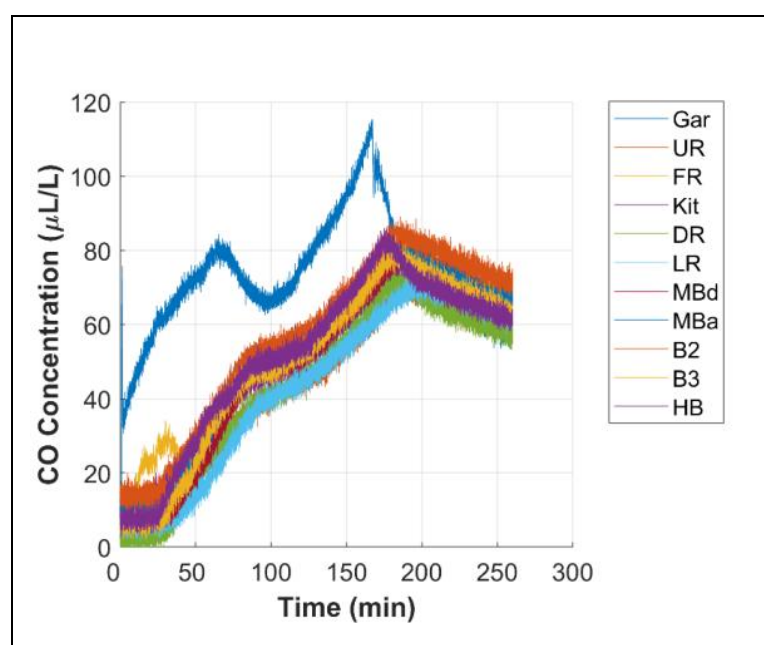

Figure 27c. $\mathrm{CO}$ concentration measured in each room of the house during Production Case 6 Test $1-$ G7S UL 2201.

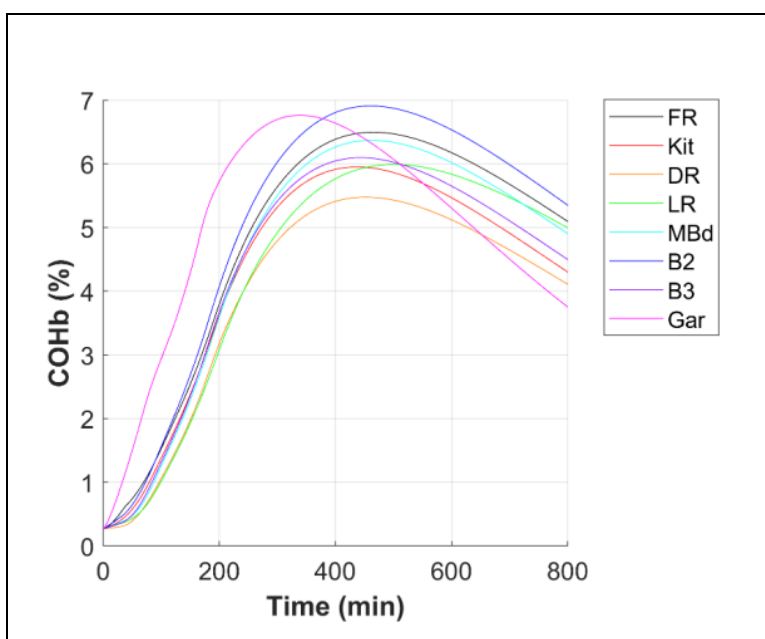

Figure 27e. $\mathrm{COHb}$ of simulated house occupants during Production Case 6 Test 1 - G7S UL 2201.

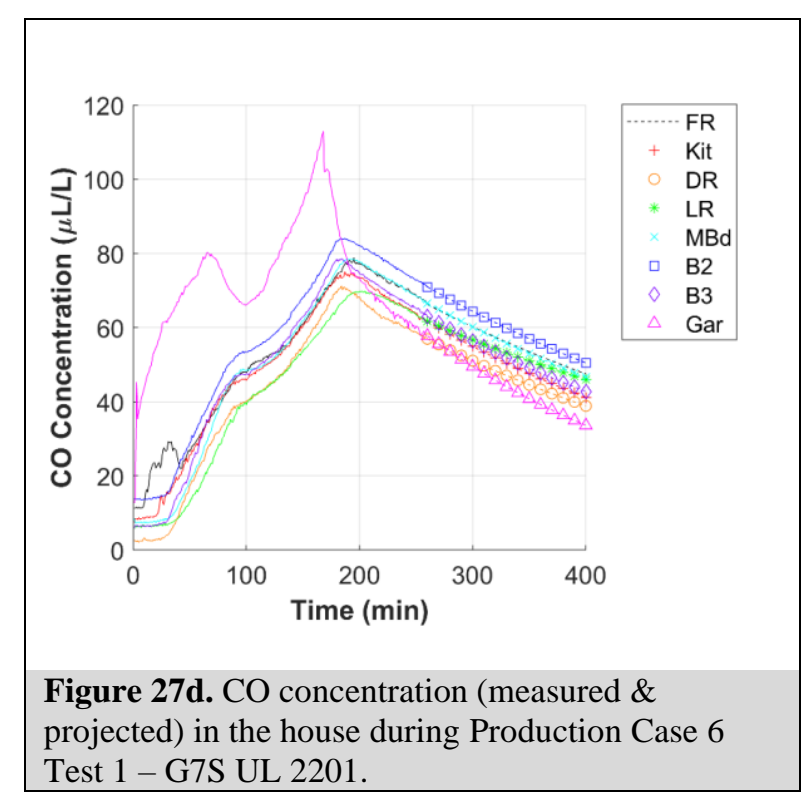

Figure 27d. CO concentration (measured \& projected) in the house during Production Case 6 Test 1 - G7S UL 2201. 


\section{Production Case 6 Test 1 - G85 G300}

The following figures illustrate the results for Production Case 6 Test 1. The G85 generator, which the manufacturer stated as being certified to PGMA G300, was fully fueled, positioned in the garage (centered, with the exhaust facing towards the family room), and tested at $10 \%$ load (625 $\mathrm{W}$ ). The interior person door (from garage to utility room) was open $10 \mathrm{~cm}$ and both the exterior person door (from garage to backyard) and the garage bay door were closed. The generator's CO safety shutoff system activated to shut off the generator after approximately $4 \mathrm{~min}$. Figure 28a shows the test house layout with generator location, generator exhaust direction, and sensor array locations. Figure 28b shows the $\mathrm{CO}$ concentrations measured in the garage by the G300 sensor (placed 3 to $5 \mathrm{~cm}$ above the approximate center of the generator's top surface), by the UL sensor (placed $30 \mathrm{~cm}$ above the approximate center of the generator's top surface), by the sensor array placed in the garage located as shown in Figure 28a (A1, A3, A5, and A7: height $183 \mathrm{~cm}$; A2, A4, A6 and A8: height $61 \mathrm{~cm}$ ), and by the NDIR analyzer sample line measuring CO near the generator's CO safety shutoff sensor. All array sensors set to a height of $183 \mathrm{~cm}$ are illustrated as orange lines whereas the array sensors set to a height of $61 \mathrm{~cm}$ are illustrated as turquoise lines. The timeframe of the figure has been selected to show the degree of $\mathrm{CO}$ uniformity among these locations near the time of shutoff. Figure 28c shows the $\mathrm{CO}$ concentration measured in each room of the house over the test. Figure 28d shows the $\mathrm{CO}$ concentration in the house, with each room represented by a single line composed of both a 'solid-line' pattern (showing measured CO concentration) and a 'dotted-line with a symbol' pattern (showing projected CO concentration). Figure 28e shows the calculated $\mathrm{COHb}$ profiles of simulated house occupants in each room of the house.
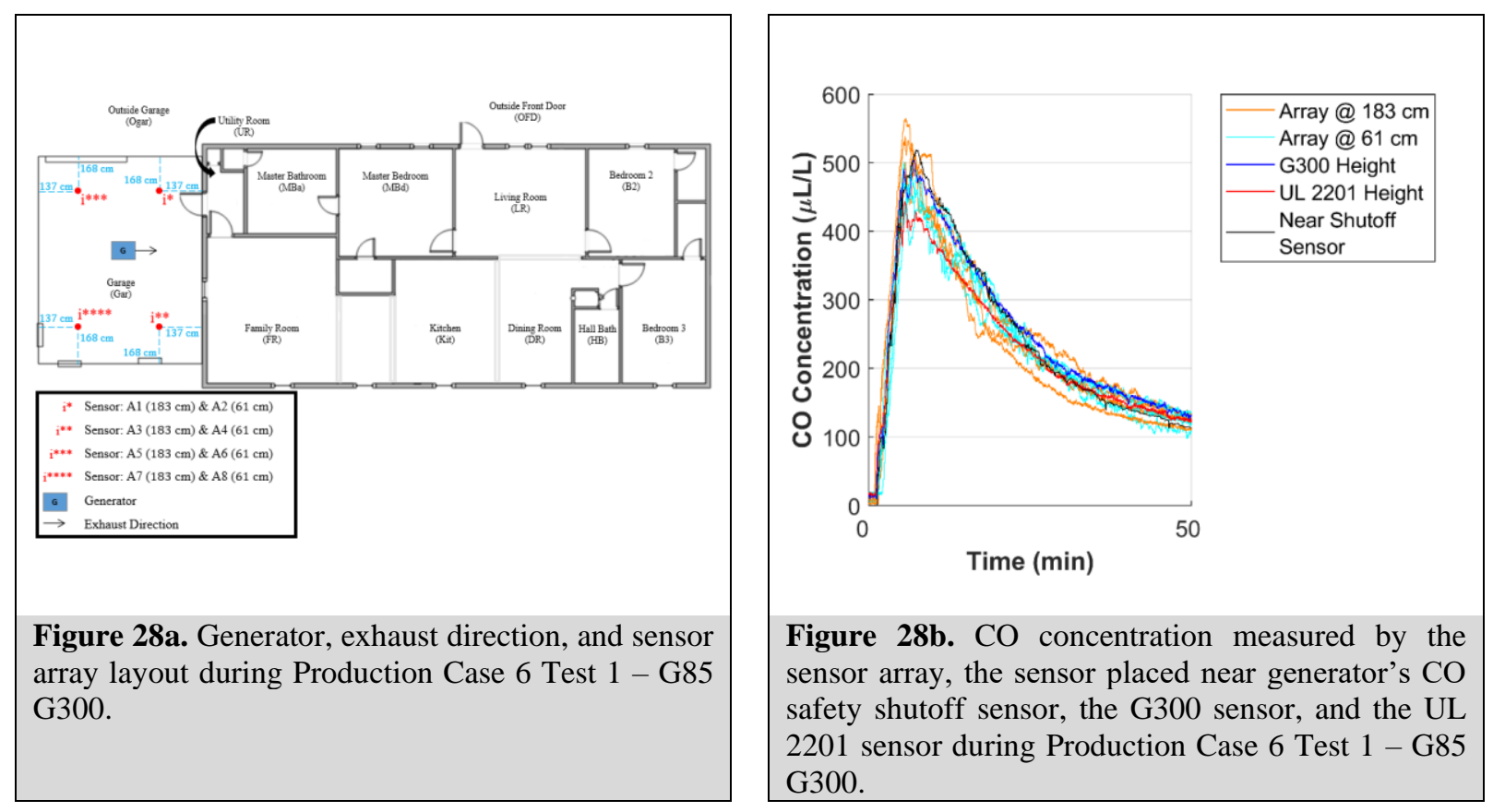


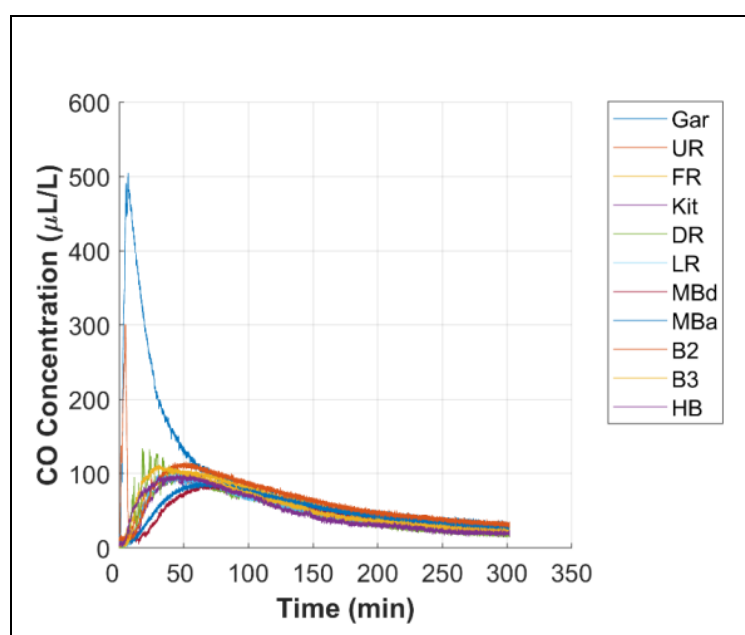

Figure 28c. $\mathrm{CO}$ concentration measured in each room of the house during Production Case 6 Test 1-G85 G300.

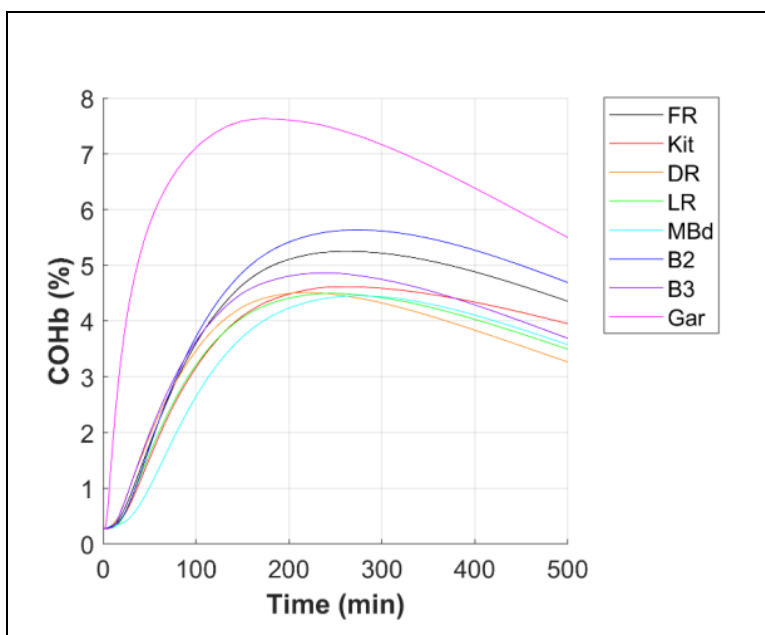

Figure 28e. $\mathrm{COHb}$ of simulated house occupants during Production Case 6 Test 1- G85 G300.

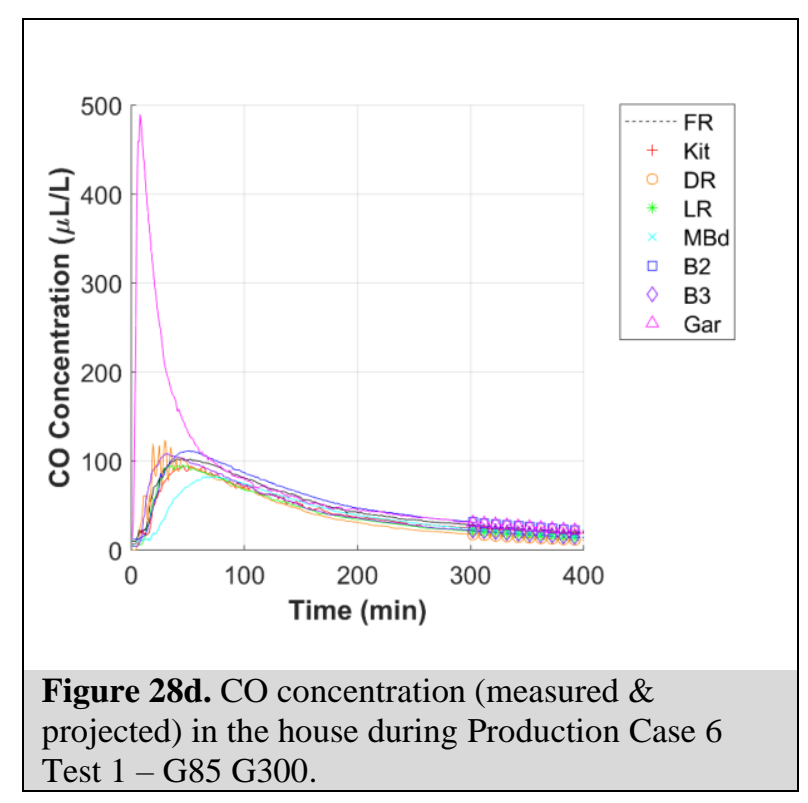

projected) in the house during Production Case 6 


\section{Production Case 7 Test 1 - G65S G300}

The following figures illustrate the results for Production Case 7 Test 1. The G65S generator, which the manufacturer stated as being certified to PGMA G300, was fully fueled, positioned in the garage (centered, with the exhaust facing towards the family room), and tested at $100 \%$ load $(6,500 \mathrm{~W})$. The interior person door (from garage to utility room) was open $10 \mathrm{~cm}$, the garage bay door was fully open, and the exterior person door (from garage to backyard) was closed. The generator's CO safety shutoff system was not activated, and the generator ran out of fuel after approximately $329 \mathrm{~min}$. Figure 29a shows the test house layout with generator location, generator exhaust direction, and sensor array locations. Figure 29b shows the $\mathrm{CO}$ concentrations measured in the garage by the G300 sensor (placed 3 to $5 \mathrm{~cm}$ above the approximate center of the generator's top surface), by the UL sensor (placed $30 \mathrm{~cm}$ above the approximate center of the generator's top surface), by the sensor array placed in the garage located as shown in Figure 29a (A1, A3, A5, and A7: height $183 \mathrm{~cm}$; A2, A4, A6 and A8: height $61 \mathrm{~cm}$ ), and by the NDIR analyzer sample line measuring $\mathrm{CO}$ near the generator's CO safety shutoff sensor. All array sensors set to a height of $183 \mathrm{~cm}$ are illustrated as orange lines whereas the array sensors set to a height of $61 \mathrm{~cm}$ are illustrated as turquoise lines. The figure shows the degree of $\mathrm{CO}$ uniformity among these locations near the time of shutdown. Figure 29c shows the $\mathrm{CO}$ concentration measured in each room of the house over the test. Figure 29d shows the calculated $\mathrm{COHb}$ profiles of simulated house occupants in each room of the house.

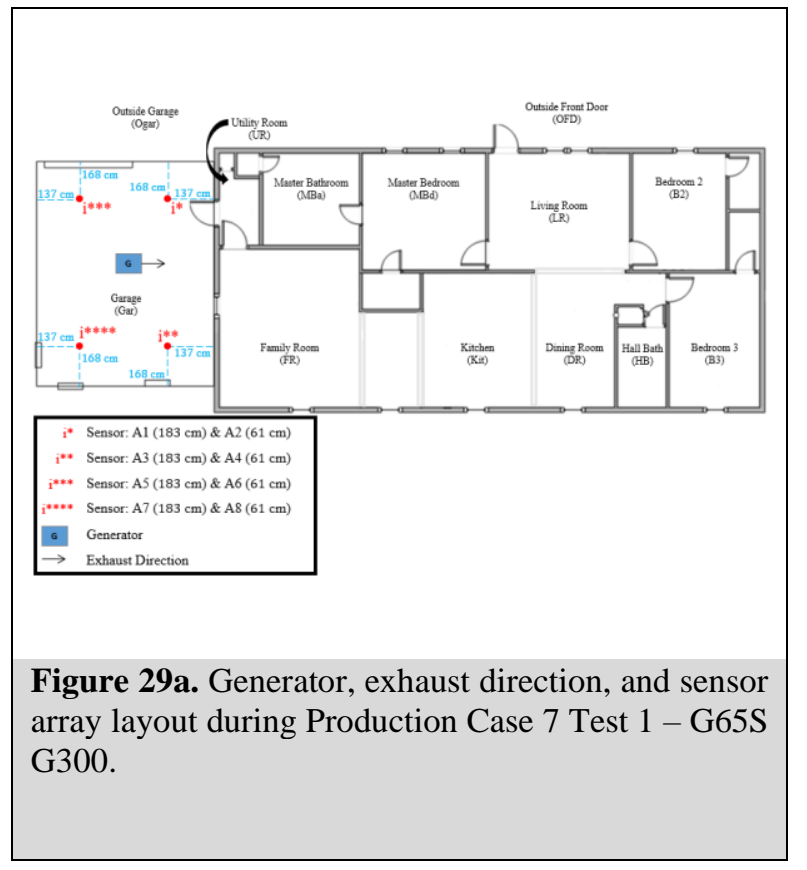

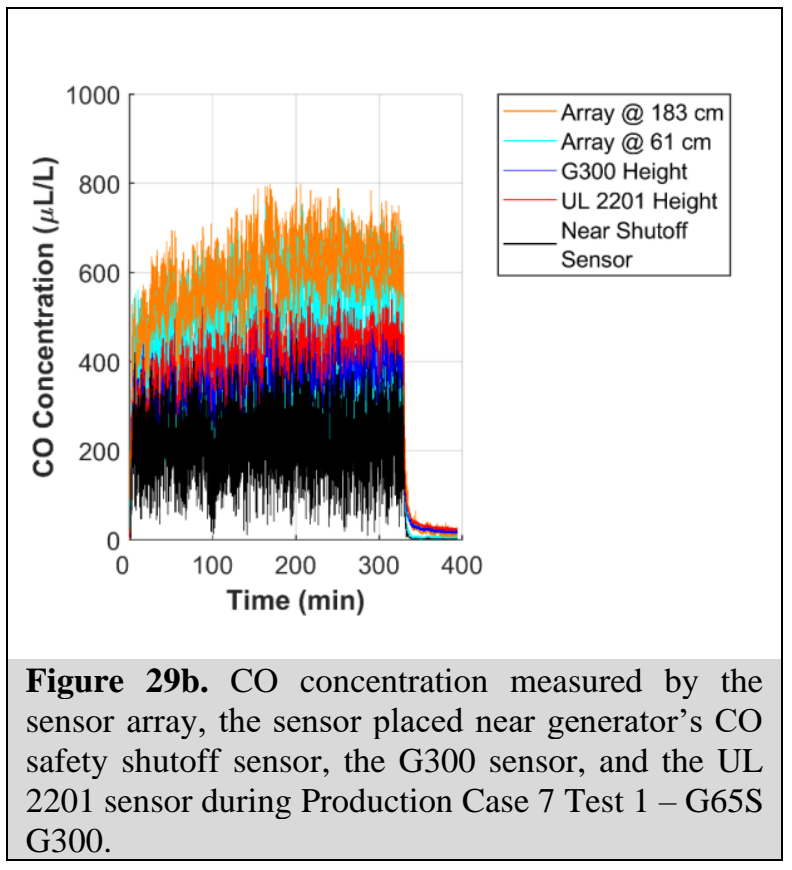




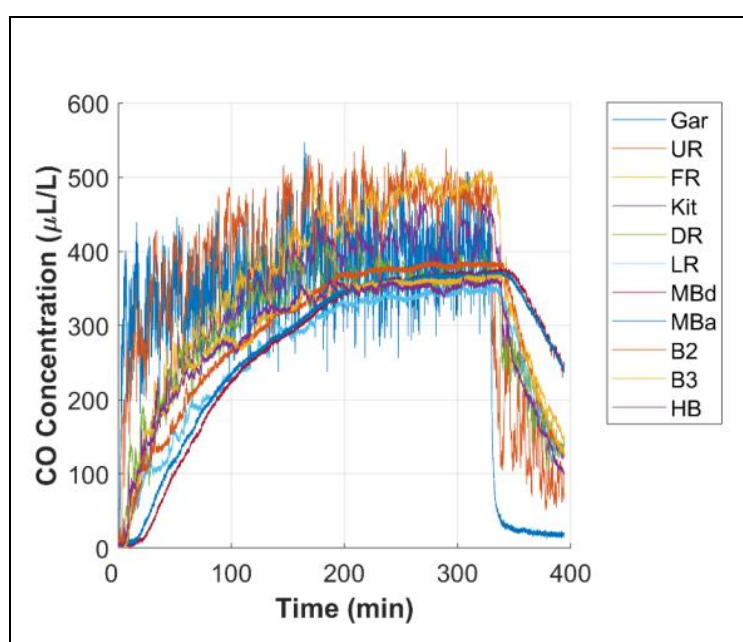

Figure 29c. $\mathrm{CO}$ concentration measured in each room of the house during Production Case 7 Test 1 - G65S G300.

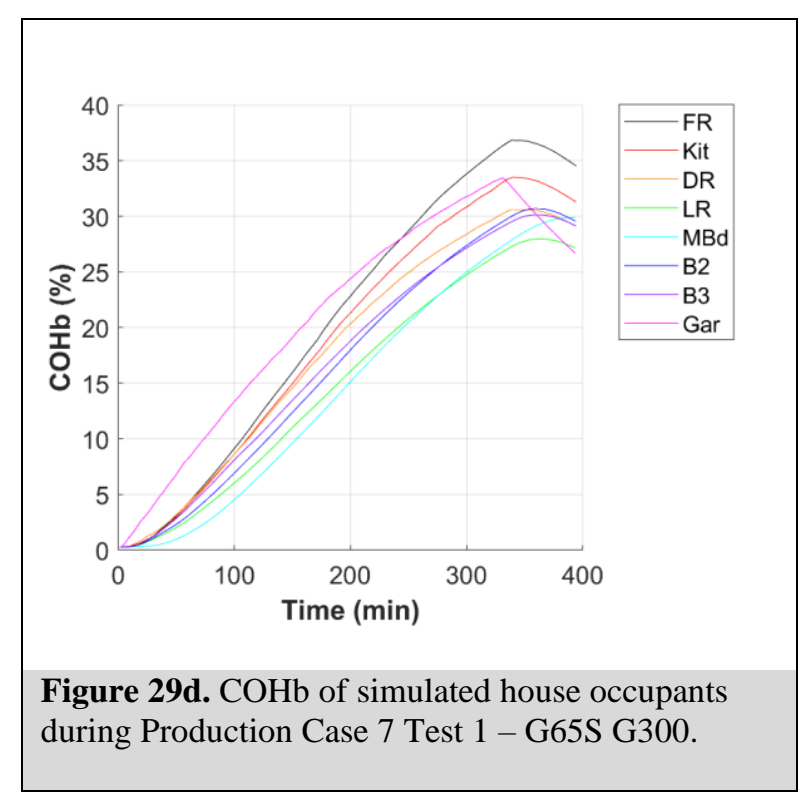




\section{Production Case 7 Test 1 - G65C G300}

The following figures illustrate the results for Production Case 7 Test 1 . The G65C generator, which the manufacturer stated as being certified to PGMA G300, was fully fueled, positioned in the garage (centered, with the exhaust facing towards the family room), and tested at $100 \%$ load $(6,500 \mathrm{~W})$. The interior person door (from garage to utility room) was open $10 \mathrm{~cm}$, the garage bay door was fully open, and the exterior person door (from garage to backyard) was closed. The generator's CO safety shutoff system activated to shut off the generator after approximately $2 \mathrm{~min}$. Figure 30a shows the test house layout with generator location, generator exhaust direction, and sensor array locations. Figure 30b shows the $\mathrm{CO}$ concentrations measured in the garage by the G300 sensor (placed 3 to $5 \mathrm{~cm}$ above the approximate center of the generator's top surface), by the UL sensor (placed $30 \mathrm{~cm}$ above the approximate center of the generator's top surface), by the sensor array placed in the garage located as shown in Figure 30a (A1, A3, A5, and A7: height 183 $\mathrm{cm}$; A2, A4, A6 and A8: height $61 \mathrm{~cm}$ ), and by the NDIR analyzer sample line measuring CO near the generator's CO safety shutoff sensor. All array sensors set to a height of $183 \mathrm{~cm}$ are illustrated as orange lines whereas the array sensors set to a height of $61 \mathrm{~cm}$ are illustrated as turquoise lines. The timeframe of the figure has been selected to show the degree of $\mathrm{CO}$ uniformity among these locations near the time of shutoff. Figure 30c shows the $\mathrm{CO}$ concentration measured in each room of the house over the test. Figure 30d shows the $\mathrm{CO}$ concentration in the house, with each room represented by a single line composed of both a 'solid-line' pattern (showing measured CO concentration) and a 'dotted-line with a symbol' pattern (showing projected CO concentration). Figure 30e shows the calculated $\mathrm{COHb}$ profiles of simulated house occupants in each room of the house.
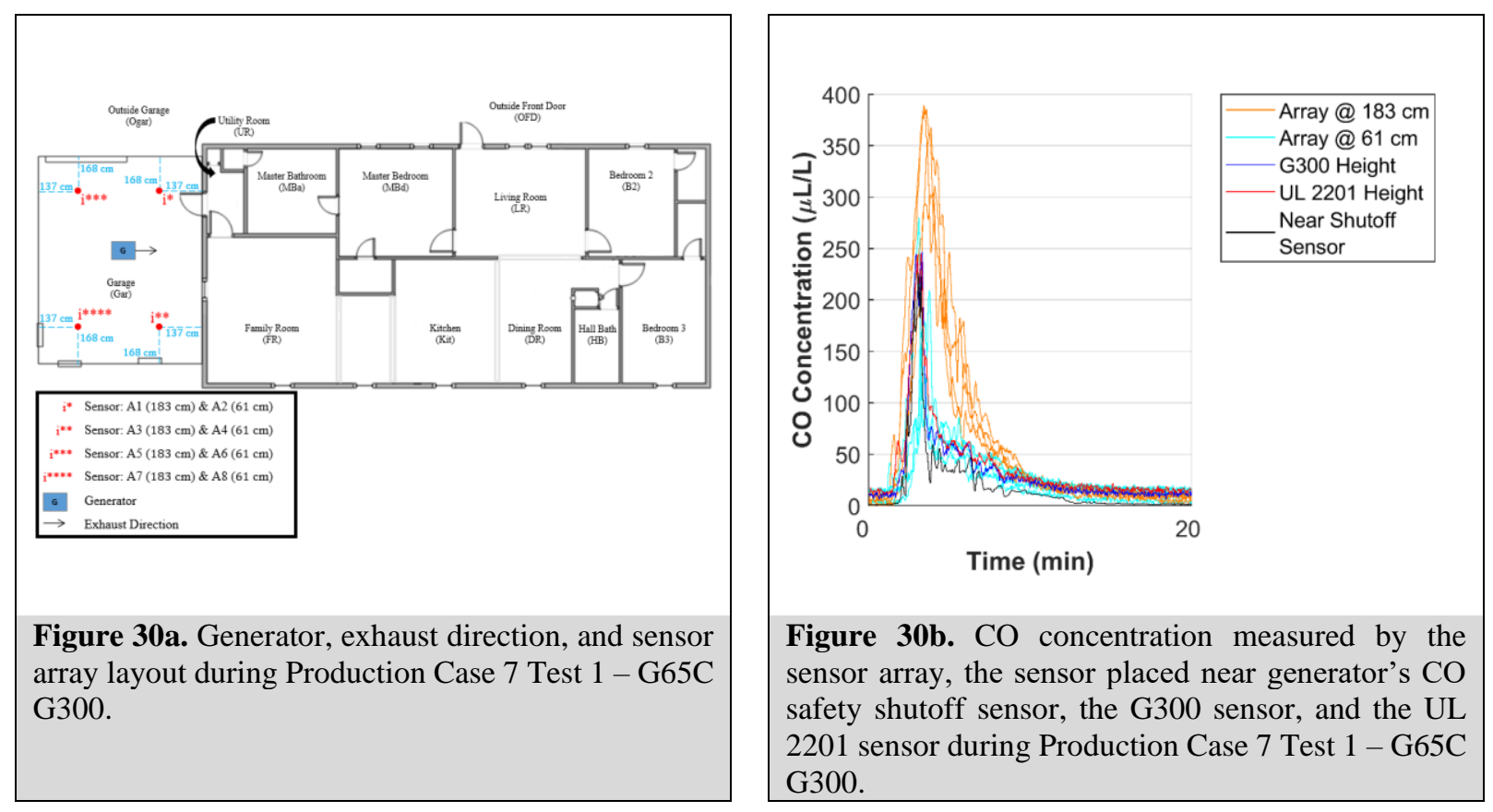


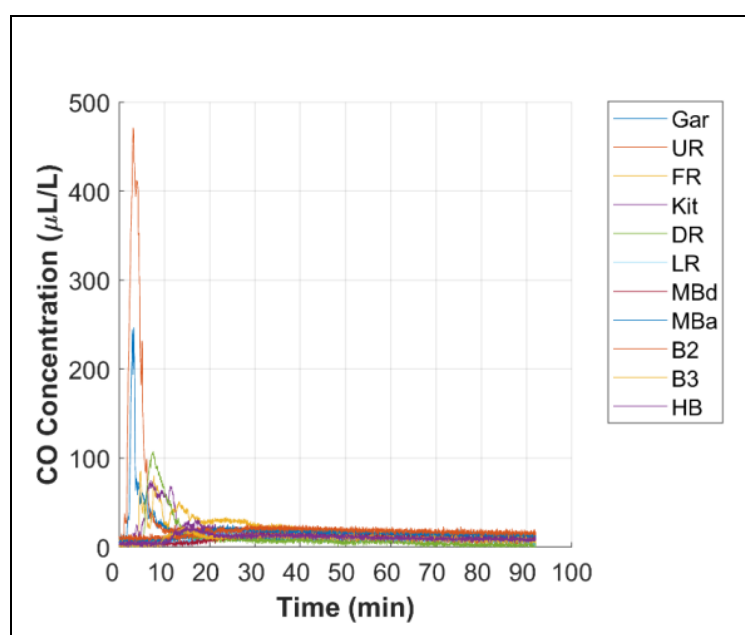

Figure 30c. $\mathrm{CO}$ concentration measured in each room of the house during Production Case 7 Test 1 - G65C G300.

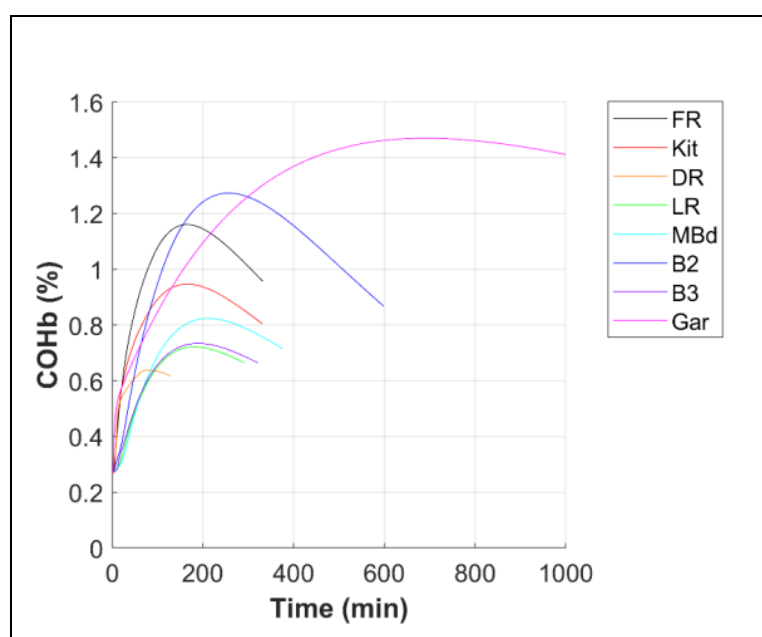

Figure 30e. $\mathrm{COHb}$ of simulated house occupants during Production Case 7 Test 1 - G65C G300.

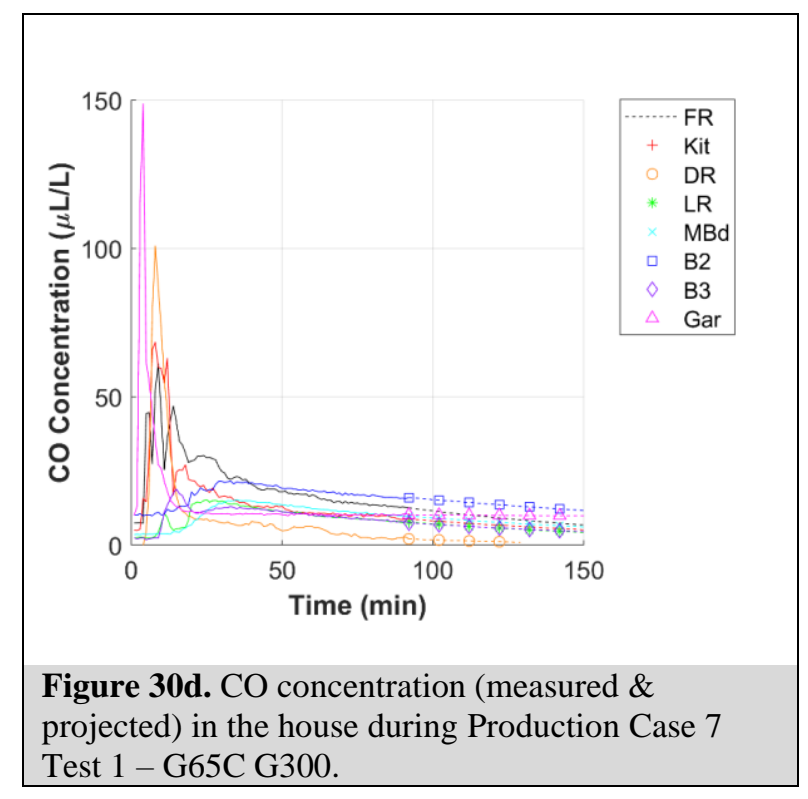

Figure 30d. CO concentration (measured \& projected) in the house during Production Case 7 Test 1 - G65C G300. 


\section{Production Case 7 Test 1 - G7S UL 2201}

The following figures illustrate the results for Production Case 7 Test 1. The G7S generator, which the manufacturer stated as being certified to UL 2201, was fully fueled, positioned in the garage (centered, with the exhaust facing towards the family room), and tested at $100 \%$ load $(7,000 \mathrm{~W})$. The interior person door (from garage to utility room) was open $10 \mathrm{~cm}$, the garage bay door was fully open, and the exterior person door (from garage to backyard) was closed. The generator's $\mathrm{CO}$ safety shutoff system was not activated, and the generator was manually shutdown after approximately $225 \mathrm{~min}$ due to low $\mathrm{CO}$ levels in the house and anticipated long runtime before running out of fuel. Figure 31a shows the test house layout with generator location, generator exhaust direction, and sensor array locations. Figure 31b shows the $\mathrm{CO}$ concentrations measured in the garage by the G300 sensor (placed 3 to $5 \mathrm{~cm}$ above the approximate center of the generator's top surface), by the UL sensor (placed $30 \mathrm{~cm}$ above the approximate center of the generator's top surface), by the sensor array placed in the garage located as shown in Figure 31a (A1, A3, A5, and A7: height $183 \mathrm{~cm} ; \mathrm{A} 2, \mathrm{~A} 4, \mathrm{~A} 6$ and A8: height $61 \mathrm{~cm}$ ), and by the NDIR analyzer sample line measuring $\mathrm{CO}$ near the generator's CO safety shutoff sensor. All array sensors set to a height of $183 \mathrm{~cm}$ are illustrated as orange lines whereas the array sensors set to a height of $61 \mathrm{~cm}$ are illustrated as turquoise lines. The figure shows the degree of $\mathrm{CO}$ uniformity among these locations near the time of shutdown. Figure 31c shows the $\mathrm{CO}$ concentration measured in each room of the house over the test. Figure 31d shows the calculated $\mathrm{COHb}$ profiles of simulated house occupants in each room of the house.
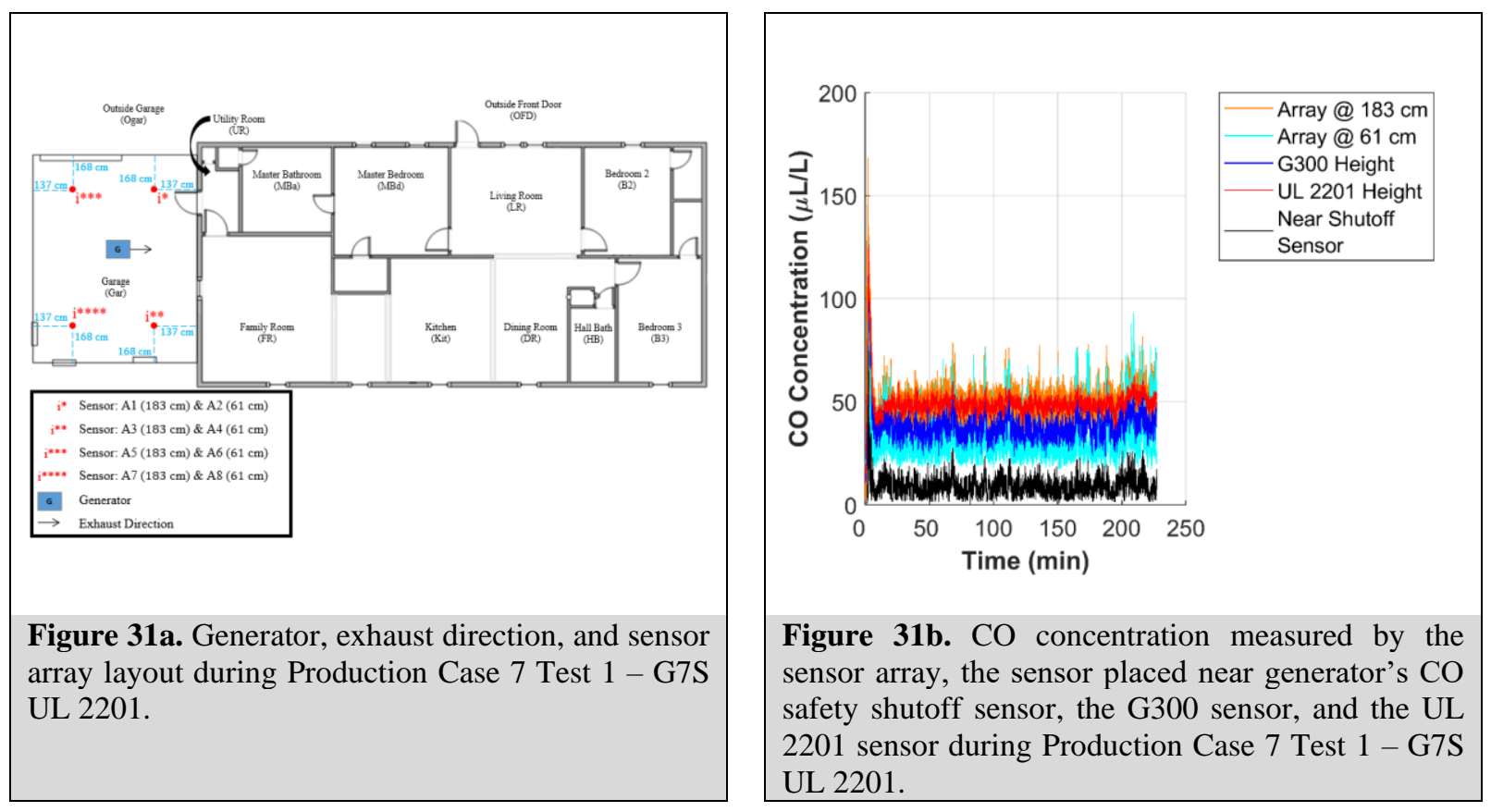

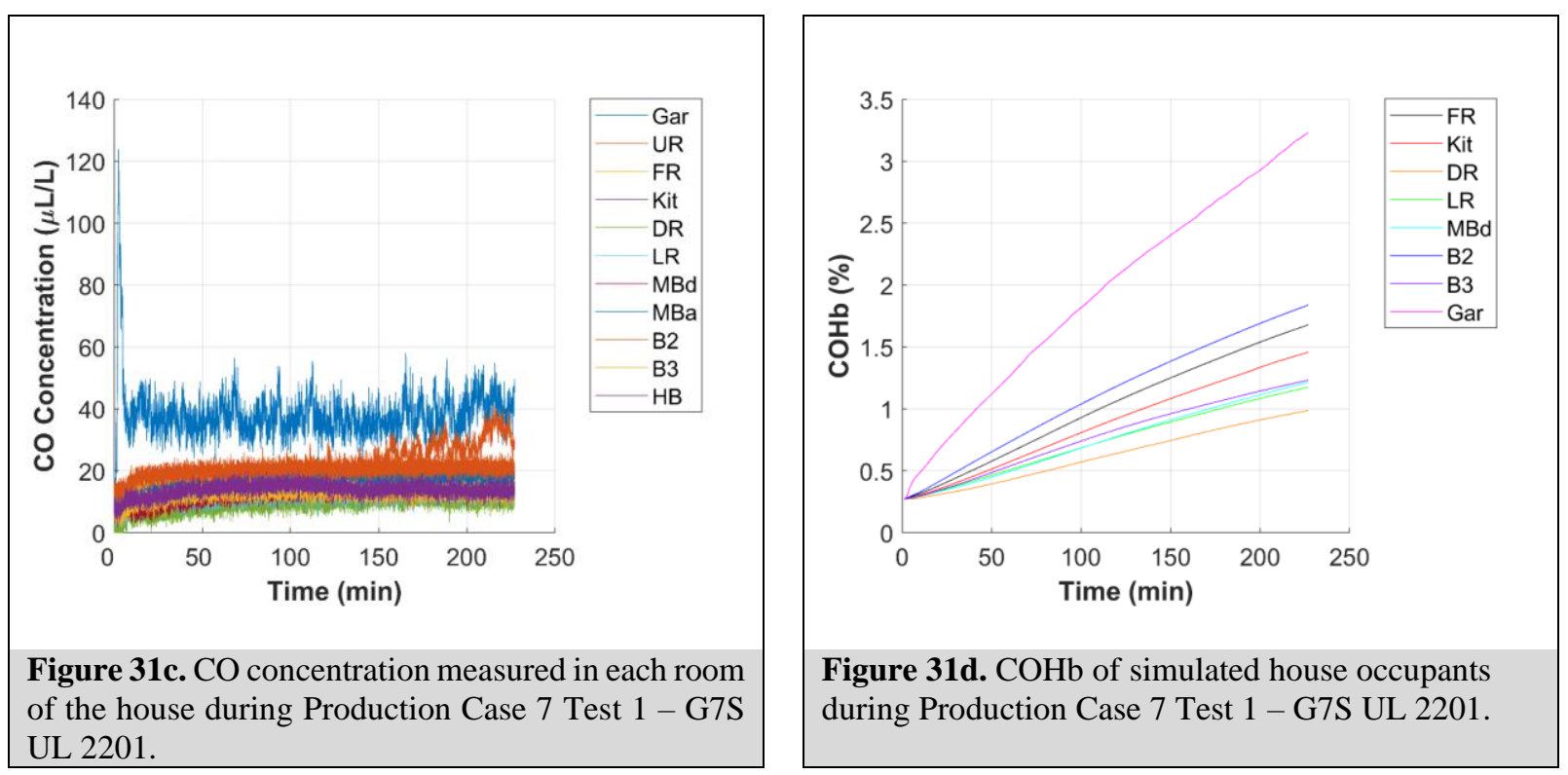


\section{Production Case 7 Test 1 - G85 G300}

The following figures illustrate the results for Production Case 7 Test 1. The G85 generator, which the manufacturer stated as being certified to PGMA G300, was fully fueled, positioned in the garage (centered, with the exhaust facing towards the family room), and tested at $100 \%$ load $(6,250 \mathrm{~W})$. The interior person door (from garage to utility room) was open $10 \mathrm{~cm}$, the garage bay door was fully open, and the exterior person door (from garage to backyard) was closed. The generator's CO safety shutoff system activated to shut off the generator after approximately $8 \mathrm{~min}$. Figure 32a shows the test house layout with generator location, generator exhaust direction, and sensor array locations. Figure 32b shows the $\mathrm{CO}$ concentrations measured in the garage by the G300 sensor (placed 3 to $5 \mathrm{~cm}$ above the approximate center of the generator's top surface), by the UL sensor (placed $30 \mathrm{~cm}$ above the approximate center of the generator's top surface), by the sensor array placed in the garage located as shown in Figure 32a (A1, A3, A5, and A7: height 183 $\mathrm{cm}$; A2, A4, A6 and A8: height $61 \mathrm{~cm}$ ), and by the NDIR analyzer sample line measuring CO near the generator's CO safety shutoff sensor. All array sensors set to a height of $183 \mathrm{~cm}$ are illustrated as orange lines whereas the array sensors set to a height of $61 \mathrm{~cm}$ are illustrated as turquoise lines. The timeframe of the figure has been selected to show the degree of $\mathrm{CO}$ uniformity among these locations near the time of shutoff. Figure 32c shows the $\mathrm{CO}$ concentration measured in each room of the house over the test. Figure 32d shows the $\mathrm{CO}$ concentration in the house, with each room represented by a single line composed of both a 'solid-line' pattern (showing measured CO concentration) and a 'dotted-line with a symbol' pattern (showing projected CO concentration). Figure 32e shows the calculated $\mathrm{COHb}$ profiles of simulated house occupants in each room of the house.
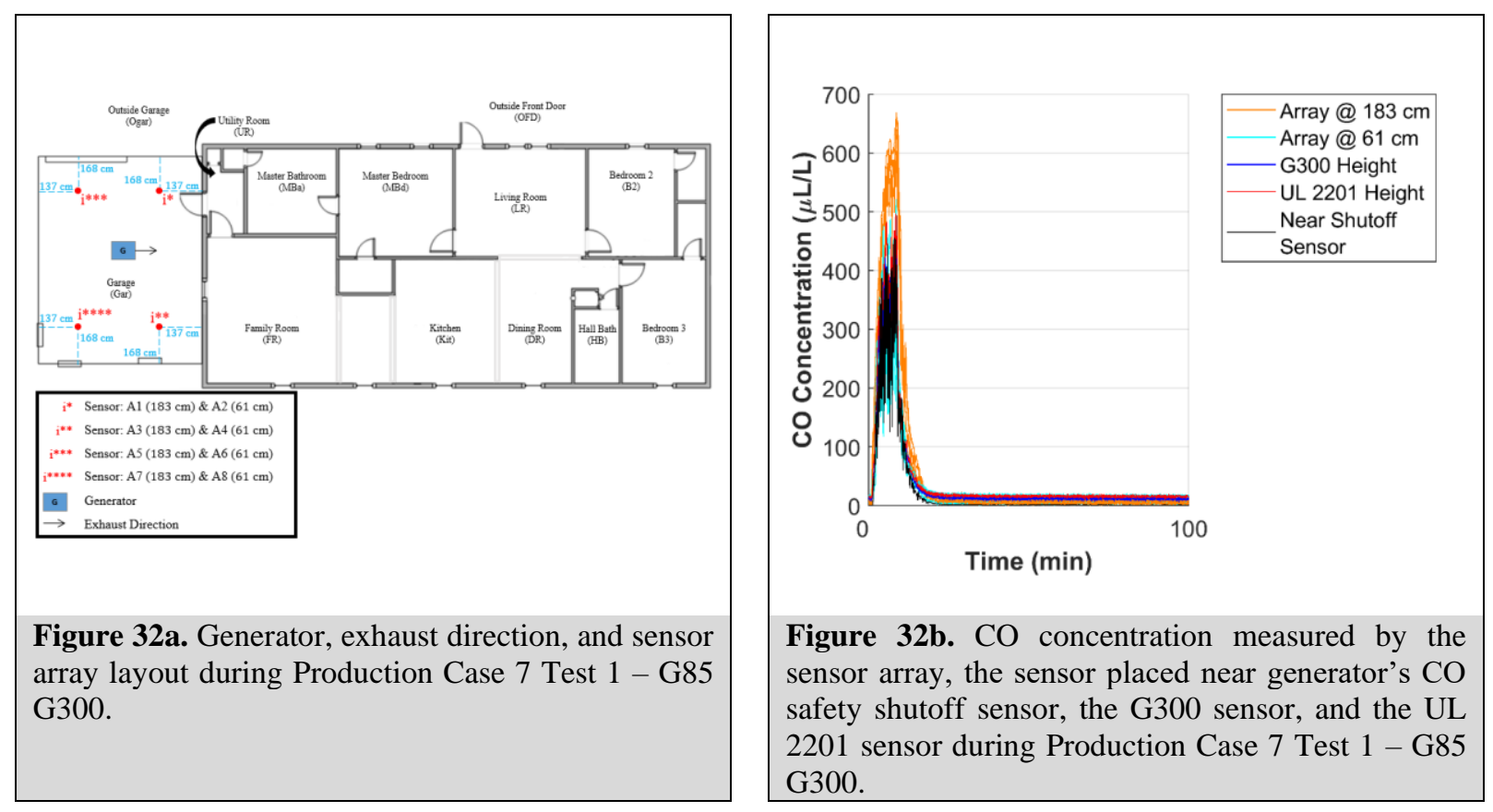


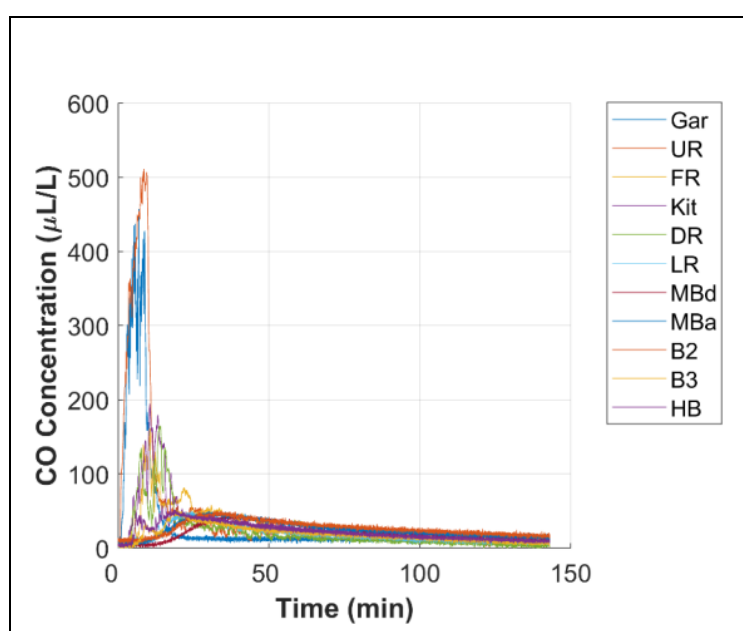

Figure 32c. $\mathrm{CO}$ concentration measured in each room of the house during Production Case 7 Test $1-$ G85 G300.

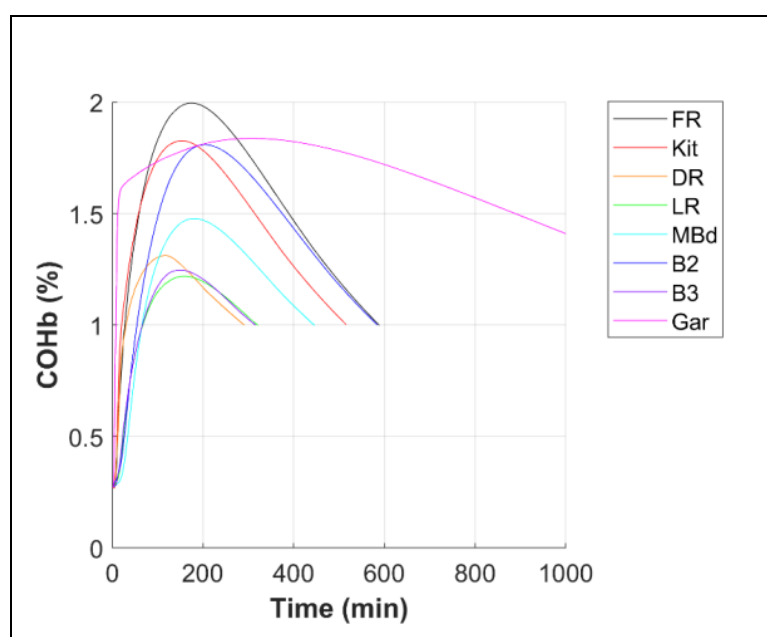

Figure 32e. $\mathrm{COHb}$ of simulated house occupants during Production Case 7 Test 1- G85 G300.

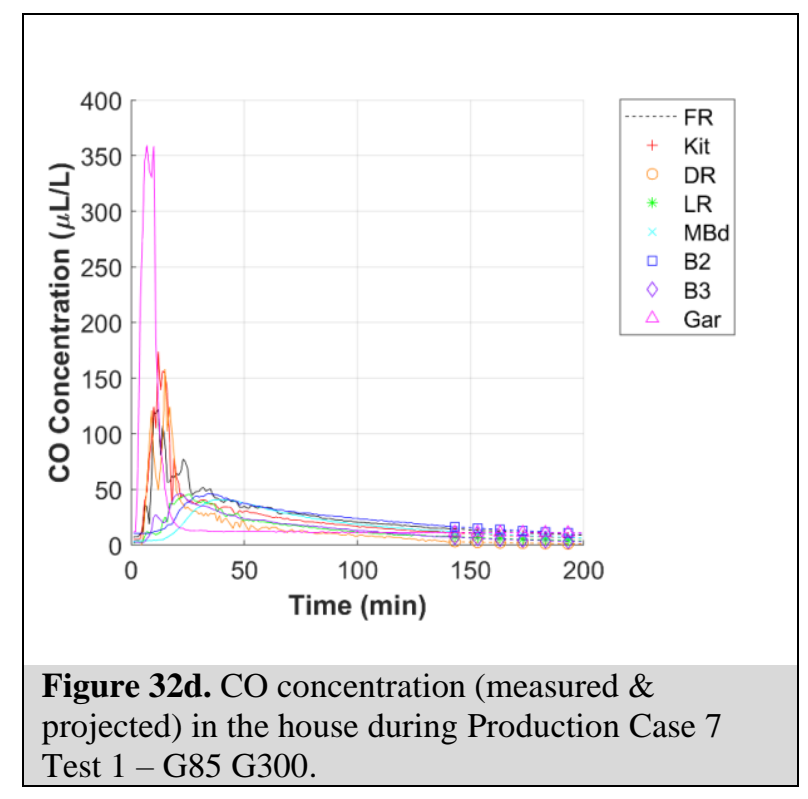

projected) in the house during Production Case 7 


\section{Production Case 8 Test 1 - G65S G300}

The following figures illustrate the results for Production Case 8 Test 1. The G65S generator, which the manufacturer stated as being certified to PGMA G300, was fully fueled, positioned in the garage (centered, with the exhaust facing towards the family room), and tested at $50 \%$ load $(3,250 \mathrm{~W})$. The interior person door (from garage to utility room) was open $10 \mathrm{~cm}$, the garage bay door was fully open, and the exterior person door (from garage to backyard) was closed. The generator's CO safety shutoff system was not activated, and the generator was manually shutdown after approximately $467 \mathrm{~min}$ due to reaching peak $\mathrm{COHb}$ levels throughout the house. Figure 33a shows the test house layout with generator location, generator exhaust direction, and sensor array locations. Figure 33b shows the CO concentrations measured in the garage by the G300 sensor (placed 3 to $5 \mathrm{~cm}$ above the approximate center of the generator's top surface), by the UL sensor (placed $30 \mathrm{~cm}$ above the approximate center of the generator's top surface), by the sensor array placed in the garage located as shown in Figure 33a (A1, A3, A5, and A7: height $183 \mathrm{~cm}$; A2, A4, A6 and A8: height $61 \mathrm{~cm}$ ), and by the NDIR analyzer sample line measuring $\mathrm{CO}$ near the generator's CO safety shutoff sensor. All array sensors set to a height of $183 \mathrm{~cm}$ are illustrated as orange lines whereas the array sensors set to a height of $61 \mathrm{~cm}$ are illustrated as turquoise lines. The figure shows the degree of $\mathrm{CO}$ uniformity among these locations near the time of shutdown. Figure 33c shows the $\mathrm{CO}$ concentration measured in each room of the house over the test. Figure 33d shows the calculated $\mathrm{COHb}$ profiles of simulated house occupants in each room of the house.

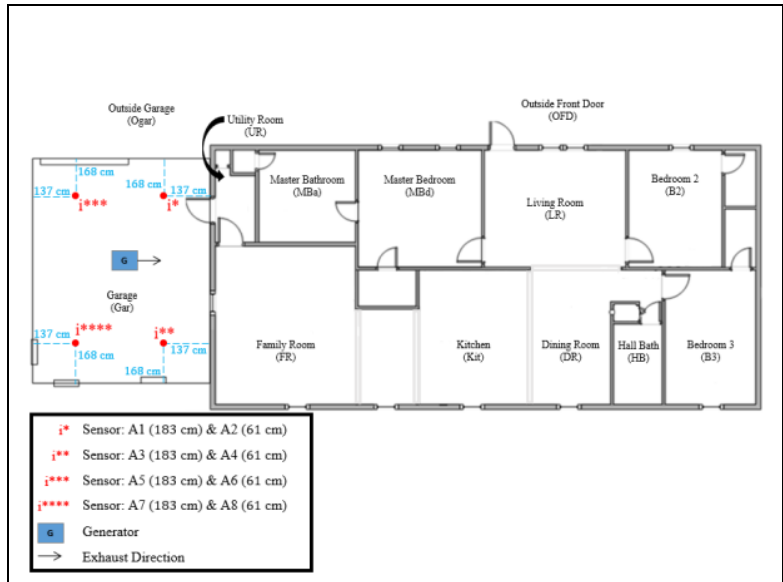

Figure 33a. Generator, exhaust direction, and sensor array layout during Production Case 8 Test 1 - G65S G300.

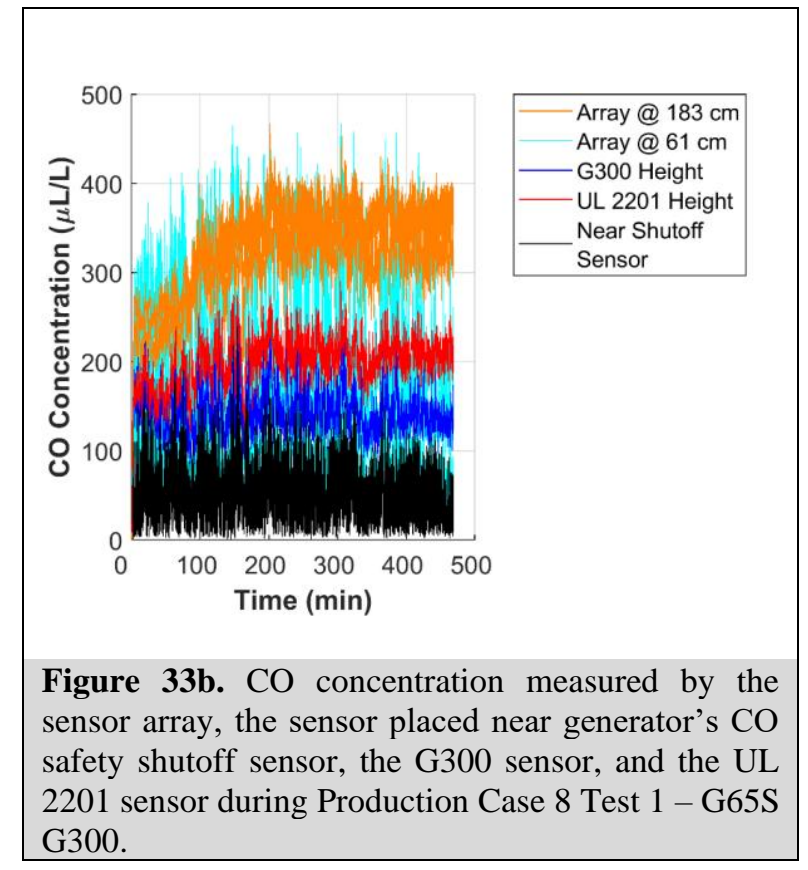




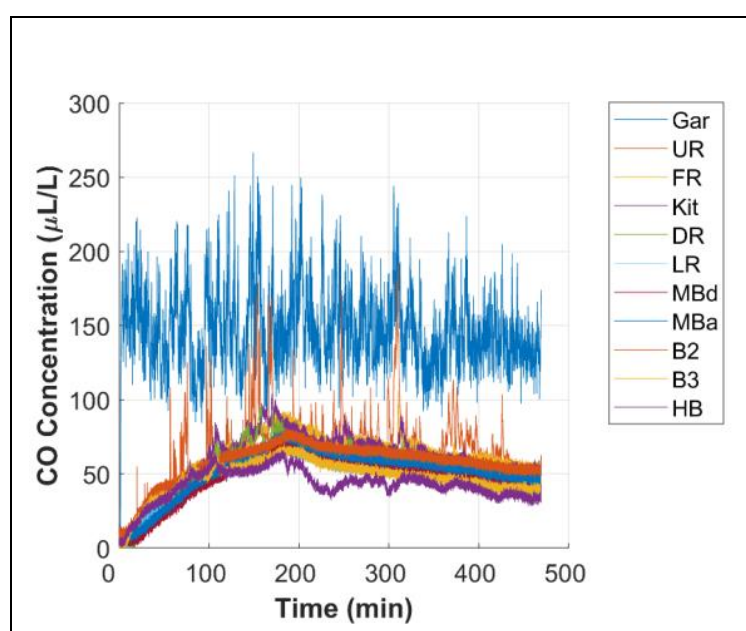

Figure 33c. $\mathrm{CO}$ concentration measured in each room of the house during Production Case 8 Test 1 - G65S G300.

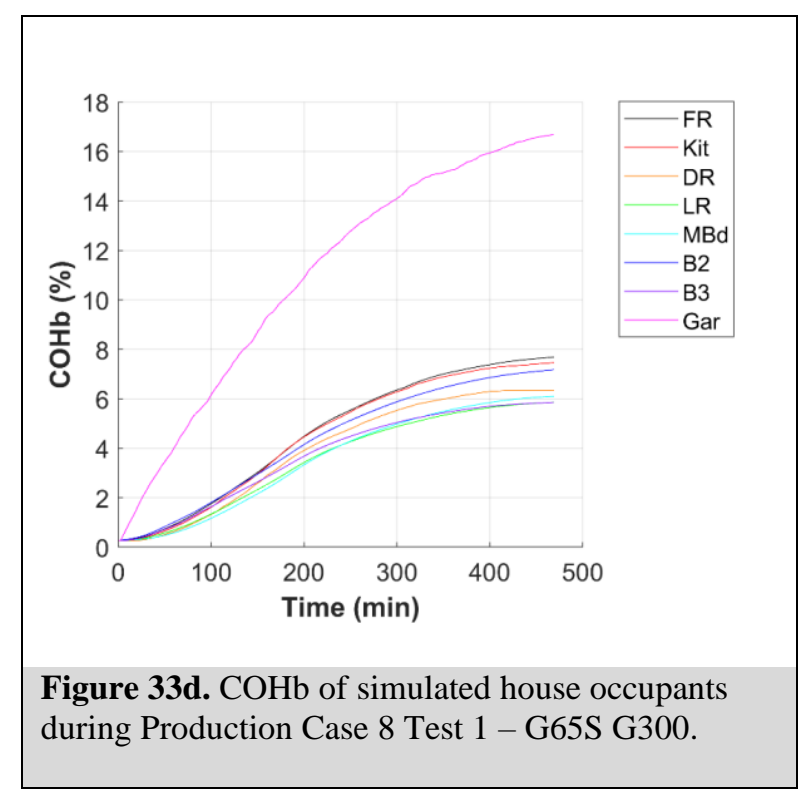




\section{Production Case 8 Test 1 - G65C G300}

The following figures illustrate the results for Production Case 8 Test 1 . The G65C generator, which the manufacturer stated as being certified to PGMA G300, was fully fueled, positioned in the garage (centered, with the exhaust facing towards the family room), and tested at $50 \%$ load $(3,250 \mathrm{~W})$. The interior person door (from garage to utility room) was open $10 \mathrm{~cm}$, the garage bay door was fully open, and the exterior person door (from garage to backyard) was closed. The generator's CO safety shutoff system was not activated, and the generator was manually shutdown after approximately $320 \mathrm{~min}$ due to low $\mathrm{CO}$ levels in the house and anticipated long runtime before running out of fuel. Figure 34a shows the test house layout with generator location, generator exhaust direction, and sensor array locations. Figure 34b shows the $\mathrm{CO}$ concentrations measured in the garage by the G300 sensor (placed 3 to $5 \mathrm{~cm}$ above the approximate center of the generator's top surface), by the UL sensor (placed $30 \mathrm{~cm}$ above the approximate center of the generator's top surface), by the sensor array placed in the garage located as shown in Figure 34a (A1, A3, A5, and A7: height $183 \mathrm{~cm}$; A2, A4, A6 and A8: height $61 \mathrm{~cm}$ ), and by the NDIR analyzer sample line measuring $\mathrm{CO}$ near the generator's CO safety shutoff sensor. All array sensors set to a height of $183 \mathrm{~cm}$ are illustrated as orange lines whereas the array sensors set to a height of $61 \mathrm{~cm}$ are illustrated as turquoise lines. The figure shows the degree of $\mathrm{CO}$ uniformity among these locations near the time of shutdown. Figure 34c shows the CO concentration measured in each room of the house over the test. Figure 34d shows the calculated $\mathrm{COHb}$ profiles of simulated house occupants in each room of the house.
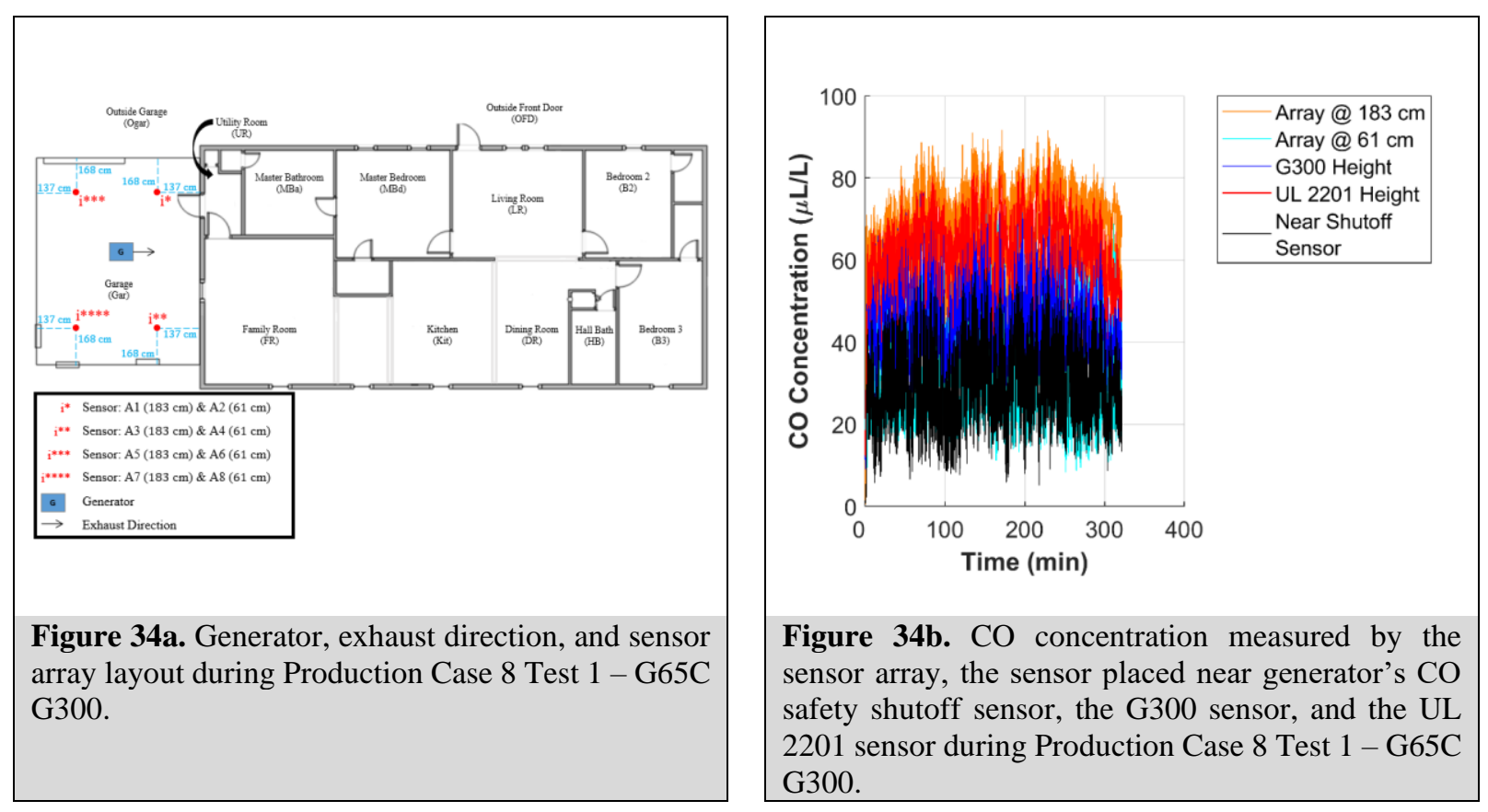

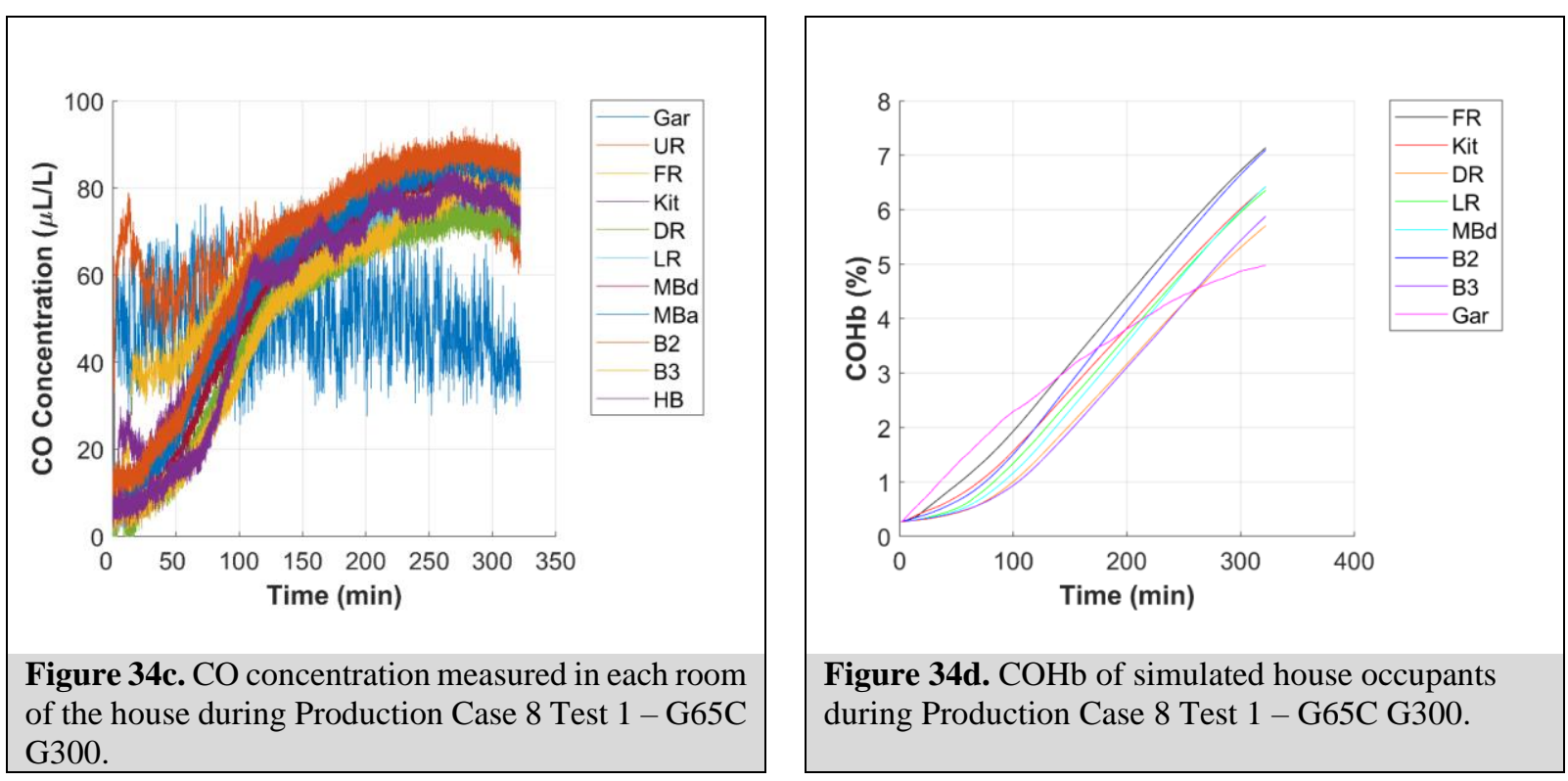
of the house during Production Case 8 Test 1 - G65C G300. 


\section{Production Case 8 Test 1 - G7S UL 2201}

The following figures illustrate the results for Production Case 8 Test 1. The G7S generator, which the manufacturer stated as being certified to UL 2201, was fully fueled, positioned in the garage (centered, with the exhaust facing towards the family room), and tested at $50 \%$ load $(3,500 \mathrm{~W})$. The interior person door (from garage to utility room) was open $10 \mathrm{~cm}$, the garage bay door was fully open, and the exterior person door (from garage to backyard) was closed. The generator's $\mathrm{CO}$ safety shutoff system was not activated, and the generator was manually shutdown after approximately $357 \mathrm{~min}$ due to low $\mathrm{CO}$ levels in the house and anticipated long runtime before running out of fuel. Figure 35a shows the test house layout with generator location, generator exhaust direction, and sensor array locations. Figure 35b shows the $\mathrm{CO}$ concentrations measured in the garage by the G300 sensor (placed 3 to $5 \mathrm{~cm}$ above the approximate center of the generator's top surface), by the UL sensor (placed $30 \mathrm{~cm}$ above the approximate center of the generator's top surface), by the sensor array placed in the garage located as shown in Figure 35a (A1, A3, A5, and A7: height $183 \mathrm{~cm} ; \mathrm{A} 2, \mathrm{~A} 4, \mathrm{~A} 6$ and A8: height $61 \mathrm{~cm}$ ), and by the NDIR analyzer sample line measuring $\mathrm{CO}$ near the generator's CO safety shutoff sensor. All array sensors set to a height of $183 \mathrm{~cm}$ are illustrated as orange lines whereas the array sensors set to a height of $61 \mathrm{~cm}$ are illustrated as turquoise lines. The figure shows the degree of $\mathrm{CO}$ uniformity among these locations near the time of shutdown. Figure 35c shows the $\mathrm{CO}$ concentration measured in each room of the house over the test. Figure 35d shows the calculated $\mathrm{COHb}$ profiles of simulated house occupants in each room of the house.
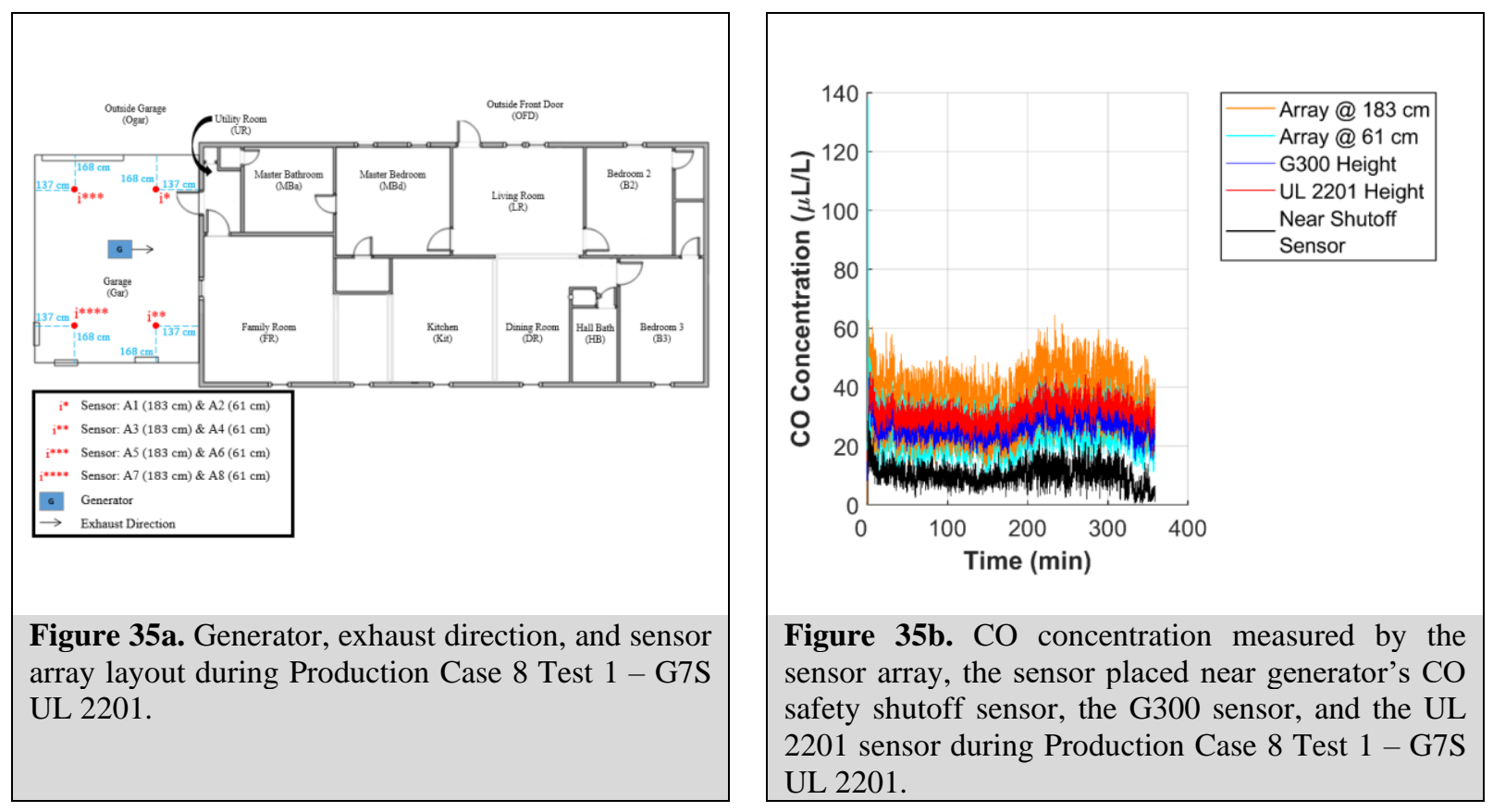


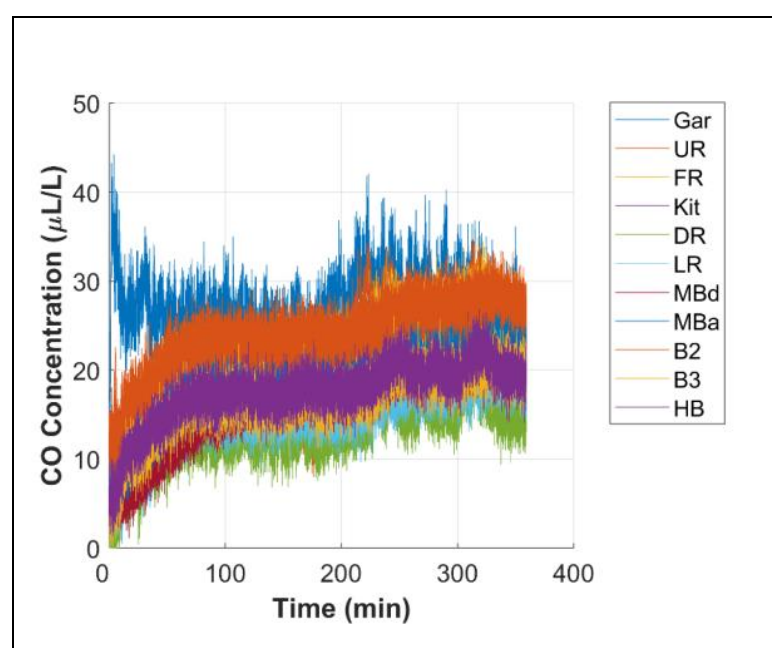

Figure 35c. $\mathrm{CO}$ concentration measured in each room of the house during Production Case 8 Test $1-$ G7S UL 2201.

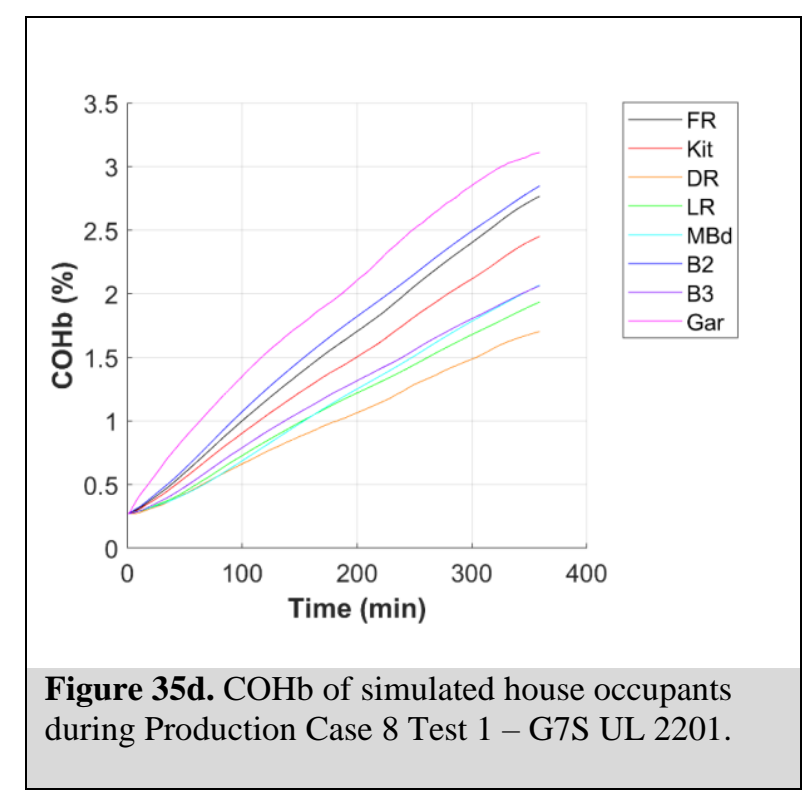




\section{Production Case 8 Test 1 - G85 G300}

The following figures illustrate the results for Production Case 8 Test 1 . The G85 generator, which the manufacturer stated as being certified to PGMA G300, was fully fueled, positioned in the garage (centered, with the exhaust facing towards the family room), and tested at $50 \%$ load $(3,125 \mathrm{~W})$. The interior person door (from garage to utility room) was open $10 \mathrm{~cm}$, the garage bay door was fully open, and the exterior person door (from garage to backyard) was closed. The generator's CO safety shutoff system was not activated, and the generator was manually shutdown after approximately $468 \mathrm{~min}$ due to low $\mathrm{CO}$ levels in the house and anticipated long runtime before running out of fuel. Figure 36a shows the test house layout with generator location, generator exhaust direction, and sensor array locations. Figure 36b shows the $\mathrm{CO}$ concentrations measured in the garage by the G300 sensor (placed 3 to $5 \mathrm{~cm}$ above the approximate center of the generator's top surface), by the UL sensor (placed $30 \mathrm{~cm}$ above the approximate center of the generator's top surface), by the sensor array placed in the garage located as shown in Figure 36a (A1, A3, A5, and A7: height $183 \mathrm{~cm} ; \mathrm{A} 2, \mathrm{~A} 4, \mathrm{~A} 6$ and A8: height $61 \mathrm{~cm}$ ), and by the NDIR analyzer sample line measuring $\mathrm{CO}$ near the generator's CO safety shutoff sensor. All array sensors set to a height of $183 \mathrm{~cm}$ are illustrated as orange lines whereas the array sensors set to a height of $61 \mathrm{~cm}$ are illustrated as turquoise lines. The figure shows the degree of $\mathrm{CO}$ uniformity among these locations near the time of shutdown. Figure 36c shows the CO concentration measured in each room of the house over the test. Figure 36d shows the calculated $\mathrm{COHb}$ profiles of simulated house occupants in each room of the house.
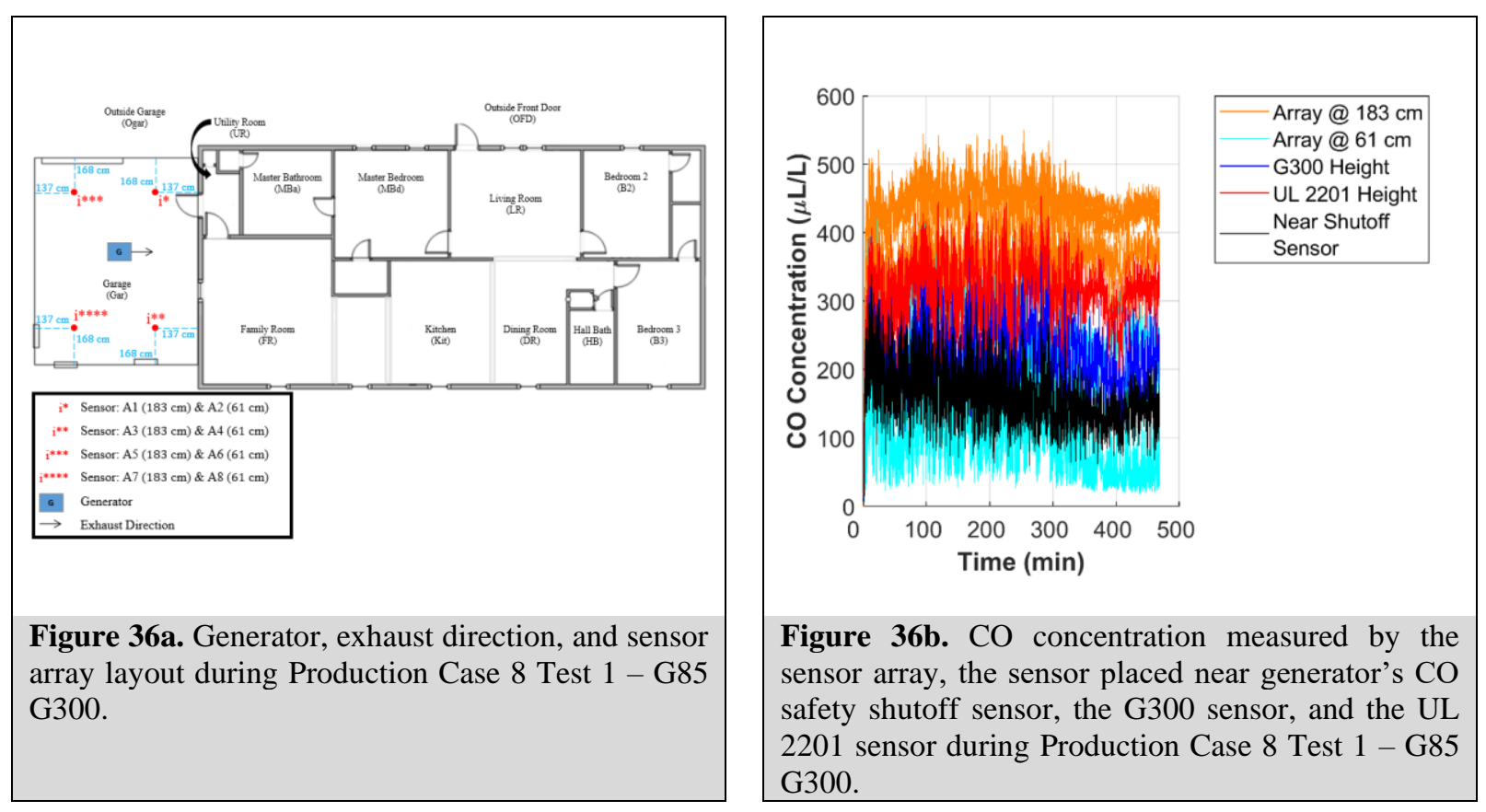


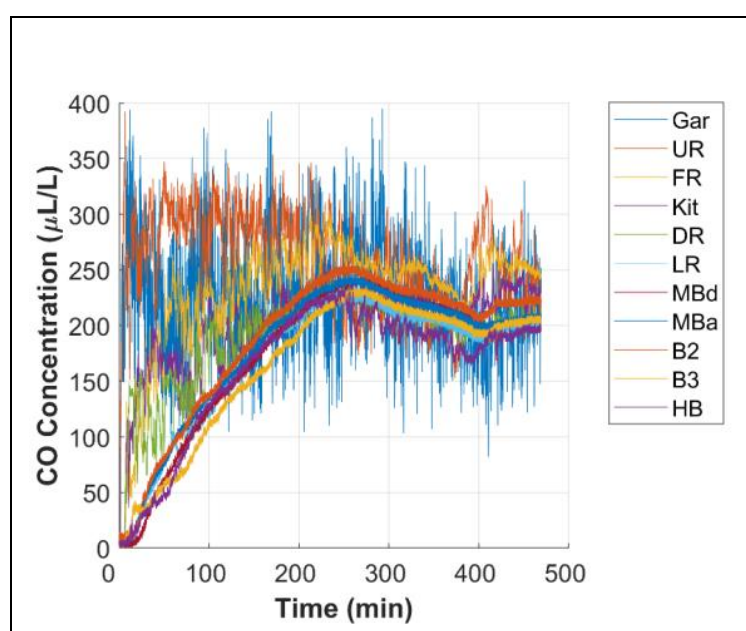

Figure 36c. $\mathrm{CO}$ concentration measured in each room of the house during Production Case 8 Test $1-$ G85 G300.

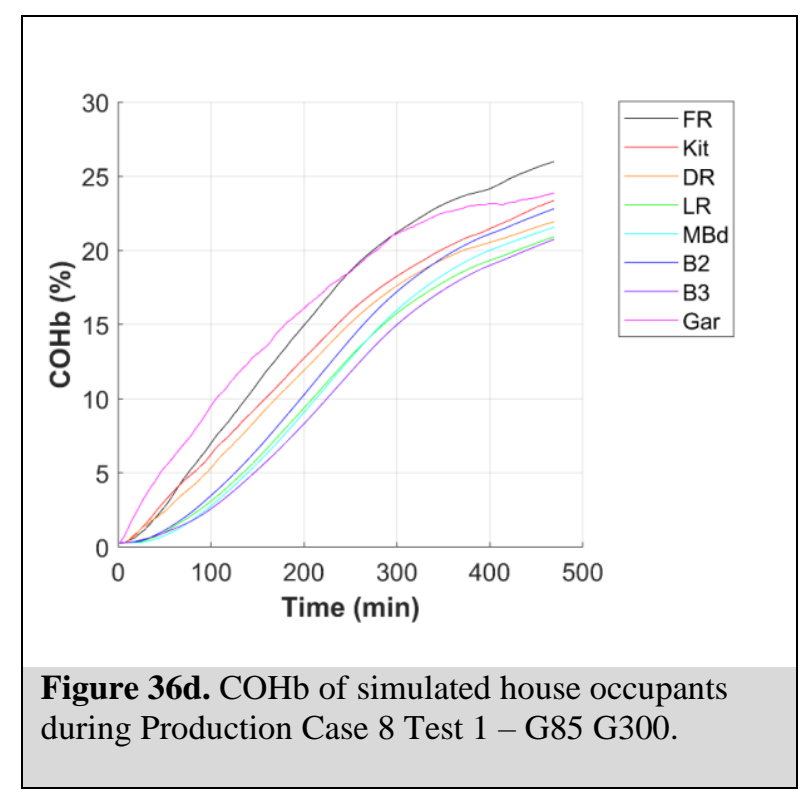




\section{CO Concentrations at Shutoff for Voluntary Standard Test Measurement Locations and the Onboard Sensor}

When the generator was tested in the garage with the overhead door closed (Production Case 4 through Production Case 6), CO sensors were placed at various locations around the generator. One such location, $3 \mathrm{~cm}$ to $5 \mathrm{~cm}$ above the approximate center of the portable generator's top surface, was based on the PGMA G300 voluntary standard. Another location, $30 \mathrm{~cm}$ above the approximate center of the portable generator's top surface, was based on the UL 2201 voluntary standard. These two positions are required in the respective standards to measure the $\mathrm{CO}$ concentration during conformance testing to the standard. A third location was near the location of the sensor for the generator's CO safety shutoff system (Near Shutoff Sensor, NSS). These locations were measured in a set of tests to evaluate the difference in concentration between these positions at the time of shutoff.

Table 3 summarizes the instantaneous $\mathrm{CO}$ concentrations measured at each of the three locations at the time of generator $\mathrm{CO}$ safety shutoff system activation for 7 of the tests, for which the generator shut off occurred in under 10 minutes.

\begin{tabular}{|c|c|c|c|c|c|c|c|c|}
\hline Gen & PCase / Test & $\begin{array}{c}\text { Load } \\
(\%)\end{array}$ & $\begin{array}{c}\text { Time To Shutoff } \\
(\mathrm{min})\end{array}$ & $\begin{array}{c}\mathbf{G 3 0 0}+ \\
(\mu \mathrm{L} / \mathrm{L})\end{array}$ & $\begin{array}{c}\text { UL } 2201+ \\
(\mu \mathrm{L} / \mathrm{L})\end{array}$ & $\begin{array}{c}\text { NSS H } \\
(\mu \mathrm{L} / \mathrm{L})\end{array}$ & $\begin{array}{c}|\Delta|(\mathbf{G 3 0 0 - N S S )} \\
(\%)\end{array}$ & $\begin{array}{c}|\Delta| \text { (UL 2201-NSS) } \\
(\%)\end{array}$ \\
\hline \multirow[t]{3}{*}{ G65S } & $4 / 1$ & 100 & 3 & 597 & $\mathrm{HH}$ & 566 & 5.3 & - \\
\hline & $5 / 1$ & 50 & 4 & 528 & 496 & 533 & 0.9 & 7.2 \\
\hline & $6 / 1$ & 10 & 5 & 527 & 487 & 543 & 3.0 & 10.9 \\
\hline G65C & $4 / 1$ & 100 & 1 & 246 & 272 & 254 & 3.2 & 6.8 \\
\hline \multirow[t]{3}{*}{ G85 } & $4 / 1$ & 100 & 2 & 281 & 275 & 251 & 11.3 & 9.1 \\
\hline & $5 / 1$ & 50 & 3 & 317 & 290 & 293 & 7.9 & 1.0 \\
\hline & $6 / 1$ & 10 & 4 & 448 & 391 & 437 & 2.5 & 11.1 \\
\hline \multicolumn{7}{|c|}{ Average $|\Delta|(\%) \mid$} & 4.9 & 7.7 \\
\hline \multicolumn{9}{|c|}{$\begin{array}{l}\text { + G300 sensor is located } 3 \text { to } 5 \mathrm{~cm} \text { above the centerline of the top of the generator. } \\
\text { H UL } 2201 \text { sensor is located } 30 \mathrm{~cm} \text { above the centerline of the top of the generator. } \\
\text { H Near Shutoff Sensor (NSS) is located near the generator's onboard shutoff sensor. } \\
\text { H H UL } 2201 \text { sensor had not yet been implemented at time of test. }\end{array}$} \\
\hline
\end{tabular}

Table 3. Summary of instantaneous CO measurements at time of generator shutoff

Table 4 summarizes the 10-min average $\mathrm{CO}$ concentrations measured at each of the three locations at the time of generator $\mathrm{CO}$ safety shutoff system activation for 5 of the tests, which resulted in generator shut off after 10 minutes. 
Gen PCase / Test Load Time To Shutoff G300 + UL $2201+\quad$ NSS $+4 \quad|\Delta|($ G300-NSS) $|\Delta|$ (UL 2201-NSS)

\begin{tabular}{|c|c|c|c|c|c|c|c|c|}
\hline & & $(\%)$ & $(\min )$ & $(\mu \mathrm{L} / \mathrm{L})$ & $(\mu \mathrm{L} / \mathrm{L})$ & $(\mu \mathrm{L} / \mathrm{L})$ & $(\%)$ & $(\%)$ \\
\hline \multirow[t]{2}{*}{ G65C } & $5 / 1$ & 50 & 12 & 253 & 241 & 236 & 7.0 & 2.1 \\
\hline & $6 / 1$ & 10 & 58 & 231 & 227 & 222 & 4.0 & 2.2 \\
\hline \multirow[t]{3}{*}{ G7S } & $4 / 1$ & 100 & 15 & 154 & 143 & 135 & 13.1 & 5.8 \\
\hline & $5 / 1$ & 50 & 14 & 159 & 151 & 147 & 7.8 & 2.7 \\
\hline & $6 / 1$ & 10 & 46 & 107 & 112 & 95 & 11.9 & 16.4 \\
\hline \multicolumn{7}{|c|}{ Average $|\Delta|(\%)$} & 8.8 & 5.8 \\
\hline
\end{tabular}

$+\mathrm{G} 300$ sensor is located 3 to $5 \mathrm{~cm}$ above the centerline of the top of the generator.

H UL 2201 sensor is located $30 \mathrm{~cm}$ above the centerline of the top of the generator.

H Near Shutoff Sensor (NSS) is located near the generator's onboard shutoff sensor.

Table 4. Summary of 10-min average CO measurements at time of generator shutoff 


\section{CONTAM Model Validation}

As discussed in the Introduction section of this report, a simulation study using the CONTAM program is planned to evaluate the impact of the generator shutoff requirements in the PGMA and UL voluntary standards on indoor CO exposure. CONTAM (Dols and Polidoro 2015) is a multizone indoor air quality (IAQ) and airflow model developed in the Engineering Laboratory (EL) at NIST. The multizone modeling approach is implemented by constructing a building model as a network of elements describing the flow paths (HVAC ducts, doors, windows, cracks, etc.) between the zones (primarily rooms) of a building. The network nodes represent the zones, which are modeled with a hydrostatically varying pressure, and uniform temperature and pollutant concentration within each zone. After calculating the airflow between zones and the outdoors, zone pollutant concentrations are calculated by applying pollutant mass balance equations. CONTAM has been used to study a variety of residential IAQ issues in the past (e.g., Emmerich and Persily 1996, Emmerich et al. 2005).

An absolute validation of a complex model, such as CONTAM, is impossible as there are infinite possible building models, contaminants and sources, and other conditions. However, several past studies (e.g., Emmerich and Nabinger (2001) and Emmerich et al. (2004)) have examined multizone IAQ model validation as reviewed in Emmerich (2001). Additionally, previous publications addressed the validation of the ability of the CONTAM model to predict CO levels due to operation of portable generators in the same NIST test house used in this study (Emmerich et al. 2013, Emmerich and Dols 2016).

As noted in Technical Note 2049, CONTAM generally assumes that the CO concentration is uniform within each zone, however for the shutoff analysis, the assumption of uniform concentration may not be valid because the distribution of $\mathrm{CO}$ in the space where the generator is operating, particularly near the generator-mounted shutoff sensor, can be dependent on multiple factors. These factors include where the generator is located within the space, how the exhaust is oriented relative to nearby surfaces, and the velocity and temperature of the exhaust jet exiting the exhaust pipe. The non-uniformity of $\mathrm{CO}$ concentration is a critical factor because generators equipped with a $\mathrm{CO}$ safety shutoff device are intended to shut off in a timely manner when operated in an enclosed space. Extended run-times will result in increased $\mathrm{CO}$ mass emitted, which for a given set of ventilation and air leakage conditions in a building will create higher COHb levels compared to cases where the generator shuts off more quickly. Therefore, the simulations that will be performed in the planned study to evaluate the impacts of shutoff requirements will account for the non-uniformity of $\mathrm{CO}$ observed in the testing as documented in the Test Results section.

Table 10 of Technical Note 2049 described a model validation effort that was applied to 13 of the experiments described earlier in that report to establish how well the CONTAM model predicts $\mathrm{CO}$ levels in the garage and the house compared and to evaluate the impact of any differences between the predictions and measurements on calculated COHB profiles of simulated occupants. Based on these comparisons, options were examined to reduce the uncertainty in the COHb levels calculated from the CO levels predicted by CONTAM, such that they will be more reliable for estimating $\mathrm{COHb}$ profiles. In part due to comments on the original simulation plan described in Technical Note 2048, an additional 6 model validation cases are described in Table 5 below. Specifically repeat tests under different weather conditions for 2 cases: Case 47 (Tests 2, 3, and 4) 
in which the G6 generator (see Technical Note 2049 for description of the generator) was fully loaded and operated outside the garage with the exhaust pointed at the open garage bay door and Case 49 (Tests 1, 2, and 3) in which the G6 generator was operated in the center of the garage with the exhaust pointed in the direction of the wall containing the person door to the house. For both of these cases, the garage bay door was fully open, all windows were closed, the door from the garage to the utility room was open $10 \mathrm{~cm}$, and interior doors were fully open. A seventh test was run for Case 47 (test 1) that is not listed in Table 5 because some test sensor data was not available to allow it to be used for validation purposes. The test house model described in Technical Note 1781 was used in these simulations.

Table 5 Additional Model Validation Tests Conducted

\begin{tabular}{|c|c|c|c|c|c|}
\hline $\begin{array}{c}\text { Case/Test } \\
\text { Number }\end{array}$ & Generator/load & $\begin{array}{c}\text { Test } \\
\text { Date }\end{array}$ & $\begin{array}{c}\text { Generator } \\
\text { Location }\end{array}$ & $\begin{array}{c}\text { Average } \\
\text { Outdoor } \\
\text { Temp } \\
\left({ }^{\circ} \mathbf{C}\right)\end{array}$ & $\begin{array}{c}\text { Average } \\
\text { Wind } \\
\text { Speed } \\
(\mathbf{m} / \mathbf{s})\end{array}$ \\
\hline $\mathbf{4 9 / 1}$ & $\mathbf{G 6 / 5 0} \%$ & $09 / 11 / 19$ & Garage & 29.4 & 1.7 \\
\hline $\mathbf{4 9 / 2}$ & $\mathbf{G 6 / 5 0} \%$ & $11 / 04 / 19$ & Garage & 14.9 & 4.7 \\
\hline $\mathbf{4 9 / 3}$ & $\mathbf{G 6 / 5 0} \%$ & $11 / 13 / 19$ & Garage & 0.4 & 1.8 \\
\hline $\mathbf{4 7 / 2}$ & $\mathbf{G 6 / 1 0 0} \%$ & $10 / 03 / 19$ & $\begin{array}{c}\text { Outside } \\
\text { garage }\end{array}$ & 23.9 & 2.8 \\
\hline $\mathbf{4 7 / 3}$ & $\mathbf{G 6 / 1 0 0} \%$ & $11 / 05 / 19$ & $\begin{array}{c}\text { Outside } \\
\text { garage }\end{array}$ & 16.2 & 1.6 \\
\hline $\mathbf{4 7 / 4}$ & $\mathbf{G 6 / 1 0 0} \%$ & $11 / 13 / 19$ & $\begin{array}{c}\text { Outside } \\
\text { garage }\end{array}$ & 0.6 & 1.5 \\
\hline
\end{tabular}

\section{Case 47}

Four tests were run for Case 47 with the goal of testing under a range of outdoor conditions, however, as stated above, test 1 was not used as a validation case because some test sensor data was not available; therefore test 1 for Case 47 is not listed in Table 5. The G6 generator was positioned outside the garage (with the termination of its exhaust pipe $1.5 \mathrm{~m}$ from the middle of the plane of the bay door facing into garage) and tested at $100 \%$ load. The interior person door (from utility room to garage) was open $10 \mathrm{~cm}$ and the garage bay door was fully open; the exterior person door (from garage to backyard) was closed. All interior doors connected to the main living space were fully open. Based on generator characterization tests conducted at CPSC (Brookman 2018), a constant CO emission rate of $1841.6 \mathrm{~g} / \mathrm{h}$ was applied in this case. The generator was manually shut down after about $3 \mathrm{~h}$. Although the generator was located outside the garage, the source was modeled as inside the garage since the generator exhaust jet was pointed directly into the garage.

Table 6 summarizes the maximum calculated $\mathrm{COHb}$ values, based on both predicted and observed $\mathrm{CO}$ concentrations, and average percent difference between them. For the Case 47 tests, the average absolute percent difference of the calculated maximum $\mathrm{COHb}$ was $39 \%$. 
Table 6 Comparison of maximum calculated $\mathrm{COHb}$ values, based on both predicted and observed CO concentrations, for Case 47 Tests 2,3 , and 4

\begin{tabular}{|c|c|c|c|}
\hline Zone & COHb (\% predicted) & COHb (\% observed $)$ & $\%$ diff \\
\hline \multicolumn{4}{|c|}{ Test 2} \\
\hline B3 & 3.1 & 20.9 & -85.1 \\
\hline LFK & 3.4 & 18.3 & -81.3 \\
\hline B2 & 3.1 & 20.5 & -84.6 \\
\hline MBd & 2.9 & 17.5 & -83.4 \\
\hline \multicolumn{4}{|c|}{ Test 3} \\
\hline B3 & 7.4 & 8.5 & -12.8 \\
\hline LFK & 8.2 & 11.3 & -27.8 \\
\hline B2 & 7.8 & 11.3 & -30.8 \\
\hline MBd & 7.6 & 11.1 & -31.8 \\
\hline \multicolumn{4}{|c|}{ Test 4} \\
\hline B3 & 9.7 & 8.4 & 15.8 \\
\hline LFK & 10.9 & 11.1 & -1.5 \\
\hline B2 & 10.5 & 10.4 & 0.5 \\
\hline MBd & 10.2 & 8.6 & 19.3 \\
\hline Average $\mid \%$ difference $\mid$ & & & 39 \\
\hline
\end{tabular}

\section{Case 49}

For the three validation cases for Case 49 Tests 1,2, and 3 under a range of weather conditions (see Table 5), the G6 generator was positioned in the garage (centered, with the exhaust facing towards the family room) and tested at $50 \%$ load. The interior person door (from utility room to garage) was open $10 \mathrm{~cm}$, and the garage bay door was fully open; the exterior person door (from garage to backyard) was closed. All interior doors connected to the living space were fully open. Based on generator characterization tests conducted at CPSC (Brookman 2018), a constant CO emission rate of $749.6 \mathrm{~g} / \mathrm{h}$ was applied in this case. The generator was manually shutdown after about $3 \mathrm{~h}$. These tests were similar to Case 32 but with a lower load to determine if a different fraction of $\mathrm{CO}$ emission in the utility room would be more appropriate for smaller generators. After finding that the same $5 \%$ fraction as used in Case 32 (see results in Technical Note 2049) significantly underpredicted CO entering the house, simulations were performed with $15 \%$ of the $\mathrm{CO}$ source placed in the utility room and the remaining $85 \%$ in the garage. Table 7 summarizes the maximum $\mathrm{COHb}$ values, both predicted and observed, and average percent difference between them for Case 49 tests with the $15 \%$ factor, which resulted in an average percent difference of $24 \%$. 
Table 7 Comparison of maximum calculated $\mathrm{COHb}$ values, based on both predicted and observed CO concentrations, for Case 49 Tests 1, 2, and 3

\begin{tabular}{|c|c|c|c|}
\hline Zone & COHb (\% predicted) & COHb (\% observed) & $\%$ diff \\
\hline \multicolumn{4}{|c|}{ Test 1} \\
\hline B3 & 14.9 & 25.6 & -41.9 \\
\hline LFK & 15.8 & 25.7 & -38.4 \\
\hline B2 & 15.2 & 27.9 & -45.6 \\
\hline MBd & 14.6 & 26.5 & -44.7 \\
\hline \multicolumn{4}{|c|}{ Test 2} \\
\hline B3 & 8.1 & 7.3 & 10.9 \\
\hline LFK & 9.6 & 10.2 & -6.4 \\
\hline B2 & 9.1 & 10.6 & -14.1 \\
\hline MBd & 8.7 & 9.3 & -5.6 \\
\hline \multicolumn{4}{|c|}{ Test 3} \\
\hline B3 & 18.2 & 15.5 & 17.2 \\
\hline LFK & 19.2 & 17.3 & 10.9 \\
\hline B2 & 18.4 & 15.3 & 20.0 \\
\hline MBd & 18.1 & 14.0 & 28.6 \\
\hline Average $\mid \%$ difference $\mid$ & & & 24 \\
\hline
\end{tabular}




\section{Summary}

This report presents measured $\mathrm{CO}$ concentrations, and calculated $\mathrm{COHb}$ profiles based on those concentrations, from tests wherein four different commercially available portable generators equipped with CO safety shutoff systems were operated in a test house under various operational and environmental conditions. The tests are intended to provide CPSC staff and other interested parties with information that will enable the comparison of residential $\mathrm{CO}$ exposures resulting from the operation of portable generators with a $\mathrm{CO}$ hazard mitigation system inside a home or attached garage or outside near a home. Peak living space $\mathrm{CO}$ concentrations ranged from under $100 \mu \mathrm{L} / \mathrm{L}$ to over $1100 \mu \mathrm{L} / \mathrm{L}$ and peak living space $\mathrm{COHb}$ levels ranged from less than $5 \%$ to over $35 \%$. Twelve tests were conducted with the generator in the kitchen with one window open 10 $\mathrm{cm}$. Automatic shutoff occurred in 11 tests in a range of 3 min to 171 min with a resulting peak $\mathrm{COHb}$ level of $5 \%$ to $30 \%$. Note that the case that did not shut off had among the lowest peak \% $\mathrm{COHb}$ levels. Twelve tests were conducted with the generator in the garage with the bay door closed. Automatic shutoff occurred in all 12 tests in 1 min to $166 \mathrm{~min}$ with a resulting peak $\mathrm{COHb}$ of under $10 \%$. Eight tests were conducted with the generator in the garage with the bay door open. Automatic shutoff occurred in two cases in $2 \mathrm{~min}$ to $8 \mathrm{~min}$ and a resulting peak $\mathrm{COHb}$ of under $5 \%$. For the 10 cases that did not shutoff, the peak $\mathrm{COHb}$ level ranged from $<10 \%$ to $37 \%$. These results apply to the specific generators and conditions tested; other generators and test conditions may produce different results. In addition, model validation tests and simulations were performed for two Cases (three tests each) to supplement those already reported in NIST Technical Note 2049. 


\section{Acknowledgements}

NIST's participation in this study was supported by an interagency agreement between the National Institute for Standards and Technology and the Consumer Product Safety Commission (CPSC-I-17-0023). The content of this publication does not necessarily reflect the views of the Commission, nor does the mention of trade names, commercial products, or organizations imply endorsement by the Commission. The authors would like to acknowledge the contributions of Janet Buyer, Matthew Hnatov, and Dr. Andrew Lock from CPSC, Dr. Sandra Inkster formerly of CPSC, and Steven Nabinger formerly of NIST. 


\section{References}

Brookman, MJ. 2018. Memo on Portable Generator Characterization for Evaluation of Carbon Monoxide Shutoff Concepts.

Burton, LE. 1996. CPSC Health Sciences Memorandum, Toxicity from Low Level Human Exposure to Carbon Monoxide.

CPSC.2016. CPSC Staff Briefing Package for Notice of Proposed Rulemaking For Safety Standard For Carbon Monoxide Hazard For Portable Generators, October 5, 2016. (available online at: https://www.cpsc.gov/s3fspublic/Proposed_Rule_Safety_Standard_for_Portable_Generators_October_5_2016.pdf )

Dols WS and Polidoro BJ. 2015. CONTAM User Guide and Program Documentation Version 3.2. NIST Technical Note 1887, National Institute of Standards and Technology.

Emmerich SJ and SJ Nabinger. 2001. Measurement and Simulation of the IAQ Impact of Particle Air Cleaners in a Single-Zone Building. International Journal of HVAC\&R Research Vol. 1, No. 7, ASHRAE.

Emmerich SJ. 2001. Validation of Multizone IAQ Modeling of Residential-scale Buildings: A Review. ASHRAE Transactions Vol. 107.2. 49.

Emmerich SJ, and AK Persily. 1996. Multizone modeling of three residential indoor air quality control options. NISTIR 5801.

Emmerich SJ, Persily AK, and SJ Nabinger. 2002. Modeling moisture in residential buildings with a multizone IAQ program. Proceedings of Indoor Air 2002.

Emmerich SJ, Reed CH, and A Gupta. 2005. Modeling the IAQ impact of HHI interventions in inner-city housing. NISTIR 5212, National Institute of Standards and Technology.

Emmerich SJ, Howard-Reed C, and SJ Nabinger. 2004. Validation of Multizone IAQ Model Predictions for Tracer Gas in a Townhouse. Building Services Engineering Research and Technology, Vol. 25 (4).

Emmerich SJ, Persily AK, and L Wang. 2013. Modeling and Measuring the Effects of Portable Gasoline Powered Generator Exhaust on Indoor Carbon Monoxide Level. NIST Technical Note 1781.

Emmerich SJ and WS Dols. 2016. Model Validation Study of Carbon Monoxide Transport due to Portable Generator Operation in an Attached Garage. Journal of Building Performance Simulation 9 (4), 397-410. 10.

Emmerich SJ, Polidoro B, and WS Dols. 2016. Simulation of Residential Carbon Monoxide Exposure Due to Generator Operation in Enclosed Spaces. NIST Technical Note 1925.

Emmerich SJ, Polidoro B, Brookman MJ, Buyer J, and M Hnatov. 2019. Simulation and Analysis Plan to Evaluate the Impact of CO Mitigation Requirements for Portable Generators. NIST Technical Note 2048. 
Emmerich SJ, Zimmerman SM, Nabinger SJ, and MJ Brookman. 2019. Carbon Monoxide Concentrations and Carboxyhemoglobin Profiles from Portable Generators with a CO Safety Shutoff Operating in a Test House. NIST Technical Note 2049.

Hnatov MV. 2021a. Incidents, Deaths, and In-Depth Investigations Associated with Non-Fire Carbon Monoxide from Engine-Driven Generators and Other Engine-Driven Tools, 2010-2020; U.S. Consumer Product Safety Commission: Bethesda, MD.

Hnatov MV. 2021b. Non-Fire Carbon Monoxide Deaths Associated with the Use of Consumer Products, 2018 Annual Estimates, U.S. Consumer Product Safety Commission, Bethesda, MD.

Inkster, S. 2012. A Comparison of the Carbon Monoxide (CO) Poisoning Risk Presented By A Commercially-Available Portable Gasoline-Powered Generator Versus A Prototype "Reduced CO Emissions" Generator, Based On Modeling of Carboxyhemoglobin (COHb) Levels From Empirical CO Data, U.S. Consumer Product Safety Commission.

Nabinger SJ, AK Persily, and WS Dols. 2010. Impacts of Airtightening Retrofits on Ventilation Rates and Energy Consumption in a Manufactured Home. NIST Technical Note 1673.

Nabinger SJ and AK Persily. 2008. Airtightness, Ventilation and Energy Consumption in a Manufactured House: Pre-Retrofit Results. NISTIR 7478.

Persily AK, A Musser, and D Leber. 2006. A Collection of Homes to Represent the U.S. Housing Stock. NISTIR 7330. National Institute of Standards and Technology.

Stewart RD. 1975. The effect of carbon monoxide on humans. Annual review of pharmacology. 15, 40923.

Wang LL, Dols WS, and Q Chen. 2010. Using CFD capabilities of CONTAM 3.0 for simulating airflow and contaminant transport in and around buildings. HVAC\&R Research. 2010 Nov 1;16(6):749-63. 


\section{Appendix 1 - COHb Analysis Method}

In 1965, Coburn, Forster and Kane developed a differential equation (CFK model) to describe the major physiological variables that determine the $\mathrm{COHb}$ in blood using data from patients with increased endogenous production of CO due to anemia (Coburn et al., 1965 ${ }^{1}$ ). The CFK model is represented by the following equation:

$$
\frac{d(\mathrm{COHb})_{t}}{d t}=\frac{V_{C O}}{V_{b}}-\frac{C O H b_{t} * P_{O_{2}}}{M * B * V b * O H b}+\frac{P_{C O}}{B * V b}
$$

where

$$
\begin{aligned}
& B=1 / D_{L}+P_{L} / V_{A} \\
& M=\text { Ratio of affinity of blood for } \mathrm{CO} \text { to that for } \mathrm{O}_{2}, M=218 \\
& O H b=\mathrm{ml} \text { of } \mathrm{O}_{2} \text { per } \mathrm{ml} \text { blood, } \mathrm{OHb}=0.2 \\
& C O H b_{t}=\mathrm{ml} \text { of } \mathrm{CO} \text { per ml blood at time } \\
& P_{O_{2}}=\text { average partial pressure of oxygen in the lung capillaries, } P_{O_{2}}=100 \mathrm{~mm} \mathrm{Hg} \\
& V_{C O}=\text { rate of endogenous } \mathrm{CO} \text { production, } V_{C O}=0.007 \mathrm{ml} / \mathrm{min} \\
& D_{L}=\text { diffusivity of the lung for } \mathrm{CO}, D_{L}=30 \mathrm{ml} / \mathrm{min} \mathrm{mm} \mathrm{Hg} \\
& P_{L}=\text { barometric pressure minus the vapor pressure of water at body temperature, } 713 \mathrm{~mm} \mathrm{Hg} \\
& V b=\text { blood volume, } V b=5500 \mathrm{ml} \\
& P_{C O}=\text { partial pressure of } \mathrm{CO} \text { in the air inhaled, mm Hg } \\
& V_{A}=\text { alveolar ventilation rate, } V_{A}=6000 \mathrm{ml} / \mathrm{min}(\text { awake), } 4000 \mathrm{ml} \text { (sleeping) } \\
& t=\text { exposure duration, min }
\end{aligned}
$$

In another study by Peterson and Stewart (1975), data from a series of human exposures to CO were analyzed to determine the fit to the theoretical CFK equation. 19 men and 3 women were exposed to concentrations of $50 \mathrm{ppm}, 100 \mathrm{ppm}$ or $200 \mathrm{ppm}$ for $0.33 \mathrm{~h}$ to $5.25 \mathrm{~h}$. Three exercise levels from sedentary or $0 \mathrm{kpm} / \mathrm{min}, 150 \mathrm{kpm} / \mathrm{min}$ or $300 \mathrm{kpm} / \mathrm{min}$ on an ergometer were used (15 subjects in total). Note: $\mathrm{kpm} / \mathrm{min}$ are used in the original reference and $6.116 \mathrm{kpm} / \mathrm{min}$ is equal to $1 \mathrm{~W}$. These resulted in mean ventilation rates of $10.1 \mathrm{l} / \mathrm{min}(9.1 \mathrm{l} / \mathrm{min}$ for women $), 14.0$ 1/min, $24.0 \mathrm{l} / \mathrm{min}$ (19.7 1/min for women) and $29.7 \mathrm{l} / \mathrm{min}$, respectively. The CFK model predicted $\mathrm{COHb}$ for both men and women as well as for resting and exercising subjects within a standard error of about $2 \%$. In contrast to the original model, which assumes all variables to be constant except $t, P_{L}, C O H b_{t}$ and $P_{C O}$, the following parameter alterations were introduced:

$P_{O_{2}}$ : When the partial pressure of oxygen in inspired air $\left(\mathrm{Pi}_{\mathrm{O}_{2}}\right)$ is less than the $149 \mathrm{~mm} \mathrm{Hg}$ found under normal conditions, the partial pressure of oxygen in the lung capillaries will be less than the value of $100 \mathrm{mmHg}$ assumed by Coburn and coworkers. From measurements of oxygen partial pressure in arterial blood, which is assumed to be the same as the oxygen partial pressure in lung capillaries, the following equation was derived:

$$
\begin{aligned}
& P_{\mathrm{O}_{2}}=1 /\left(0.072-0.00079 \mathrm{Pi}_{\mathrm{O}_{2}}+0.000002515\left(\mathrm{Pi}_{\mathrm{O}_{2}}\right)^{2}\right) \text { and } \\
& \mathrm{Pi}_{\mathrm{O}_{2}}=F i_{\mathrm{O}_{2}}\left(P_{B}-47-\mathrm{Pi}_{\mathrm{CO}}\right)_{\text {with }} \mathrm{FiO}_{\mathrm{O}_{2}}=\text { fraction of oxygen in inspired air, } \\
& P_{\mathrm{B}}=\text { barometric pressure }(\mathrm{mm} \mathrm{Hg}), P i_{C O}=\text { partial pressure of } \mathrm{CO} \text { in inspired air }
\end{aligned}
$$

\footnotetext{
${ }^{1}$ Coburn, R.F., Forster, R.E. and Kane, P.B. 1965. Considerations of the physiological variables that determine the blood carboxyhemoglobin concentration in man. Journal of Clinical Investigation, 44 (11), 1899-1910.
} 
$D_{L}$ : Body size effects on diffusivity at rest were was calculated from published data as:

$D_{L}=1 /(-0.0287+0.1188 / A)$ with $A=$ body surface in $\mathrm{m}^{2}$

$V b$ : the published blood volume relationship of $74 \mathrm{mg} / \mathrm{kg}$ of body weight for men and $73 \mathrm{ml} / \mathrm{kg}$ for women was used.

$V_{A}$ : The alveolar ventilation rate was expressed as: $V_{A}=V_{E}-f V_{D}$; with $V_{E}=$ total rate of ventilation $(\mathrm{ml} / \mathrm{min}), f=$ respiration rate $\left(\mathrm{min}^{-1}\right)$ and $V_{D}=$ dead space $(\mathrm{ml})$

$\mathrm{OH}_{t}$ : At standard concentrations, $1 \mathrm{~g}$ of hemoglobin will hold $1.38 \mathrm{ml}$ of oxygen and thus

$O H b_{\max }=1.38[\mathrm{Hb}] / 100$, with [2] being the hemoglobin concentration in blood $(\mathrm{g} / 100 \mathrm{ml})$.

During and after $\mathrm{CO}$ exposure, the value of $\mathrm{OH}_{t}$ that must be used is actually

$\mathrm{OHb}_{t}=\mathrm{OHb}_{\max }-\mathrm{COHb}_{t}$. In this case, the CFK equation can only be solved by iterative

procedures.

$C O H b$ : This value can be converted to the more conventional, percentage saturation by:

$$
\% \mathrm{COHb}=\mathrm{COH} b^{*} 100 / \mathrm{OHb}_{\max }
$$

For the calculation of concentration-time combinations that result in a certain $\mathrm{COHb}$, the model of Coburn, Forster and Kane (CFK model) was used. Since this model in the formulation of Peterson and Stewart (1975) calculates $\mathrm{COHb}$ larger than $100 \%$ at high exposure concentrations, the following correction proposed by Peterson and Stewart (1975) was used: the amount of bound oxygen is actually not constant, but is dependent on the $\mathrm{COHb}$, therefore:

$$
\mathrm{OHb}_{t}=\mathrm{OHb}_{\max }-\mathrm{COHb}_{t}
$$

Since in this case, the CFK equation can only be solved iteratively (EPA, 2006), calculations were done using time steps $(\Delta t)$ of 1 minute for the period of 24 hours. In each step, the $C O H b$ of the step before was used to calculate $\mathrm{OHb}_{t}$. For the first step, a background $\mathrm{COHb}$ of $0.24 \%$ was assumed.

Calculations using the following equation were carried out in a NIST-developed computer program:

$$
\begin{aligned}
& \Delta(\mathrm{COHb})_{t}=\left(\frac{V_{C O}}{V_{b}}-\frac{(\mathrm{COHb})_{t-1} * P_{O 2}}{M^{*} B^{*} V b\left(O H b_{\text {max }}-(C O H b)_{t-1}\right)}+\frac{P_{C O}}{B^{*} V b}\right) \Delta t \\
& (\mathrm{COHb})_{t}=(\mathrm{COHb})_{t-1}+\Delta(\mathrm{COHb})_{t}
\end{aligned}
$$

where

$(\mathrm{COHb})_{t}=\mathrm{ml}$ of $\mathrm{CO}$ per $\mathrm{ml}$ blood at time $\mathrm{t}, \mathrm{min}$

Conversion: $\% \mathrm{COHb}=(\mathrm{COHb})_{t} * 100 / \mathrm{OH}_{\max }$

$(\mathrm{COHb})_{0}=$ initial level, background $=0.0024$ for non-smokers

$O H b_{\max }=\mathrm{ml}$ of $\mathrm{O}_{2}$ per ml blood under normal conditions, $O H b_{\max }=1.38[\mathrm{Hb}] / 100$

$[2]=$ hemoglobin concentration, $\mathrm{g} / 100 \mathrm{ml}$ blood, $[\mathrm{Hb}]=15$ for healthy adults

$V_{C O}=$ rate of endogenous $C O$ production, $V_{C O}=0.007 \mathrm{ml} / \mathrm{min}$

$V b=$ blood volume, $\mathrm{ml} ; \mathrm{Vb}(70-\mathrm{kg} \operatorname{man})=5500 \mathrm{ml}$

$M=$ Ratio of affinity of blood for $\mathrm{CO}$ to that for $\mathrm{O}_{2} ; M=218$ (newborn: $M=240$ )

$B=1 / D_{L}+P_{L} / V_{A}$ with: 
$D_{L}=$ diffusivity of the lung for $\mathrm{CO}, D_{L}=35 * V_{O_{2}} * \exp (0.33)$

$P_{L}=$ barometric pressure minus the vapor pressure of water at body temperature,

$P_{L}=P b-43 \mathrm{mmHg}$

$V_{O_{2}}=$ rate of oxygen consumption, $\mathrm{L} / \mathrm{min} . V_{O_{2}}=R M V / 22.274-0.0309$

$V_{A}=$ alveolar ventilation rate, $\mathrm{ml} / \mathrm{min}, V_{A}=0.933 V_{e}-132 f$

$f=$ respiration rate, $1 / \mathrm{min} . f=\exp [0.0165 R M V+2.3293]$

$R M V=$ respiratory minute volume, $1 / \mathrm{min} . R M V=15 \mathrm{l} / \mathrm{min}$ for the person between light activity $(10 \mathrm{l} / \mathrm{min})$ and moderate activity $(20 \mathrm{l} / \mathrm{min})$

$P_{\mathrm{PO}_{2}}=$ partial pressure of inhaled $\mathrm{O}_{2}$, torr. $P i_{\mathrm{O}_{2}}=148.304-0.0208 P_{C O}=F i_{O_{2}}\left(P b-47-P_{C O}\right)$

$P_{\mathrm{O}_{2}}=$ average partial pressure of oxygen in the lung capillaries; torr

$P_{O_{2}}=P i_{O_{2}}-49$, for $P i_{O_{2}} \geq 149$ torr

$P_{O_{2}}=1 /\left[0.072-0.00079 P i_{O_{2}}+0.000002515\left(P i_{O_{2}}\right)^{2}\right]$, for $P i_{O_{2}}<149$ torr

$\mathrm{Fi}_{2}=$ fraction of inhaled $\mathrm{O}_{2}$, normally $\mathrm{Fi}_{\mathrm{O}_{2}}=0.209$

$P b=$ barometric pressure, torr, 760 at sea level.

$P_{C O}=$ partial pressure of $\mathrm{CO}$ in the air inhaled, $\mathrm{mm} \mathrm{Hg}$,

Conversion: $P_{C O}(m m H g)=P_{C O}(p p m) / 1316$

$\Delta t=$ exposure time interval, $\mathrm{min} ; \Delta t=1 \mathrm{~min}$. 